For Online Publication

Supplementary material to:

\title{
Does Extending Unemployment Benefits Improve Job Quality?
}

Arash Nekoei and Andrea Weber

Thursday $8^{\text {th }}$ December, 2016, 15:06 


\section{Online Appendix A: Theoretical Extensions}

\section{A.1 Positive findings}

\section{A.1.1 Proposition 1}

\section{Effect of UI on the expected reemployment job quality}

We will start with the equation (2) in the paper is

$$
U(t)=\max _{\substack{V, s \\ \lambda=E(V, s, t)}} \lambda V+(1-\lambda)(u(b(t))+\beta U(t+1))-\psi(s) .
$$

In this general setting, jobs can differ in infinite dimensions, and agent's decision is based on the aggregate utility of each job. In a special Case where jobs differ only in one dimension, i.e. wage, the individual optimization would be

$$
U(t)=\max _{\substack{w, s, \lambda \\ \lambda=E(V(w), s, t)}} \lambda V(w)+(1-\lambda)(u(b(t))+\beta U(t+1))-\psi(s) .
$$

With a change in variable so that $s$ measure search effort in disutility unit, we can rewrite the problem as

$$
U(t)=\max _{\substack{V, s, \lambda \\ \lambda=E(V, s, t)}} \lambda V+(1-\lambda)(u(b(t))+\beta U(t+1))-s
$$

First order condition of individual optimization $(A 3)$ with respect to $V$ is:

$$
V^{\tau}(t)-u(b(t))-\beta U(t+1)=-\frac{E}{E_{V}} .
$$

It would become useful to define $\rho=-\frac{E}{E_{V}}$, as a measure of responsiveness of likelihood of finding a job to selectiveness of agent.

If the search margin is fixed, so that agent only chooses the target job, then the first order condition implies that agents are more selective, when current or future UI levels are higher, larger $b(t)$ or $U$. Agents are more selective also when the likelihood of finding a job is less elastic with respect to $V$. In fact, the cost of being more selective stems from decreasing likelihood of getting a better job, so lower this elasticity the more 
selective agent becomes. If we make the functional form assumption that $\rho$ is constant, then $V$ is explicitly defined by this FOC, independently of $s$.

The first order condition with respect to $s$ is:

$$
V^{\tau}(t)-u(b(t))-\beta U(t+1)=\frac{1}{E_{s}},
$$

where $E_{S}$ stands for the partial derivative of function $E$ with respect to $s$. If we assume for a moment that there is no selectivity margin, $V$ is constant, then this FOC implies that higher current or future UI benefit levels imply lower search effort from the agent, and thus lower likelihood of finding a job. In presence of both margins, then the FOC with respect to $s$ can be written as, $\rho E_{s}=1$, or $E_{V}+E E_{s}=0$.

The expected job quality at time $t, V^{e}(t)$, can be written recursively as:

$$
V^{e}(t)=V^{e}(t+1)+\lambda(t)\left(V^{\tau}(t)-V^{e}(t+1)\right) .
$$

Taking the derivative of equation $(A 6)$ for $t=0$ with respect to the initial UI benefit level, $b(0)$, we get:

$$
V_{b(0)}^{e}(0)=\lambda(0) V_{b(0)}^{\tau}(0)+\lambda_{b(0)}(0)\left(V^{\tau}(0)-V^{e}(1)\right)
$$

Proposition 1 below will generalize this result to the case of any change in UI schedule:

Proposition 1 For $t \geq k$,

$$
\frac{\partial V^{e}(k)}{\partial u(b(t))}=\sum_{k \leq i \leq t} \beta^{t-i} \frac{S(k, t)}{1-\lambda(i)} \frac{\partial V^{e}(i)}{\partial u(b(i))}
$$

where $S(k, t)$ represent the survival likelihood between $k$ and $t$, and

$$
V_{b(i)}^{e}(i)=\lambda(i) V_{b(i)}^{\tau}(i)+\lambda_{b(i)}(i)\left(V^{\tau}(i)-V^{e}(i+1)\right)
$$

Before providing the proof, we would like to point out that in term of UI benefit, Proposition 1 can be written as:

$$
\begin{aligned}
V_{b(t)}^{e}(k) & =\sum_{k \leq i \leq t} \beta^{t-i} \frac{S(k, t)}{1-\lambda(i)} \frac{u_{c}(b(t))}{u_{c}(b(i))} V_{b(i)}^{e}(i) \\
& =\sum_{k \leq i \leq t} \beta^{t-i} \frac{S(k, t)}{1-\lambda(i)} \frac{u_{c}(b(t))}{u_{c}(b(i))}\left(\lambda(i) V_{b(i)}^{\tau}(i)+\lambda_{b(i)}(i)\left(V^{\tau}(i)-V^{e}(i+1)\right)\right) .
\end{aligned}
$$


Or in case of of $k=0$, we have:

$$
V_{b(t)}^{e}(0)=S(t) \sum_{i \leq t} \beta^{t-i} \frac{u_{c}(b(t))}{u_{c}(b(i))}\left(\frac{\lambda(i)}{1-\lambda(i)} V_{b(i)}(i)+\frac{\partial \ln (1-\lambda(i))}{\partial b(i)}\left(V(i)-V^{e}(i+1)\right)\right)
$$

This equation illustrates how the UI wage effect (the effect of UI on the expected wage) is connected to the UI effect on target wage path $\left(V_{b(i)}^{\tau}(i)\right)$ as well as the local measures of duration effect of UI $\left(\frac{\partial \ln (1-\lambda(i))}{\partial b(i)}\right)$. The latter is affecting the UI wage effect proportional to the local measure of duration dependence $\left(V^{\tau}(i)-V^{e}(i+1)\right)$ over the unemployment spell. We will come back to this point in Corollary 1, let us first to show the proof of this proposition.

Proof. (Proposition 1)

Envelope theorem and $(A 3)$ provide us with:

$$
\begin{aligned}
& \frac{\partial U(t)}{\partial u(b(t))}=1-\lambda(t) \\
& \frac{\partial U(t)}{\partial U(t+1)}=\beta(1-\lambda(t)) .
\end{aligned}
$$

We denote by $S(k, t)$ the survival from $k$ to $t$ when $k \leq t$, i.e. $S(k, t)=\prod_{k \leq i \leq t}(1-\lambda(i))$ (and $\left.S(t)=S(0, t), \frac{S(k, t)}{S(k+1, t)}=1-\lambda(k)\right)$. The above envelope conditions $(A 8)$ imply that for all $k \leq t$,

$$
\frac{\partial U(k)}{\partial u(b(t))}=(1-\lambda(t)) \frac{\partial U(k)}{\partial U(t)}=\beta^{t-k} S(k, t),
$$

whereas for $k>t$, we have $\frac{\partial U(k)}{\partial U(t)}=\frac{\partial U(k)}{\partial b(t)}=0$. The two FOCs of agent optimization (A3) implies that $\left(V^{\tau}(t), \lambda(t)\right)$ is a function of $u(b(t))+\beta U(t+1)$ and $t$, leading to $\frac{\partial V^{\tau}(k)}{\partial u(b(k))}=\frac{1}{\beta} \frac{\partial V^{\tau}(k)}{\partial U(k+1)}$ and for $k<t:$

$$
\frac{\partial V^{\tau}(k)}{\partial u(b(t))}=\beta^{t-k} S(k+1, t) \frac{\partial V^{\tau}(k)}{\partial u(b(k))}
$$

, where the last equality is based on (A9). Replicating the same argument, we can show that, for $k<t$ :

$$
\begin{aligned}
\frac{\partial V^{\tau}(k)}{\partial u(b(t))} & =\beta^{t-k} S(k+1, t) \frac{\partial V^{\tau}(k)}{\partial u(b(k))} \\
\frac{\partial \lambda(k)}{\partial u(b(t))} & =\beta^{t-k} S(k+1, t) \frac{\partial \lambda(k)}{\partial u(b(k))}
\end{aligned}
$$

, whereas for $k \geq t$, both derivatives are zero. Equations $(A 10)$ show that the importance 
of the change in UI benefits at time $t$ from the eyes of the unemployed agent at time $k$, agent takes into account both the time-discounting, $\beta^{t-k}$, and the survival likelihood until time $t, S(k+1, t)$. Now differentiating our recursive formula for UI effect on expected job quality, i.e.

$$
V^{e}(k)=\lambda(k) V^{\tau}(k)+(1-\lambda(k)) V^{e}(k+1),
$$

we have

$$
\frac{\partial V^{e}(k)}{\partial u(b(t))}=\lambda(k) \frac{\partial V^{\tau}(k)}{\partial u(b(t))}+\left(V^{\tau}(k)-V^{e}(k+1)\right) \frac{\partial \lambda(k)}{\partial u(b(t))}+(1-\lambda(k)) \frac{\partial V^{e}(k+1)}{\partial u(b(t))}
$$

Using $(A 10)$ and the fact that $\frac{\partial V^{e}(k+1)}{\partial u(b(t))}=0$ for $k=t$, we have

$$
\frac{\partial V^{e}(k)}{\partial u(b(t))}=\beta^{t-k} S(k+1, t) \frac{\partial V^{e}(k)}{\partial u(b(k))}+S(k, k) \frac{\partial V^{e}(k+1)}{\partial u(b(t))},
$$

for $k<t$. Solving the recursive formula of $(A 12)$, we get that for $k<t$ :

$$
\frac{\partial V^{e}(k)}{\partial u(b(t))}=\sum_{k \leq i \leq t} \beta^{t-i} \frac{S(k, t)}{1-\lambda(i)} \frac{\partial V^{e}(i)}{\partial u(b(i))} .
$$

Intuition: A change in future UI benefit, $\Delta b(t)$, affect the $V^{e}(k)$, by affecting target wages and hazard rates of all period between, $k \leq i \leq t$. We need to discount each of these changes with $S(k, i-1)$ that measures the likelihood of getting to the period $i$. Then this proposition proves that the target wages and hazard rate changes in period $i$ due to are equivalent to a change in future UI benefit, $\Delta b(t)$ are equivalent to such changes due to a change in UI benefit of that period, $\Delta b(i)$, once adjusted for time and survival discounting, $\beta^{t-i}$ and $S(i+1, t)$.

Corollary 1 If there is no duration dependence, then for $t>0$ :

$$
\frac{\partial V^{e}(k)}{\partial b(t+k)}=\frac{1-\beta^{t+1}}{1-\beta} \lambda(1-\lambda)^{t-1} \frac{\partial V^{\tau}}{\partial b} .
$$

Proof. If there is no duration dependence, then $V^{\tau}(i)$ and $\lambda(i)$ are constant, so that $V^{e}(i)=V^{\tau}$. This implies that $\frac{\partial V^{\tau}(t)}{\partial u(b(t))}$ is also independent of $t$, so that the Proposition 1 implies the corollary.

Intuition: The instantaneous change is the same everywhere, $\frac{\partial V^{\tau}}{\partial b}$, the likelihood of findings job time the likelihood of getting to the exhaustion is stable too in each period, $\lambda(1-\lambda)^{t-1}$, i.e. $S(k, i-1) S(i+1, t)$ is independent of $i$. So net present value of these 
changes after discounting is the answer.

Equation (A10) in the proof of Proposition 1 has several interesting insight for the dynamic effect of UI extension. This implies that the UI effect on target wage (selectivity) is smaller the further away in the future. This is due to

$$
\frac{\frac{\partial V^{\tau}(k)}{\partial u(b(t+1))}}{\frac{\partial V^{\tau}(k)}{\partial u(b(t))}}=\beta(1-\lambda(t+1)) .
$$

In contrast, the UI wage effect is not always smaller the further away is the change in the future. We can see this in the case where we start from stationary setting. In fact, Corollary 1 implies that

$$
\frac{\frac{\partial V^{e}(0)}{\partial b(t+1)}}{\frac{\partial V^{e}(0)}{\partial b(t)}}=\frac{1-\beta^{t+1}}{1-\beta^{t}}(1-\lambda),
$$

which implies that the UI wage effect is smaller the further away in the future is the UI benefit change if only if the job-finding rate is large enough relative to the discount factor. When UI benefit of a further date is changed, although its effect is smaller on target wage of each period (equation (A15)), but agent's decisions, and thus expected wage, are affected for a longer period.

In our empirical setting, we are interested in investigating effect of given UI extension, namely from 30 to 39 weeks, at target wage path during unemployment spells. In fact, using equation $(A 10)$, we have

$$
\frac{\frac{\partial V^{\tau}(k+1)}{\partial u(b(t))}}{\frac{\partial V^{\tau}(k)}{\partial u(b(t))}}=\frac{1}{\beta(1-\lambda(k+1))} \frac{\frac{\partial V^{\tau}(k+1)}{\partial u(b(k+1))}}{\frac{\partial V^{\tau}(k)}{\partial u(b(k))}} .
$$

This implies that the effect of UI extension is more pronounces closer to exhaustion, if instantaneous selectiveness (i.e. the responsiveness of target wage with respect to the current benefit level, $\left.=\frac{\partial V^{\tau}(k)}{\partial u(b(k))}\right)$ is not decreasing over time at higher pace than an unemployed discount future benefits, that is the result of discount factor and the likelihood of staying unemployed. The latter assumption validity depends on how the matching function $E$ evolves with time. For example, this is always the case under the functional form assumption presented below. This assumption also holds with the absence of structural duration dependence. Equation (A16) also shows that the more impatient the agent is or the shorter the expected unemployment duration is, the more concentrated is the UI effect around benefit exhaustion. 


\section{Decomposing the UI wage effect into responses on the search and selectivity mar- gins}

Without loss of generality, we assume that $\psi(s)=s$, i.e. $s$ is effective search effort, per disutility level, similar to equation $(A 3)$. The likelihood of finding a job is

$$
E(V, s, t)=a(t) s^{1-\frac{1}{\sigma(t)}} \exp \left(-\frac{V}{\rho(t)}\right)
$$

so that the two parameters of $\rho$ and $\sigma$ capture the elasticity and semi-elasticity of job finding rate with respect to selectivity and search, respectively. We assume that $\rho, \sigma>1$, and $a(t)=\alpha(t)^{\frac{1}{\sigma(t)}}\left(\rho(t)\left(1-\frac{1}{\sigma(t)}\right)\right)^{-\left(1-\frac{1}{\sigma(t)}\right)}$. The FOC with respect to target job, $V$, equation $(A 4)$, can be written as:

$$
V^{\tau}(t)=b(t)+\beta U(t+1)+\rho(t)
$$

where for simplicity we assume risk neutrality, i.e. $u(c)=c$. Using the latter, the second FOC can be written as $s(t)=\rho(t)\left(1-\frac{1}{\sigma(t)}\right) \lambda(t)$. The latter helps us to rewrite the hazard rate as a function of optimal targeted job value, $V(t)$, that is:

$$
\lambda(t)=\alpha(t) \exp \left(-\frac{\sigma(t)}{\rho(t)} V^{\tau}(t)\right)
$$

We can decompose the UI effect on job-finding rate to search and wage margins:

$$
\frac{\partial \ln \lambda(t)}{\partial b(t)}=\frac{E_{V} V_{b(t)}^{\tau}(t)}{\lambda(t)}+\frac{E_{s} s_{b(t)}(t)}{\lambda(t)}=-\frac{1}{\rho(t)}-\frac{\sigma(t)-1}{\rho(t)}=-\frac{\sigma(t)}{\rho(t)}
$$

This decomposition illustrates that $\sigma$ measure the ratio between the two margins of search and selectivity, so that moving $\sigma$, keeping $\rho$ constant, will change the search margin while keeping the selectivity margin constant. Using equation $(A 18),(A 19)$ and Proposition 1, we get

$$
\frac{\partial V^{e}(t)}{\partial b(t)}=\lambda(t)\left[1-\frac{\sigma(t)}{\rho(t)}\left(V^{\tau}(t)-V^{e}(t+1)\right)\right]
$$

We can already see the intuition behind a negative correlation between UI duration and wage effect using equation (A21). Consider an increase in job finding elasticity, due a change in search margin, keeping the level of job-finding rate constant. This is equivalent of assuming the same likelihood of treatment and corresponds to an increase in $\sigma(t)$, compensated by a change in $\alpha(t)$ and keeping $\rho(t)$ constant. This leads to a decrease in 
the UI wage effect, proportional to the level of negative duration dependence.

More generally, consider a population with the same unemployment duration but heterogenous in unemployment duration elasticity. This heterogeneity can stem from heterogeneity along two margins of search and selectivity, as we saw in the equation (A20). In order to discuss the more general case where there is heterogeneity in both margins, we need to impose more structure on the shape of duration dependence, i.e. $\{b(t), \rho(t), \sigma(t)\}$. We thereafter investigate the heterogeneity in matching function keeping the job finding rate constant.

Approach 1: Stationarity after time $t$

We will assume that the environment is stationary after time $t, b\left(t^{\prime}\right)=b+1_{t^{\prime}=t} \Delta b$, and $\rho\left(t^{\prime}\right)=\rho+1_{t^{\prime}=t} \Delta \rho$ for $t^{\prime} \geq t$, we will have $V^{e}\left(t^{\prime}\right)=V^{\tau}\left(t^{\prime}\right)=V$ for $t^{\prime}>t$. This assumption is equivalent to keep the problem stationary in the periods after the one that is affect by the UI experiment. In our setting, this is equivalent of neglecting the structural stationarity after the 39 weeks of unemployment. This assumption implies that the target wage is $V^{\tau}(t)=\Delta b(t)+\Delta \rho+V$, and UI wage effect can be written as

$$
\frac{\partial V^{e}(t)}{\partial b(t)}=\lambda(t)\left(1-\frac{\sigma(t)}{\rho(t)}(\Delta b(t)+\Delta \rho)\right) .
$$

The time pattern of $\sigma$ does not appear in the duration dependence as it shapes the negative force in the UI wage effect. The reason can be see in the FOC of $V$, equation $(A 18)$, as target job quality is independent of instantaneous $\sigma$. However, the future value of $\sigma$ affects the target job through their effect on the value of unemployment, $U(t+1)$. The sign of the covariance between duration and wage effect, denoted by $\pi$, can be written as:

$$
\pi=-\operatorname{sgn}\left(\operatorname{var}\left(\frac{\partial \ln \lambda(t)}{\partial b(t)}\right) \Delta b(t)+\operatorname{cov}\left(\frac{\partial \ln \lambda(t)}{\partial b(t)}, \frac{\partial \ln \lambda(t)}{\partial b(t)} \Delta \rho\right)\right)
$$

The first term is always positive and correspond to the heterogeneity in UI duration effect, time the UI-driven duration dependence. The second term is also positive, roughly speaking, if the structural duration dependence is not strongly negatively correlated with UI duration effect. In the following we will show that under plausible assumptions the first term prevails.

Case 1: Additive heterogeneity

In this case, the individual heterogeneity is the sum the time pattern plus individual idiosyncratic element, i.e. $\rho(t, i)=\rho(t)+\tilde{\rho}(i)$. In this case, it is easy to see that the 
correlation between two effects is always negative.

$$
\pi=-\operatorname{sgn}(\Delta b+\Delta \rho) \text {. }
$$

More generally, the correlation is negative whenever there is no or relatively small amount of heterogeneity in structural duration dependence.

Case 2: Multiplicative heterogeneity

In this case, we have $\rho(t, i)=\bar{\rho}(t) \tilde{\rho}(i), \sigma(t, i)=\bar{\sigma}(t) \tilde{\sigma}(i)$, implying that $\Delta \rho(t, i)=$ $\tilde{\rho}(i) \Delta \bar{\rho}(t)$. We will denote by $\hat{V}$ and $\hat{S}$ the two selectivity and search margins, respectively. By definition, the duration elasticity as the sum of two margins, i.e. $\frac{\partial \ln \lambda(t)}{\partial b(t)}=$ $\hat{V}+\hat{S}$. The sign of UI duration and wage effects correlation can be written as:

$$
\pi=-\operatorname{sgn}\left(\Delta b+\eta \frac{\mathbb{E}(\Delta \rho(t, i))}{\mathbb{E}(\rho(t, i))}\right)
$$

where $\eta$ is the coefficient of heterogeneity in the relative role of search margin role on the UI duration effect, $\eta=-\frac{\operatorname{cov}\left(\frac{\hat{S}}{\hat{V}}, \hat{S}+\hat{V}\right)}{\operatorname{var}(\hat{S}+\hat{V})} \cdot{ }^{1}$ The correlation between UI duration and wage effects is negative unless there are simultaneously a strong negative correlation between UI duration effect and the importance of search margin, a sufficient heterogeneity in the latter, and the duration dependence is mainly structural and not UI driven. The first condition is equivalent of a negative correlation between the search and selectivity margins.

Approach 2: No heterogeneity after time $t$

Assume that there is no individual differences in the matching function after time $t$, e.g. $\rho\left(t^{\prime}, i\right)=\rho\left(t^{\prime}\right)+1_{t^{\prime}=t} \Delta \rho(i)$. Using equations $(A 18)$ and $(A 21)$, the sign of the covariance between duration and wage effect is:

$$
\pi=-\operatorname{sgn}\left(\mathbb{E}\left(V^{\tau}(t)-V^{e}(t+1)\right)+\eta-\mathbb{E}(\rho(t, i))\right) .
$$

Like the previous case, if all the heterogeneity in the data stems from search margin, then the right hand side is equal to the expected duration dependence and the correlation is negative. If variation mainly stems from selectivity margin, then $\eta$ would be negative, and the correlation might turn positive. More generally, in order to get a positive correlation between two UI effects, we need a sufficiently negative $\eta$, relative to UI-driven duration dependence, which implies a strong negative correlation between UI duration effect and the importance of search margin, and that sufficient heterogeneity the lat-

\footnotetext{
${ }^{1}$ We normalize the heterogeneity by assuming that $\mathbb{E}(\tilde{\rho}(i))=1$
} 
ter. These are similar conditions than the ones necessary in the case of multiplicative heterogeneity of approach 1 .

In order to see the connection between two approaches consider the hybrid scenario where the environment is stationary after time $t$. Moreover, there is no heterogeneity after time $t$, but we do not assume further structure on heterogeneity (additive or multiplicative heterogeneity). In this case, as we showed before the total duration dependence can be decomposed to UI driven and structural duration dependence, $\Delta b(t)+\Delta \rho(t)$. The sign of the covariance between duration and wage effect is then determined as follows:

$$
\pi=-\operatorname{sgn}(\Delta b(t)+\mathbb{E}(\Delta \rho(t, i))+\eta-\mathbb{E}(\rho(t, i))) .
$$

This equation emphasizes again the importance of UI-driven duration dependence and the coefficient of heterogeneity in the relative role of search margin role on the UI duration effect in shaping the sign of the correlation.

The intuitions developed under the specific matching function of $(A 17)$ can be generalized as follows. One can write the UI effect on job finding rate as:

$$
\frac{\partial \ln \lambda(t)}{\partial b(t)}=\frac{E_{V} V_{b(t)}^{\tau}(t)}{\lambda(t)}+\frac{E_{s} s_{b(t)}(t)}{\lambda(t)}=\frac{1}{\rho(t)}\left(-V_{b(t)}^{\tau}(t)+\frac{s_{b(t)}(t)}{\lambda(t)}\right) .
$$

, where $\rho(t)$ is defined as a measure of responsiveness of likelihood of finding a job to selectiveness of agent, $=-\frac{E}{E_{V}}$. Note that now $\rho(t)$ is not a constant any more (see the discussion of equation $(A 4)$ ). We follow the approach 1 above and assume stationarity after time $t$ and write the UI wage effect as

$$
V_{b(t)}^{e}(t)=\lambda(t)\left(V_{b(t)}^{\tau}(t)+\frac{\partial \ln \lambda(t)}{\partial b(t)}(\Delta b+\Delta \rho)\right) .
$$

The sign of the covariance between duration and wage effect is then determined as follows:

$$
\pi=-\operatorname{sgn}\left(\operatorname{cov}\left(\frac{\partial V^{\tau}(t)}{\partial b(t)}, \frac{\partial \ln \lambda(t)}{\partial b(t)}\right)+\operatorname{cov}\left((\Delta b+\Delta \rho) \frac{\partial \ln \lambda(t)}{\partial b(t)}, \frac{\partial \ln \lambda(t)}{\partial b(t)}\right)\right)
$$

The second term in the right hand side is positive, similar to the equation (A23). However, the first term is likely negative, i.e. individuals whose job finding rate is more responsive to UI have also more responsive selectiveness. To see this, note that the first 
term can be written as

$$
\frac{1}{\lambda(t)} \operatorname{cov}\left(V_{b(t)}^{\tau}(t), \frac{1}{\rho(t)} s_{b(t)}(t)\right)-\operatorname{cov}\left(V_{b(t)}^{\tau}(t), \frac{V_{b(t)}^{\tau}(t)}{\rho(t)}\right)
$$

which is zero, if there is only search margin. In this case, we are back to the case discussed following the equation (A23). However, in case where there is only wage margin, the sign of the covariance between duration and wage effect is

$$
\pi=-\operatorname{sgn}\left(\operatorname{cov}\left((\Delta b-\rho) \frac{V_{b(t)}^{\tau}(t)}{\rho(t)}, \frac{V_{b(t)}^{\tau}(t)}{\rho(t)}\right)\right) .
$$

If we assume no heterogeneity after time $t$, then we will have a negative correlation between the two UI effects iff we have a high UI-driven duration dependence, that is $\Delta b>\rho$. This is exactly the same condition implied by the equation (A18).

Alternatively, let us consider a one standard deviation increase in search margin, denote by $\alpha(\hat{S})$, implies an increase in UI wage effect by $(\Delta b+\Delta \rho) \alpha(\hat{S})$ using equation (A29). A one standard deviation increase in selectivity margin, denote by $\alpha(\hat{V})$, implies a change in UI wage effect by $(\Delta b-\rho) \alpha(\hat{V})$ using equation $(A 29)$. If all the heterogeneity in the data stems from search margin, and the correlation between UI duration and wage effects is negative. The same is true if all heterogeneity in the data stems from selectivity margin, but there is a high UI-driven duration dependence, that is $\Delta b>\rho$. In case where both types of heterogeneity are present in the date, the correlation between UI duration and wage effects is negative if the heterogeneity in UI duration effect is mainly due to search margin than selectivity margin or there is a high UI-driven duration dependence, that is $\Delta b>\rho$.

\section{A.1.2 Effect of UI on the distribution of reemployment job quality}

It is easier to work with continuous time in this part of the proof. Consider the case where the only source of non-stationarity is the limited duration of the UI program, denoted by $B$, such that the target wage becomes stable at benefit exhaustion. In this case, the agent problem can be written as a function of the length of the remaining UI period, $B-t$, with $t \in[0, B]$ : 


$$
\begin{aligned}
w^{\tau}(t, B) & =\omega(B-t) \\
\lambda(t, B) & =\phi(B-t),
\end{aligned}
$$

where $\phi$ is a decreasing, and $\omega$ is an increasing function over the positive domain, and strictly decreasing/increasing in $[0, \bar{t}]$. Here $\bar{t}$ marks the remaining UI benefit duration above which the agent's response is not dependent on the remaining UI duration. This is the case if the UI benefit duration is long enough, such that at the beginning of the unemployment spell the limited benefit duration is not creating duration dependence. In theory, $\bar{t}$ could be infinity, but our empirical results suggests that it has a finite value. For example, Figure 5, panel c and d suggests that in our sample $\frac{\partial}{\partial B} w^{\tau}(0, B)=0$.

In principle this result suggests a direct test for existence of structural duration dependence by investigating whether the hazard rate is a function of the time since layoff or if it is only a function of the time to benefit exhaustion. However, the dynamic selection problem as explained in section 3.3 make the implementation of such a test difficult.

We define cumulative hazard function by $\Lambda(t, B)=\int_{0}^{t} \lambda(x, B) d x$ for $t \in[0, B]$. The survival rate in non-employment, defined as the likelihood of not finding a job by time $t$ after layoff, is given by $S(t, B)=e^{-\Lambda(t, B)}$. It is straight forward to show that survival rate is decreasing function in time since layoff and increasing in the UI benefit duration, that is

$$
\begin{aligned}
S_{t}(t, B) & =-\phi(B-t) S(t, B)<0 \\
S_{B}(t, B) & =(\phi(B-t)-\phi(B)) S(t, B)>0 .
\end{aligned}
$$

We are interested in the CDF of the reemployment wage distribution. Let us denote the realized wage at re-employment for a given UI duration $B$ by the random variable $\tilde{w}^{\tau}(B)$. To connect this to our previous notation, note that $w^{e}=\mathbb{E}\left(\tilde{w}^{\tau}\right)$.

We start by considering the area in which the wage function, $\omega$, is strictly increasing. For a point $a$ in the support of the target wage distribution, $a \in(\omega(0), \min (\omega(B), \omega(\bar{t})))$, we can write:

$$
\begin{aligned}
P\left(\tilde{w}^{\tau}(B)=a\right) & =P(\omega(B-\tilde{T})=a)=P\left(\tilde{T}=B-\omega^{-1}(a)\right) \\
& =\phi\left(\omega^{-1}(a)\right) S\left(B-\omega^{-1}(a), B\right)
\end{aligned}
$$

where the random variable $\tilde{T}$ denotes the time of finding a job. With the help of equa- 
tions (A32), we can look at the effect of a UI benefit extension on the distribution of realized reemployment wages:

$$
\begin{aligned}
\frac{\partial}{\partial B} P\left(\tilde{w}^{\tau}(B)=a\right) & =\phi\left(\omega^{-1}(a)\right)\left(S_{t}\left(B-\omega^{-1}(a), B\right)+S_{B}\left(B-\omega^{-1}(a), B\right)\right) \\
& =-\phi(B) P\left(\tilde{w}^{\tau}(B)=a\right)<0
\end{aligned}
$$

The intuition behind this result is the following. There are two offsetting forces determining the effect of a UI extension on the wage distribution. These are mirror images of the two offsetting forces driving the average wage effect discussion in Section 3 of the paper. On the one hand, the longer the UI benefit duration, the longer is the part of the unemployment spell with a target wage above $a$, because individuals are more selective. On the other hand, the individuals are less likely to leave the unemployment at each point of time. Our result shows that in the case where negative duration dependences is only due to the limited UI benefit duration, the latter force prevails.

Next we turn to the case where the wage function, $\omega$, is not always strictly increasing, i.e. $\bar{t}<\infty$ and $\omega(t)=\omega(\bar{t})$ when $t>\bar{t}$, which implies that the target wage is constant at the beginning of the unemployment spell. For example, this is the case if UI is generous enough so that the unemployed agent is reaching the upper limit of target wage $\bar{w}$ for $B>\bar{t}$. The probability of choosing this limit is given by:

$$
P\left(\tilde{w}^{\tau}(B)=\bar{w}\right)=P(B-\bar{t}>\tilde{T})=1-S(B-\bar{t}, B),
$$

where we denote $\omega(\bar{t})$ by $\bar{w}$. This implies that the likelihood of finding a job with the highest wage is increasing in the UI benefit duration:

$$
\frac{\partial}{\partial B} P\left(\tilde{w}^{\tau}(B)=\bar{w}\right)=-S_{t}(B-\bar{t}, B)-S_{B}(B-\bar{t}, B)=\phi(B) S(B-\bar{t}, B)>0
$$

After benefit exhaustion $\omega$ is not any more strictly increasing and we consider this case separately as well.

$$
P\left(\tilde{w}^{\tau}(B)=\omega(0)\right)=P(\tilde{T} \geq B)=S(B, B)
$$

which leads to

$$
\frac{\partial}{\partial B} P\left(\tilde{w}^{\tau}(B)=\omega(0)\right)=\frac{\partial}{\partial B} S(B, B)=-\phi(B) P\left(\tilde{w}^{\tau}(B)=\omega(0)\right)<0
$$

Summarizing our findings, we have shown that if the distribution of realized reem- 
ployment wages is bounded by the lowest and highest levels of the target wage, an increase in the potential UI benefit duration $B$, leads to (i) a decrease in bunching at the lower level of the target wage which is reached at benefit exhaustion, (ii) an increase in bunching at the highest level of the target wage, which is chosen at the beginning of the unemployment spell, and (iii) a decline in the PDF of realized wages everywhere in between these levels. In the case where the benefit system is not generous enough for individuals to ever choose the highest level of the target wage, the support of the realized wage distribution is expanding to the right as a result of a benefit extension.

\section{A.1.3 Directed vs. random search models}

This subsection discusses the differences between our model in the paper, i.e. a targetwage model of directed search, and the often used reservation-wage (McCall) model of undirected search. In the latter model, the worker receives independent job draws and decides whether to accept or reject an offer. Her search effort affects the likelihood of receiving offers, which are draws from a cumulative distribution function $F(V ; s, t)$, where $s$ is the agent's search effort and $t$ is time since layoff. The agent's decision is characterized by search effort and a threshold, i.e. reservation job quality $\left(V^{r}\right)$. The unemployed agent's optimization problem, equivalent of equation (2) in the paper, is:

$$
U(t)=\max _{\substack{V, s \\ \lambda=1-F(V ; s, t)}} \int_{V} x d F(x ; s, t)+(1-\lambda)(u(b(t))+\beta U(t+1))-s
$$

This is a generalized version of McCall model since it is usually assumed that agent receive an offer from distribution $F(V)$ with probability $p(s)$. In the following, we show that this generalized class of McCall models is equivalent of the class of directed search models presented in our paper.

In order to see the similarity between the reservation and target wage models, we can rewrite this optimization as

$$
U(t)=\max _{\substack{V, s, \lambda \\ \lambda=E(V ; s, t)}} \lambda V+(1-\lambda)(u(b(t))+\beta U(t+1))-s
$$

where

$$
\begin{aligned}
& E\left(V^{\tau} ; s, t\right)=1-F\left(\Phi^{-1}\left(V^{\tau} ; s, t\right) ; s, t\right), \text { and } \\
& \Phi\left(V^{r} ; s, t\right)=\frac{1}{1-F\left(V^{r} ; s, t\right)} \int_{V^{r}} x d F(x ; s, t),
\end{aligned}
$$


where the function $\Phi$ determines the intra-temporal expected job quality as a function of the reservation job quality and search effort in period $t$. The function $E$ is well-defined since the truncated expectation function, $\Phi$, is strictly increasing in $V^{r}$.

Equation $(A 34)$ is identical with the individual optimization in our direct-search model, e.g. (A3) in the Online Appendix A.1.1. This implies that for any random search model with a given offer distribution $F$, there exists a matching function corresponding to a directed search model, in which the agent's optimization results in the same level of search effort, the same job finding rate, as well as the same intra-temporal expected job quality.

This further implies that all results on utilities in the target-wage model are applicable to the reservation-wage model. In other words, the utility of being unemployed and the expected utility of finding a job in equilibrium are the same across both models, i.e. the same $U$ and $V^{\tau}=\Phi\left(V^{r}\right)$. In this sense, the directed search model nests the random search model.

In the following we investigate under which conditions, there exists a reservation model that nests a given directed search model. Taking the derivative of equation (A35) with respect to $V^{r}$, dropping search and time for simplicity, we get

$$
\Phi^{-1}\left(V^{\tau}\right)=V^{\tau}+\frac{E\left(V^{\tau}\right)}{E_{V}\left(V^{\tau}\right)}
$$

This condition can be written as $V^{r}=V^{\tau}+\frac{E\left(V^{\tau}\right)}{E_{V}\left(V^{\tau}\right)}$, which shows how the reservation job quality and the target job quality are related. This implies that the first order condition with respect to $V$ in the directed search model, $(A 4)$, is equivalent to the familiar first order condition of reservation wage models, i.e. $V^{r}(t)=u(b(t))+\beta U(t+1)$.

The functional equation $(A 36)$ needs to have a solution for $\Phi$. As long as the right hand side of equation $(A 36), v+\frac{E(v)}{E_{V}(v)}$, is an increasing function, we can construct a new distribution such that its inverse truncated expected value function matches the value of this increasing function. So the necessary and sufficient condition for the existence of a random-search model that nests a directed search model is that $v+\frac{E(v)}{E_{V}(v)}$ is increasing. This condition is equivalent to $2>\frac{E_{V V}(v)}{E_{V}(v)} / \frac{E_{V}(v)}{E(v)}$, which is equivalent of the second order condition of agent maximization.

Note that the two random and directed search models are not equivalent if one is interested in reemployment wage because of risk aversion. In fact, the expected utility from working is the same in both models, which implies that the expected wage is higher in the reservation-wage model than its equivalent (in the utility sense) in the target-wage model due to the Jensen's inequality. 


\section{A.2 Normative findings}

The welfare cost of a change in potential benefit duration is the fiscal externality it creates, which can be decomposed into two parts:

$$
\text { Fiscal Externality }=\underbrace{\tau(1-n) \Delta w^{e}}_{\begin{array}{c}
\text { Fiscal Externality } \\
\text { due to wage effect }
\end{array}}-\underbrace{\left(\tau w^{e} \Delta n+b \Delta \tilde{n}\right)}_{\begin{array}{c}
\text { Fiscal Externality } \\
\text { due to duration effect }
\end{array}},
$$

where $n$ stands for the expected duration of non-employment, $\tilde{n}$ stands for the expected non-employment duration covered by UI, and $\tau$ is the total tax on labor earnings including UI tax.

The first term is the effect of the UI wage effect on the government budget, a positive fiscal externality which has been overlooked in the prior literature. Agents do not internalize that their search decisions has an externality: a change in reemployment wage implies a change in future labor income tax. This externality is directly due to the proportionality of tax. The second and third terms represent the traditional negative fiscal externality in case of limited UI duration: lower tax revenue due to longer non-employment and higher UI expenditure.

Our estimates from Table 2 show that a nine-week extension of UI benefit eligibility increases reemployment wages by .5 percent, and increases the average non-employment spell, $\Delta n$, by two days. The change in $\tilde{n}$ has two components, marginal and inframarginal, equal to 1.5 and 6.4 days, respectively. Finally, the average post-unemployment job tenure is 81 weeks. Inserting these values, the total fiscal externality is equal to $(20 \%-45 \%) w^{e}$. This implies that the positive fiscal externality of the nine-week UI benefit extension is equal to $20 \%$ of the average weekly wage, as compared to the traditional negative moral-hazard externality of $-45 \%$. The overall fiscal externality is thus equal to $-25 \%$, only half as big as the externality of $-45 \%$ if we had ignored the wage effect.

More generally, we can characterize the optimal UI design in the presence of two real-world features of UI: limited duration and proportional UI tax.

Proposition 2 (Optimal UI with limited duration) Suppose that the agent has a separable utility between consumption and leisure $(u(c)-v(l))$, and does not discount the future $(r=0){ }^{2}$ Then

\footnotetext{
${ }^{2}$ As we discussed in footnote 33 , this is a good approximation for realistic values of the discount rate (For a similar argument, see Shimer and Werning (2007)).
} 
optimal UI satisfies the following conditions:

$$
\begin{gathered}
\mathbb{E}\left(\frac{w}{w^{e}} \frac{u_{c}((1-\tau) w)}{u_{c}(b)}\right)=\frac{1}{\varepsilon_{\tau, b}}, \\
\kappa \frac{u(b)-u(0)}{b u_{c}(b)}=\frac{\varepsilon_{\tau, B}}{\varepsilon_{\tau, b}},
\end{gathered}
$$

where the two measures of fiscal externality can be written as

$$
\begin{aligned}
& \varepsilon_{\tau, b}=1+\left(1_{n<B}+\frac{n}{1-n}\right) \varepsilon_{n, b}-\varepsilon_{w^{e}, b} \\
& \varepsilon_{\tau, B}=1_{n \geq B}+\left(1_{n<B}+\frac{n}{1-n}\right) \varepsilon_{n, B}-\varepsilon_{w^{e}, B},
\end{aligned}
$$

$\kappa$ is the proportion of total UI benefits received by agents who exhaust their benefits, $\kappa=\frac{S(B) B}{\tilde{n}}, n$ stands for expected duration of non-employment, and $\tilde{n}$ is the expected non-employment duration covered by UI, $\tilde{n}=\max (n, B) \cdot \varepsilon_{y, x} \equiv \frac{\partial \ln (y)}{\partial \ln (x)}$ represents the elasticity of $y$ with respect to $x$.

If the left-hand side of equation A38 is larger than the right-hand side, a marginal increase in UI generosity (benefit level or duration) is welfare-improving. If the left-hand side of equation A39 is larger than the right-hand side, a marginal increase in UI benefit and a decrease in UI duration is welfare-improving.

The first condition trades off the cost of fiscal externality and the benefits of consumption smoothing. It nests the Baily-Chetty formula (Baily (1978), Chetty (2006)) as a special case, under stationarity and the absence of the UI wage effect. More importantly, the second condition weighs the trade-off between the benefit level and duration. The relative welfare gain from benefit duration and level, the left-hand side, is the gain from increasing the utility of agents who receive benefits until exhaustion from $u(0)$ to $u(b)$ normalized by the marginal utility of consumption. The parameter $\kappa$ is a measure of the option value of search as the extension is more valuable to agents who are more likely to exhaust benefits (Section 3).

Proof. (Proposition 2) Let us denote $U(0)$ when agent is facing UI benefit with level $b$ and duration $B$, by $W$. The planner problem then is:

$$
\begin{aligned}
& \max _{b, B, \tau} W(b, B, \tau) \\
b \tilde{n}= & \tau(1-n) w^{e}
\end{aligned}
$$

where $n$ is the non-employment duration and $\tilde{n}$ is the expected non-employment du- 
ration covered by UI. Differentiating the government budget constraint with respect to benefit level and duration,

$$
\begin{gathered}
\varepsilon_{\tau, b}=1+\varepsilon_{\tilde{n}, b}+\frac{n}{1-n} \varepsilon_{n, b}-\varepsilon_{w^{e}, b} \\
\varepsilon_{\tau, B}=\varepsilon_{\tilde{n}, B}+\frac{n}{1-n} \varepsilon_{n, B}-\varepsilon_{w^{e}, B} .
\end{gathered}
$$

Given that $\tilde{n}=\min (n, B)$, we have $\varepsilon_{\tilde{n}, B}=1_{n \geq B}+\varepsilon_{n, B} 1_{n<B}, \varepsilon_{\tilde{n}, b}=\varepsilon_{n, b} 1_{n<B}$, which leads to

$$
\begin{gathered}
\varepsilon_{\tau, b}=1+\left(1_{n<B}+\frac{n}{1-n}\right) \varepsilon_{n, b}-\varepsilon_{w^{e}, b} \\
\varepsilon_{\tau, B}=1_{n \geq B}+\left(1_{n<B}+\frac{n}{1-n}\right) \varepsilon_{n, B}-\varepsilon_{w^{e}, B} .
\end{gathered}
$$

The planner optimization leads to two first-order conditions: $\frac{W_{\tau}}{W_{b}}=-\frac{1}{\tau_{b}}$ and $\frac{W_{B}}{W_{b}}=\frac{\tau_{B}}{\tau_{b}}$. Using (A9) and ignoring the discounting, $\beta=1$, we get:

$$
\begin{aligned}
& W_{B}=S(B)(u(b)-u(0)) \\
& W_{b}=\tilde{n} u_{c}(b) \\
& W_{\tau}=-\mathbb{E}\left(w V_{w}((1-\tau) w)\right)
\end{aligned}
$$

Replacing $A 41$ in the first first-order condition, we get:

$$
\mathbb{E}\left(\frac{w}{w^{e}} \frac{u_{c}((1-\tau) w)}{u_{c}(b)}\right)=\frac{1}{\varepsilon_{\tau, b}}
$$

In case of stationarity, we are back to Baily-Chetty formula as wage is constant across unemployment spell. For the second first-order condition, after using $A 41$ we get:

$$
\mathcal{\kappa} \frac{u(b)-u(0)}{b u_{c}(b)}=\frac{\varepsilon_{\tau, B}}{\varepsilon_{\tau, b}}
$$

where $\kappa=\frac{S(B) B}{\tilde{n}}$ is the proportion of total UI benefits received by agents who exhaust their benefits.

What is the difference between the fiscal externality of UI extension calculated here in this proposition, $\varepsilon_{\tau, B}$, and the one discussed in Section 6 of the paper? $\varepsilon_{\tau, B}$ is a marginal fiscal externality, whereas the second one is the one measured for the UI extension in our empirical setting, namely an extension from 30 to 39 weeks. Therefore the latter involve infra-marginal effect as discussed above. 
The first direct consequence of Proposition 2 in our empirical setting is illustrated in the following Corollary.

Corollary 2 Given the benefit level $b$ and $n<B$, then the optimal benefit duration is characterized by:

$$
\frac{S(B)}{n} \frac{\frac{u(b)-u(0)}{b u_{c}(b)}}{\mathbb{E}\left(\frac{w}{w^{e}} \frac{u_{c}((1-\tau) w)}{u_{c}(b)}\right)} \simeq \frac{\partial \ln n}{\partial B}-\frac{\partial \ln w^{e}}{\partial B}
$$

Both elements of the right hand side of this equation is measured in our setting. On the left hand side, the only element related to benefit duration is the survival rate. Consider the case where a policy maker is choosing UI benefit duration, given level of benefit. Assume that if she neglects the UI wage effect, the optimal duration is $B^{*}$. Once taking into account the wage effect, the optimal duration would be $B^{* *}$, so that $S\left(B^{* *}\right) \simeq \frac{3}{4} S\left(B^{*}\right)$. In other words, taking UI wage effect into account would increase the optimal UI duration such that the share of unemployed exhausting their benefit decrease by one fourth.

Following the consumption-based approach (Baily (1978), Gruber (1997), Chetty (2006)), we can write our optimal UI conditions as a function of consumptions in different states.

Corollary 3 The optimal UI is approximately defined by

$$
\begin{aligned}
& \gamma\left(\frac{1}{\rho}-1\right) \approx 1-\frac{1}{\varepsilon_{\tau, b}} \\
& \kappa\left(1+\frac{\gamma}{2}\right) \approx \frac{\varepsilon_{\tau, B}}{\varepsilon_{\tau, b}}
\end{aligned}
$$

where $\gamma \equiv \frac{-b u_{c c}(b)}{u_{c}(b)}$ denotes the relative coefficient of risk aversion, and $\rho=\frac{b}{(1-\tau) w^{e}}$ is the average net replacement rate. Note that the latter is defined as a ratio of UI benefit to post-unemployment wage..

Proof. (Corollary 3) Starting from Proposition 2, using Taylor expansion, we can be write the conditions as:

$$
\begin{aligned}
& \gamma\left(\frac{1}{\rho}-1\right)=1-\frac{1}{\varepsilon_{\tau, b}} \\
& \kappa\left(1+\frac{\gamma}{2}\right)=\frac{\varepsilon_{\tau, B}}{\varepsilon_{\tau, b}}
\end{aligned}
$$


Two insights are illustrated in this Corollary 3. First, a higher degree of risk aversion implies longer (lower) UI duration (benefit) at the optimum. As there is no consensus on the empirical value of risk aversion, we will instead use the two conditions to eliminate the coefficient of relative risk aversion. This implies, for instance, that for the optimal replacement rate to be below $2 / 3$, which is the case in most countries, the fiscal externality of the UI benefit level should be higher than that of UI duration $\left(\varepsilon_{\tau, b}>\varepsilon_{\tau, B} \Longleftrightarrow \frac{2}{3}>\rho\right)$.

To see this, use the two conditions in the Corollary 3 to eliminate $\gamma$, we get:

$$
\frac{\frac{1}{\kappa}-1}{1-\frac{1}{2} \frac{\rho}{1-\rho}}=\frac{\varepsilon_{\tau, b}}{\varepsilon_{\tau, B}}-1
$$

so that $\varepsilon_{\tau, b}>\varepsilon_{\tau, B} \Rightarrow \frac{2}{3}>\rho$. In most settings, average unemployment duration is below UI duration, $n<B$. Under this assumption, we will have

$$
\begin{aligned}
\varepsilon_{\tau, b} & =1+\frac{1}{1-n} \varepsilon_{n, b}-\varepsilon_{w^{e}, b} \\
\varepsilon_{\tau, B} & =\frac{1}{1-n} \varepsilon_{n, B}-\varepsilon_{w^{e}, B},
\end{aligned}
$$

which support the assumption that fiscal externality of UI benefit increase would be larger than fiscal externality of UI extension, $\varepsilon_{\tau, b}>\varepsilon_{\tau, B}$.

\section{A.3 Censored data}

The focus of this section is to estimate the effect of UI on non-employment duration and wage when data is censored by an ending date, that is the last date of data collection for administrative data or the interview date for survey data.

Before getting to the formal treatment of this issue, consider the following simple hypothetical example to illustrate the problem. We have a dataset containing all the layoff between 2000-2010. We can follow these individual and see whether they found a job only until the beginning of 2015. The non-employment duration is censored for all individuals in this dataset, e.g. for the ones laid-off in 2000(2010), the non-employment spells are censored at 15(5) years. This implies that if we focus on the layoffs occurred only in 2000, then the censoring problem is less problematic, but we are loosing many observations. In contrast, if we keep all observations, the censoring problem is more important. The goal of this section is to find a balance in this trade-off.

Let us denote the true uncensored distribution of non-employment duration by $\tilde{t}$ and uncensored distribution of post-unemployment wage by $\tilde{w}$. We are interested in UI 
effects on $\mathbb{E}(\tilde{t})$ and $\mathbb{E}(\tilde{\mathfrak{w}})$, denoted by $\frac{\partial \mathbb{E}(\tilde{t})}{\partial B}$ and $\frac{\partial \mathbb{E}(\tilde{w})}{\partial B}$.

As a result of censored data, the expected values of non-employment duration and uncensored distribution of post-unemployment wage, $\mathbb{E}(\tilde{t})$ and $\mathbb{E}(\tilde{w})$ are not observed. However, for sub-population who looses their jobs at least $t$ period before the end of the data we can measure the truncated averages, i.e. $\mathbb{E}(\tilde{t} \mid \tilde{t}<t)$, and $\mathbb{E}(\tilde{w} \mid \tilde{t}<t)$, as well as $S(t)$, where $S$ is the survival function. We can then always identify the effect of UI on survival rate, $\frac{\partial S(t)}{\partial B}$, for this population in a quasi-experiment setting. However, $\frac{\partial \mathbb{E}(\tilde{t} \mid \tilde{\epsilon}<t)}{\partial B}$ and $\frac{\partial \mathbb{E}(\tilde{w} \mid \tilde{t}<t)}{\partial B}$ only can be identified if there is no selection, that is $\frac{\partial S(t)}{\partial B}=0$. Otherwise the unemployed population in control and treatment groups are systematically different due to treatment and thus not comparable.

As a result of censored data, the following statistics, $S(t), \mathbb{E}(\tilde{t} \mid \tilde{t}<t)$ and $\mathbb{E}(\tilde{w} \mid \tilde{t}<t)$, are well defined for sub-population who looses their jobs at least $t$ period before the end of the data. This implies that $\frac{\partial S(t)}{\partial B}$ can be identified for this sub-population. But $\frac{\partial \mathbb{E}(\tilde{t} \mid \tilde{\mid}<t)}{\partial B}$ and $\frac{\partial \mathbb{E}(\tilde{w} \mid \tilde{t}<t)}{\partial B}$ are identifiable iff there is no selection, that is $\frac{\partial S(t)}{\partial B}=0$.

We can write the expected non-employment duration either as:

$$
\mathbb{E}(\tilde{t})=(1-S(t)) \mathbb{E}(\tilde{t} \mid \tilde{t}<t)+S(t) \mathbb{E}(\tilde{t} \mid \tilde{t}>t),
$$

for any $t$. Differentiating with respect to UI duration, $B$, we get:

$$
\begin{aligned}
\underbrace{\frac{\partial \mathbb{E}(\tilde{t})}{\partial B}}_{\text {UI durat. Eff. }}= & \underbrace{\frac{\partial \mathbb{E}(\tilde{t} \mid \tilde{t}<t)}{\partial B}}_{\text {UI Eff. on censored durat. }} \\
& +\underbrace{S(t)\left(\frac{\partial \mathbb{E}(\tilde{t} \mid \tilde{t}>t)}{\partial B}-\frac{\partial \mathbb{E}(\tilde{t} \mid \tilde{t}<t)}{\partial B}\right)+\frac{\partial S(t)}{\partial B}(\mathbb{E}(\tilde{t} \mid \tilde{t}>t)-\mathbb{E}(\tilde{t} \mid \tilde{t}<t))}_{\text {Bias of using censored duration }}
\end{aligned}
$$

This equation shows the biased in the estimate of UI duration effect while using the UI effect on the censored duration. The fact that the effect of extension on survival at time $t, \frac{\partial S(t)}{\partial B}$, is not statistically significant does not imply that the censored measure of UI duration effect is a good approximation of the total UI duration effect. In fact, equation $(A 44)$ shows that when $\frac{\partial S(t)}{\partial B}$ is zero, the bias is most probably negative, as the UI effect is decreasing over unemployment spell given limited duration of UI benefit, implying $\frac{\partial \mathbb{E}(\tilde{t} \mid \tilde{\mid}>t)}{\partial B}<\frac{\partial \mathbb{E}(\tilde{t} \mid \tilde{t}<t)}{\partial B}$. A partial correction could be to adjust the UI effect on censored duration by one minus survival rate, namely use $(1-S(t)) \frac{\partial \mathbb{E}(\tilde{t} \mid \tilde{t}<t)}{\partial B}$ instead of the $\frac{\partial \mathbb{E}(\tilde{t} \mid \tilde{t}<t)}{\partial B}$. However, we will offer a more complete correction.

If we decompose the right hand side of equation $(A 44)$ to observable and unobserv- 
able part, we will have the following decomposition:

$$
\frac{\partial}{\partial B} \mathbb{E}(\tilde{t})=\left[(1-S(t)) \frac{\partial \mathbb{E}(\tilde{t} \mid \tilde{t}<t)}{\partial B}+\frac{\partial S(t)}{\partial B}(\mathbb{E}(t-\tilde{t} \mid \tilde{t}<t))\right]+\chi(t)
$$

, where we denoted by $\chi(t)$, the terms that we are unable to estimate due to censored data, that is

$$
\chi(t)=\frac{\partial S(t)}{\partial B} \mathbb{E}(\tilde{t}-t \mid \tilde{t}>t)+S(t) \frac{\partial \mathbb{E}(\tilde{t} \mid \tilde{t}>t)}{\partial B} .
$$

Again, one can see that the fact that the effect of UI on survival at time $t, \frac{\partial S(t)}{\partial B}$, is not statistically significant does not imply that the bias is zero, $\chi(t)=0$. Most importantly, the decomposition into observed and unobserved part of the UI duration effect, the equation $(A 46)$, has a simple interpretation when using winsorized measure of duration. The following proposition formalize this idea.

Proposition 3 The UI effect on winsorized duration captured the observed part of the total UI duration effect. The total UI duration effect can be decomposed into two parts. The first part is the UI effect on winsorizied duration which can be estiamted. The second unobserved part is capturing the UI effect on the duration above the censoring point.

$$
\frac{\partial}{\partial B} \mathbb{E}(\tilde{t})=\underbrace{\frac{\partial \mathbb{E}(\min (\tilde{t}, t))}{\partial B}}_{\text {UI Eff. on winsorized duration }}+\underbrace{\int_{t} \frac{\partial S(x)}{\partial B} d x}_{\text {bias of using winsorized }}
$$

Using the UI effect on winsorized measure of duration the bias is zero if the integral of UI effect on survival rates is zero. These later effects are unobserved, so this condition can not be directly tested. However, equation $(A 47)$ can help us to find condition for the unbiasness of our estimates. Namely, if the UI effect on survival rate at $t$ is negligible (and statistically insignificant), but the sign of this effect remains unchanged for larger level of $t$, then the integral on the right hand side of equation $(A 47)$ can not be neglected. More pragmatically, if our point estimates of $\frac{\partial S(x)}{\partial B}$ are all positive for $x>t$ although statistically insignificant the bias may remain considerable.

The proof of this proposition is simple once that we write the expected value as the sum of expected winsorized value and the sum of surviving rate above censoring level, that is:

$$
\mathbb{E}(\tilde{t})=\mathbb{E}(\min (\tilde{t}, t))+\int_{t} S(x) d x
$$

Moreover, we showed before that the UI effect on winsorized duration is the observed part of UI duration effect. 
In the same vein, for UI wage effect, we are interested in $\frac{\partial \mathbb{E}(\tilde{w})}{\partial B}$, but we can only estimate $\frac{\partial \mathbb{E}(\tilde{w} \mid \tilde{t}<t)}{\partial B}$. Following the prior literature, we reported the latter in the paper. Here we offer a correction, by decomposing the unobserved UI wage effect to observed and unobserved parts, that is:

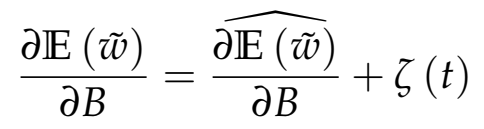

where $\zeta(t) \equiv \frac{\partial S(t)}{\partial B} \mathbb{E}(\tilde{w} \mid \tilde{t} \geq t)+S(t) \frac{\partial \mathbb{E}(\tilde{w} \mid \tilde{t} \geq t)}{\partial B}$, the terms that we are unable to estimate due to censored data, and

$$
\frac{\partial \widehat{\mathbb{E}(\tilde{w})}}{\partial B}=(1-S(t)) \frac{\partial \mathbb{E}(\tilde{w} \mid \tilde{t}<t)}{\partial B}-\frac{\partial S(t)}{\partial B} \mathbb{E}(\tilde{w} \mid \tilde{t}<t) .
$$

\section{Implementation}

We can identify part of the UI duration effect that is UI effect on winsorized duration. We do that with the help of our RD design. In the Figure A5 and A6 in the Online Appendix, we investigate the UI non-employment duration effect, by plotting the best approximation of the total UI effect, namely $\frac{\partial \mathrm{E}(\min (\tilde{t}, t))}{\partial B}$, i.e. measures of winsorized non-employment duration effect. We also present the UI censored duration effect $\frac{\partial \mathbb{E}(\tilde{t} \tilde{t}<t)}{\partial B}$ similar to the prior literature, and for sake of completeness, also present $(1-S(t)) \frac{\partial \mathbb{E}(\tilde{t} \mid \tilde{t}<t)}{\partial B}$ which is a partially corrected measure using censored spells. In order to assure that the size of the bias is negligible, we offer the following solution: we plot the winsorized duration effect over different censoring levels to show that for relatively large $t$ it is not sensitive to $t$. This can be interpreted as the small change in the bias term, which given the decreasing $\frac{\partial S(x)}{\partial B}$, indicate a relatively small bias. For the UI wage effect, in the Figure A6 in the Online Appendix, we report: the corrected measure of $\frac{\widehat{\partial \mathbb{E}(\tilde{w})}}{\partial B}$ in addition to the usual censored UI wage effect $\frac{\partial \mathbb{E}(\tilde{w} \mid \tilde{t}<t)}{\partial B}$.

\section{A.4 Wage vs Non-employment Duration Effects: Econo- metric Setting}

Denotes by $y_{0}$ and $y_{1}$ the outcomes with and without treatment. Following the textbook case (e.g. Wooldridge, Chapter 18), we decompose the counterfactual outcomes into 
average and stochastic parts. For $s \in\{C, T\}$, then we have

$$
y_{s}=\mu_{s}+g_{s}(x)+e_{s}
$$

where the first term is the average outcome in state $s, \mu_{s}=\mathbb{E}\left(y_{i}\right)$, the second term is the explained heterogeneity $g_{s}(x)=\mathbb{E}\left(y_{s} \mid x\right)-\mu_{s}$, and the last term captures unobserved factors that determine potential outcomes, $\mathbb{E}\left(e_{s} \mid x\right)=0$. The difficulty is that we observe either $y_{0}$ or $y_{1}$. The observed outcome is

$$
y=(\Delta \mu+\Delta g(x)+\Delta e) w+\mu_{C}+g_{C}(x)+e_{C},
$$

where $w$ denotes the indicator for treatment which we assume is randomly assigned. To operationalize equation (A49), we assume the functions of $x$, namely $g$ and $g_{0}$ are linear in parameters. In fact, when implementing this equation, we will use a nonparametric approach in our setting. Then with some simplifications in notations, we will rewrite the equation $(A 49)$ as:

$$
y=\underbrace{(\gamma+\beta x+\eta)}_{\theta} w+\alpha+\rho x+\varepsilon
$$

where $\mathbb{E}(\varepsilon \mid x)=\mathbb{E}(\eta \mid x)=0$. So we denoted by $\theta$ the total treatment effect, which consists of a mean, observed treatment heterogeneity, and unexplained heterogeneity.

In the following, I will assume that we have the population data and there is no misspecification in equation $(A 50)$. Otherwise, one need to replace the parameters instead with their estimated value. Let us denote by $\hat{y}$ the predicted value of regression (A50), $\hat{y}(x)=(\hat{\gamma}+\hat{\beta} x) w+\hat{\alpha}+\hat{\rho} x$, and by $\tilde{y}$ the residual, that is $\tilde{y}(x)=y-\hat{y}(x)=\eta w+\varepsilon$. The latter is equal to $e_{s}$, where $s$ is the treatment indicator.

In our empirical analysis, we consider two outcomes, non-employment duration and wage change, denoted here by $y^{1}$ and $y^{2}$. We are interested in the relationship between treatment effects on these two outcomes, denoted by $\theta^{1}$ and $\theta^{2}$. This can be decomposed into observable and unobservable heterogeneity in treatment:

$$
\sigma\left(\theta^{1}, \theta^{2}\right)=\sigma\left(\beta^{1} x, \beta^{2} x\right)+\sigma\left(\eta^{1}, \eta^{2}\right)
$$

where $\sigma(.,$.$) denotes the covariance of two random variables, since \sigma\left(\beta^{i} x, \eta^{j}\right)=0$ for $i \neq j$. The first term, $\sigma\left(\beta^{1} x, \beta^{2} x\right)$ is the covariance between heterogeneous treatments due to observables for the two outcomes.

To implement this idea, we will run the equivalent of equation $(A 50)$ in our RD case 
to estimate both $\beta^{i}$. More precisely, the treatment indicator would be the indicator of age cutoff, $w=1(a \geq 40)$, that is

$$
y=\underbrace{(\gamma+\beta x+\eta)}_{\theta} \times 1(a \geq 40)+\alpha+\rho x+f(a)+\varepsilon,
$$

where the set of covariates includes non-parametric controls similar to the prediction exercise (see Section 2.1). Once we estimate both $\beta^{i}$, Online Appendix Figure A13 plots the prediction treatment effect for wage and non-employment against each other to graphically illustrate $\sigma\left(\widehat{\beta}^{1} x, \widehat{\beta}^{2} x\right)$.

\section{Alternative approaches}

Here we explain a different method to estimate $\sigma\left(\beta^{1} x, \beta^{2} x\right)$ that we are using in the main text. Ideally, we would like to estimate both UI effects for each agent, and then investigate the correlation between these two effects. However, given our RD design, we can only estimate each UI effect in a subpopulation. We first use pre-determined observable characteristics to generate subpopulations. More precisely, we partition the population into 2 or 4 sub-population at each round. These partitions are based on either using categorical variables, e.g. gender, occupation, industry, etc., or quantiles of continuous variables, e.g. pre-unemployment tenure, work experience, etc. For each subsample, we replicate the RD estimate of the UI effects on non-employment duration and wage. The correlation between these two sets of estimates informs us about the potential correlation at the individual level (see Figure 4, panel b).

Random resampling would lead to an estimate of $\sigma\left(\theta^{1}, \theta^{2}\right)$ biased toward $\sigma\left(y^{1}, y^{2}\right)$. To see this, consider the case with no observables. In this case, $\sigma\left(\hat{\theta}^{1}, \hat{\theta}^{2}\right)=\sigma\left(\bar{y}_{T}^{1}-\bar{y}_{C}^{1}, \bar{y}_{T}^{2}-\bar{y}_{C}^{2} \mid R\right)$ where $R$ is the set of random subsamples. The problem is that $\sigma\left(\bar{y}_{T}^{1}, \bar{y}_{T}^{2} \mid R\right) \simeq \sigma\left(y^{1}, y^{2}\right)$. For example, if $\sigma\left(y^{1}, y^{2}\right)>0$, then when $\hat{\theta}^{1}$ is higher in the subsample than in the population since treated share of the subsample includes a subset of agents with unusually high $y^{1}$, then the same agents $y^{2}$ increases $\hat{\theta}^{2}$. Once that resampling is done using observables, then such agents have their equivalent in control group.

The role of unobservable heterogeneity

Measuring the covariance between heterogeneous treatments due to unobservables, $\sigma\left(\eta^{1}, \eta^{2}\right)$, is more difficult. The covariance between the two residuals can be written as:

$$
\sigma\left(\tilde{y}^{1}, \tilde{y}^{2}\right)=\left(\sigma\left(\eta^{1}, \eta^{2}\right)+\sigma\left(\eta^{1}, \varepsilon^{2}\right)+\sigma\left(\varepsilon^{1}, \eta^{2}\right)\right) w+\sigma\left(\varepsilon^{1}, \varepsilon^{2}\right)
$$

The difference in this covariance between treatment and control groups is equal to what 
we were after

$$
\sigma\left(\tilde{y}^{1}, \tilde{y}^{2} \mid w=1\right)-\sigma\left(\tilde{y}^{1}, \tilde{y}^{2} \mid w=0\right)=\sigma\left(\eta^{1}, \eta^{2}\right)+\sigma\left(\eta^{1}, \varepsilon^{2}\right)+\sigma\left(\varepsilon^{1}, \eta^{2}\right)
$$

If we assume that $\sigma\left(\eta^{1}, \varepsilon^{2}\right)+\sigma\left(\varepsilon^{1}, \eta^{2}\right)>0$, or simply $\sigma\left(\eta^{i}, \varepsilon^{j}\right) \simeq 0$ for $i \neq j$ (which is equivalent to $\sigma\left(e_{T}^{i}, e_{C}^{j}\right) \simeq \sigma\left(e_{C}^{i}, e_{C}^{j}\right)$ for $\left.i \neq j\right)$, then this provides us with upper-bound for the covariance between heterogeneous treatments due to unobservables, that is:

$$
\sigma\left(\tilde{y}^{1}, \tilde{y}^{2} \mid w=1\right)-\sigma\left(\tilde{y}^{1}, \tilde{y}^{2} \mid w=0\right) \geq \sigma\left(\eta^{1}, \eta^{2}\right)
$$

The upper-bound is the effect of treatment on the correlation between residual. Using our notation of equation $(A 48)$, this correlation is equivalent to correlation between the residual

$$
\sigma\left(e_{T}^{1}, e_{T}^{2}\right)-\sigma\left(e_{C}^{1}, e_{C}^{2}\right) \geq \sigma\left(\eta^{1}, \eta^{2}\right)
$$

Empirically, in order to estimate this upper bound, we will use our RD design. First, we measure the correlation between the two residuals, $\sigma\left(\tilde{y}^{1}, \tilde{y}^{2}\right)$, at each age bin, then the discontinuity at the cutoff detects the treatment effect on this correlation, i.e. the upper bound of interest. In this way, Figure A9, panel a illustrates the effect of treatment (UI extension of 9 weeks) on the correlation between the two residuals. Point estimate of the corresponding RD regression is 0.0000014(.0000170). This evidence suggests a small role of uncorrelated unobservable variables in driving the correlation between two causal effects of UI on duration and wage. 


\section{Online Appendix B: Empirical Extensions}

\section{B.1 Prediction Exercise}

Appendix Table B1 below lists the variables used for the within-sample prediction of non-employment duration and wage change between the post- and pre-unemployment job. We use a non-parametric specification. For all discrete variables, we use a dummy for each level. For continuous variables, we use an indicator for each decile, expect for the pre-unemployment wage for which we use percentile indicators. At the firm level, the proportion of laid-off workers are calculated excluding the worker himself. We define an extra category for missing values of any variable with missing value.

\section{Appendix Table B1}

\begin{tabular}{clccc}
\hline & & & \multicolumn{2}{c}{ F-stat } \\
\hline & \multicolumn{1}{c}{ Variables } & \# vars & BE & WGC \\
\hline Individual & $\begin{array}{l}\text { Gender, Married, Education, Austrian; } \\
\text { Lecall expectation }\end{array}$ & 29 & 2602 & 1548 \\
Location & Region & 9 & 880 & 85 \\
Firm & Industry; Firm size, Male fraction; & 59 & 122 & 167 \\
Time & $\begin{array}{c}\text { Proportion of Layoff and Recall } \\
\text { Time of layoff (month) }\end{array}$ & 256 & 52 & 44 \\
Seasonality & $\quad$ Calendar week of layoff & 51 & 80 & 24 \\
Wage & $\quad$ Pre-unemployment wage & 99 & 25 & 2597 \\
Work & Tenure, Experience (last 2 and 5 years), & 26 & 1240 & 154 \\
\hline Total & Occupation & 530 & 811.8 & 787.6 \\
\hline
\end{tabular}

Table also shows the results of two of the within-sample prediction exercises: First, the benefit exhaustion (BE), that is an indicator of non-employment duration being larger than 30 weeks. Second, change in log of wage between pre- and post-unemployment wage rate. The r-squares of respective regressions are .21 and .26 .

\section{B.2 Sources for Figure 4, Panel a}

Card et al. (2007a) (CCW) investigate a 10 week extension of UI benefits from 20 to 
30 weeks. The paper uses a sharp RD design and Austrian administrative data. The potential benefit duration is extended from the base of 20 weeks for agents who worked more than 3 years at any firm within five years before job loss. Card et al. (2007a) only report the UI extension effect on job-finding rates in the first 20 weeks of search. There is only graphical evidence on the effect of UI extension on non-employment duration (in Figure VIIIa of the paper). In order to get the point estimate and its standard error for the UI effect on non-employment duration, we use the sample provided at http: //www.rajchetty.com and run the corresponding RD regression. The UI benefit effect on the reemployment wage is taken from the estimates presented in Table III of their paper.

Lalive (2007) (Lalive) investigates a 13-week UI benefit extension from 39 to 52 weeks. The paper uses an age-based RD design exploiting the fact that agents in Austria who become unemployed aged 50 years or older and who satisfy a previous work requirement are eligible for an UI extension. The estimates used in the meta-analysis are taken directly from the results presented in Table 1 of the paper, which provides separate estimates for males and females. The non-employment duration effect is converted from weeks to days.

Schmieder et al. (2013) (SWB) investigate the effect at two UI benefit extension cutoffs. The first extension is of 6 months based on an initial benefit level of 1 year. Another extensions of 4 months starts after 1.5 years of benefits received. The paper uses an RDD approach in Germany based on the age of agents at time of layoff with thresholds at 42 and 44 years. The UI effect on non-employment duration is provided in Table 2. We converted the non-employment duration effect from months to days by multiplying it by 30 . The UI wage effects are taken from the estimates presented in Table $3 .^{3}$

\footnotetext{
${ }^{3}$ The latest version of the paper, Schmieder et al. (2016), does not report separate estimates for the two extension cutoffs.
} 
Appendix Table B2: Sources for Figure 4, panel a

\begin{tabular}{|c|c|c|c|c|c|c|}
\hline \multirow[t]{2}{*}{ Study } & \multirow[t]{2}{*}{$\mathrm{CCW}^{3}$} & \multirow[t]{2}{*}{$\mathrm{NW}^{3}$} & \multicolumn{2}{|c|}{ Lalive $^{3}$} & \multicolumn{2}{|c|}{$\mathrm{SWB}^{3}$} \\
\hline & & & (a) & (b) & (a) & (b) \\
\hline Population & Austria & Austria & \multicolumn{2}{|c|}{ Part of Austria } & \multicolumn{2}{|c|}{ Germany } \\
\hline Period & $1981-2001$ & $1989-2011$ & \multicolumn{2}{|c|}{$1989-1991$} & \multicolumn{2}{|c|}{ 1987-1999 } \\
\hline $\begin{array}{l}\text { UI initial level/ } \\
\text { extension (wks.) }\end{array}$ & $20 / 10$ & $30 / 9$ & \multicolumn{2}{|c|}{$39 / 13$} & $52 / 26$ & $78 / 17$ \\
\hline \multirow[t]{2}{*}{ Discontinuity } & Work experience & Age & \multicolumn{2}{|c|}{ Age } & \multicolumn{2}{|c|}{ Age } \\
\hline & 3 yrs. & 40 yrs. & \multicolumn{2}{|c|}{50 yrs. } & 42 yrs. & 44 yrs. \\
\hline \multirow[t]{2}{*}{ \# Obs. ${ }^{1}$} & 553,607 & $1,187,476$ & 17,572 & 7,063 & 420,311 & 346,850 \\
\hline & & & Male & Female & & \\
\hline \multicolumn{7}{|l|}{ Sample restrictions } \\
\hline $\begin{array}{l}\text { Minimum } \\
\text { work experience }{ }^{2}\end{array}$ & $1 / 2,1 / 5$ & $\begin{array}{c}1 / 2,3 / 5 \\
6 / 10\end{array}$ & \multicolumn{2}{|c|}{$14 / 40$} & \multicolumn{2}{|c|}{$1 / 3,3.6 / 7$} \\
\hline Tenure & $1-5 \mathrm{yrs}$. & & \multirow{2}{*}{\multicolumn{2}{|c|}{ Non-steel sector }} & & \\
\hline Others & $\begin{array}{l}\text { Non-construction } \\
\text { No recall }\end{array}$ & & & & \multicolumn{2}{|c|}{$\begin{array}{l}\text { No UI benefits } \\
\text { last } 7 \mathrm{yrs} .\end{array}$} \\
\hline
\end{tabular}

1. Number of observations in the main specification reported in each paper.

2. $\mathrm{x} / \mathrm{y}$ stands for $\geq \mathrm{x}$ yrs. work experience in $\mathrm{y}$ yrs. before separation.

3. CCW: Card et al. (2007a), NW: This paper, Lalive: Lalive (2007), SWB: Schmieder et al. (2013)

\section{B.3 Wage vs. Non-employment Duration Effect}

\section{B.3.1 Figure 4, panel b}

For the subgroup analysis in Figure 4, panel b, individuals are first grouped into subsamples based on pre-determined observable characteristics. We use 16 characteristics. First we use each characteristics and define 16 dummy variables and categorize people by pairwise interactions between the binary version resulting in 480 groups. Second, we use each characteristics by itself using a more nuanced version of each variables, resulting in 51 groups.

Variables 1-5 are binary. The variables 6-14 are continuous so there are used either as binary Above/below median or in 4 categories by quartiles. The last two variables are categorical with more than 2 categories, so we either bunch them in two category and use them as binary or use their full categorizations. 


\section{Appendix Table B3: Sources for Figure 4, panel b}

\begin{tabular}{|c|c|c|c|}
\hline \multirow{3}{*}{ Variable } & \multicolumn{2}{|l|}{ Variable List II } & \\
\hline & \multirow[t]{2}{*}{ Explanation } & & \\
\hline & & Direct & Interactions \\
\hline Gender & & 2 & 2 \\
\hline Married & married; unmarried & 2 & 2 \\
\hline Blue collar & blue or white collar worker & 2 & 2 \\
\hline Austrian nationality & & 2 & 2 \\
\hline Recall expectation & Recall expected or not & 2 & 2 \\
\hline Work experience 5 & Work experience 5 yrs. before job separation & 4 & 2 \\
\hline Tenure & Tenure in pre-unemployment job & 4 & 2 \\
\hline Layoff date & & 4 & 2 \\
\hline Seasonality & Month and day of layoff & 4 & 2 \\
\hline Region $^{1}$ & & 4 & 2 \\
\hline Sector code & Four-digit Nace code & 4 & 2 \\
\hline Firm size & Pre-unemployment firm size & 4 & 2 \\
\hline Work experience 10 & Work experience 10 yrs. before job separation & 4 & 2 \\
\hline Wage & Pre-unemployment daily wage & 4 & 2 \\
\hline Education $^{2}$ & & 7 & 2 \\
\hline Industry & & 8 & 2 \\
\hline Total \# of groups & & & 2 \\
\hline & & 61 & 480 \\
\hline
\end{tabular}

\section{Notes:}

1. The partition for the binary version \{Wien, Kärnten, Niederösterreich, Steiermark, Burgenland\}; \{Salzburg, Tirol, Vorarlberg, Oberösterreich, Missing\}

2. For the binary version, we use the indicator of the highest education achieved being compulsory school

We subsequently estimate a RDD regression as specified in Appendix Table B3 separately for each subgroup. In every regression, observations are weighted by the inverse of predicted non-employment percentile. This is done in order to isolate the heterogeneity in search and selectivity margin, keeping the option value constant. It also makes the subsamples comparable with respect to the other observable characteristics.

In sum, there are 541 subgroups and for each subgroup we obtain estimates for both the UI effect on non-employment duration and wage. The average group size is 297,745 with a median of 296,497 and the smallest subgroup has 10,753 observations. The UI effects on non-employment duration and wage are statistically significantly different 
from zero $57 \%$ and $30 \%$ of subgroups, respectively. They are jointly significant for $16 \%$ of subgroups.

\section{B.3.1.1 Figure A13, panel b}

For the subgroup analysis in Figure A13, panel b, we create a dummy indicator for each category of the covariates presented in Appendix Table B3. We then apply a LARS (least angle regression) algorithm in order to identify the most important predictors of non-employment durations from the initial covariates. We choose the 10 first variables chosen by the algorithm:

1. Indicator recall expectation

2. Indicator whether tenure in highest quintile

3. Indicator whether industry $=3$

4. Indicator blue collar

5. Indicator female

6. Indicator whether tenure in $2^{\text {nd }}$ quintile

7. Indicator whether job lost in $4^{\text {th }}$ quarter

8. Indicator whether job lost in $2^{\text {nd }}$ quarter

9. Indicator whether work experience in $4^{\text {rd }}$ quintile

10. Indicator whether job lost in $3^{r d}$ quarter

We then group individuals by full interactions of these 10 categories. This leads to 381 groups, far less than $2^{11}=2048$ potential groups due to empty cells. We then combine all groups with less than 50 observations per treatment or control group in one residual group, ending with 249 groups. We run a weighted RDD regression separately for each group so that each group has the same distribution of predicted non-employment duration. We obtain estimates of the UI effects for 249 sub-samples with on average 1459 observations per sub-sample. 


\section{B.3.1.2 Figure A14}

We repeat the methods in Figures 4, panel b and A12 described above for the sample in Card et al. (2007a). The raw data is obtained from http://www.rajchetty.com/ and we use the provided files to obtain the same analysis sample as in the original paper. For Figure A13a, individuals are first grouped into sub-samples based on predetermined observable characteristics. The first set of groups in Variable List IV is defined by 9 dummy variables (resulting in 18 groups) and by pairwise interactions between them (144 groups).

For Figure A13a, individuals are first grouped into sub-samples based on predetermined observable characteristics. The first set of groups is defined by pairwise interactions between the 12 dummy variables in Variable List V. The second set of groups is defined by grouping observables as presented in Variable List V.

\section{Appendix Table B4: Sources for Figure A14}

\section{Variable List V}

\begin{tabular}{|c|c|c|c|}
\hline \multirow[t]{2}{*}{ Variable } & & \multicolumn{2}{|c|}{ \# groups } \\
\hline & & Direct & Interactions \\
\hline Recall $^{1}$ & & 2 & 2 \\
\hline Female & & 2 & 2 \\
\hline Married & & 2 & 2 \\
\hline Blue collar & blue or white collar worker & 2 & 2 \\
\hline Austrian & & 2 & 2 \\
\hline Education & & 4 & 2 \\
\hline Layoff date & & 4 & 2 \\
\hline Seasonality & & 6 & 2 \\
\hline Region & binary: Vienna or not & 4 & 2 \\
\hline Industry & binary: sales/services or not & 5 & 2 \\
\hline \multirow[t]{2}{*}{ Firm Size } & & 4 & 2 \\
\hline & & 4 & 2 \\
\hline Total \# of groups & & & 2 \\
\hline & & 39 & 262 \\
\hline
\end{tabular}

Notes:

1. Recalled to job before previous job

2. For the binary version, we use the indicator of the highest education achieved being compulsory school 
We subsequently estimate a RDD regression as specified in Table II (using nonemployment durations instead of hazards) and Table III (wage change) of Card et al. (2007a) separately for each group. In every regression, observations are weighted by the inverse of the number of observations in its subgroup and predicted non-employment percentile. This is done in order to make the sub-samples comparable with respect to the other observable characteristics. In sum, there are 303 subgroups and we obtain 303 estimates for both the UI effect on non-employment duration and wage. The average group size is 131,167 . The UI effect on non-employment duration and wage is statistically significantly different from zero for 180 (59.4\%) and 29 (9.6\%) subgroups, respectively. They are jointly significant for $21(6.9 \%)$ subgroups.

For Figure A13b, we create a dummy indicator for each category of the variables in Variable List VI. We then apply a LARS (least angle regression) algorithm in order to decide about which variables we are going to use to define subgroups. We choose the 14 first variables chosen by the algorithm:

1. Indicator whether married

2. Blue collar indicator

3. Indicator whether Austrian

4. Indicator whether end date job lost in $2^{\text {nd }}$ quartile

5. Indicator whether end date job lost in $4^{\text {th }}$ quartile

6. Indicator whether previous employer in Lower Austria

7. Indicator whether previous employer in Upper Austria

8. Indicator whether previous employer in Steiermark

9. Indicator whether previous employer in Tirol

10. Indicator whether previous employer in Salzburg or Missing

11. Indicator whether firm size in highest quartile

12. Indicator whether previous wage in $2^{\text {nd }}$ quartile

13. Indicator whether previous wage in $3^{\text {rd }}$ quartile

14. Indicator whether previous wage in $4^{\text {th }}$ quartile 
We then group individuals by full interactions of these 14 categories $\left(2^{14}=16,384\right.$ potential groups) and combine all groups with less than 100 observations. per treatment or control group in one residual group. We run a RDD regression separately for each group weighted by the inverse of the number of observations in its subgroup and predicted non-employment percentile. There are 449 subgroups. We obtain estimates of the UI effects for 449 sub-samples. A subgroup consists of on average 1135 observations. The UI effect on non-employment duration and wage is statistically significantly different from zero for $94(20.9 \%)$ and $94(20.9 \%)$ subgroups, respectively. They are jointly significant for $36(8.0 \%)$ subgroups.

\section{B.4 Option Value of Search, Figure VII and Figure A10}

The main body of literature summarizes the effect of an UI benefit extension on search behavior in a single statistic: either mean non-employment duration or the average jobfinding hazard over the first thirty or thirty-nine weeks of the spell. Figure VII and VIII explore how the effect of the UI extension on non-employment durations and wages varies with the duration of unemployment. Figure VII plots job-finding hazards in different intervals. Panel a illustrates graphically the discontinuities of hazard rates at the cutoff, whereas the Panel $b$ plots the coefficients of a series of RD models estimated for each month of non-employment.

The UI effect on the hazard of finding a job decreases in the period before benefit exhaustion at week 30 . The period when around the time when both groups lose coverage with UI (21 to 39 weeks) is divided into two parts: at unemployment durations between

21 and 30 weeks, individuals eligible for extended UI benefits and who are further away from the benefit exhaustion date have lower hazard rates. The negative difference persists in the second period between 31 and 39 weeks of unemployment. Interestingly, in the first two months after both groups have exhausted benefit eligibility, individuals with higher UI benefit durations have higher hazard rate of finding jobs. The magnitude of the positive effect is of the same size as the negative effect in weeks 21 - 39. At nonemployment durations further away from UI exhaustion for both groups, the differences at the age discontinuity disappear.

The finding that the UI effect on the hazard rate of finding a job decreases during the first 30 weeks suggests that workers are forward-looking: the value of finding a job depends on the time to benefit exhaustion. This is similar to option value idea of Stock and Wise (1990). To build on the language of Coile and Gruber (2007), if the worker finds a job before benefit exhaustion, the option of an extra UI is lost. Continuing to search 
preserves the option of using the UI extension, hence the terminology: the "option value" of search.

There are two unexpected features of the hazard rate pattern. First, during the last month of benefit eligibility, the hazard rate of finding a job increases at the discontinuity increases for the group whose benefits are expiring relatively to the other group. The magnitude of this effect is the same for both groups. Second, agents eligible for the UI benefit extension to 39 weeks have higher finding a job rates in the first two months after benefit exhaustion compared to agents whose UI benefits were exhausted at 30 weeks. One can show that the first finding is equivalent to a convex hazard rate curve close to benefit exhaustion. However, the second finding cannot be explained by the job search model presented in the Section 3.1. The main difficulty stems from the fact that in the search model, UI has no impact on the likelihood of finding a job after benefit exhaustion. Instead, a spike in the job finding rate at benefit exhaustion would be consistent with both findings. ${ }^{4}$ This can be interpreted as suggestive evidence for leisure-subsidy model. ${ }^{5}$

Can the hazard rate patterns in Figure VII be explained by selection? As the pool of unemployed agents shrinks with unemployment duration, the change in the discontinuity in non-employment durations at the age cutoff in one period could be caused by selection in the previous periods. To produce the pattern observed in Figure VII, i.e. the drop and subsequent rise in the discontinuity, individuals with a higher hazard rates (shorter unemployment duration) would have to be more responsive to the UI extension. In that case, the change in UI duration would shift agents with higher hazard rates to find jobs later relative to those with lower hazard rates. This would result in an increase in the average hazard rate after an initial drop, exactly the pattern of Figure VII, panel $b$. However, the finding reported in Section 3.3 and Appendix table A7 shows the opposite, namely that agents with longer predicted non-employment durations are more responsive to a UI extension. This suggests that selection is not driving the observed hazard rate pattern over the unemployment spell.

One important finding depicted in Figure 5, panel b deserves attention. Namely, UI extension from 30 to 39 weeks affects the likelihood of finding a job within the first month of unemployment. Note that this finding is not affected by selection problems

\footnotetext{
${ }^{4}$ There is a large literature on the spike at benefit exhaustion, see for example Moffitt (1985), ?, Meyer (1990) , and Card et al. (2007b). However, the spike needed to explain the pattern in Figure VII seems to be wider than the average spike observed in that literature (i.e. a week around benefit exhaustion).

${ }^{5}$ Relatedly, Boone and van Ours (2012) suggest a model in which employer and unemployed agent agree on a starting date of the new contract. Agents covered with UI ask for a delay that creates bunching before benefit exhaustion. Also see Gauthier-Loiselle (2011).
} 
as it does not refer to a conditional likelihood. It depicts a change in the unemployed's search decisions around 30 weeks prior to UI extension. To the best of our knowledge, this is the first evidence of long-term forward-looking behavior of unemployed agents.

\section{B.4.1 Bounding exercise of the dynamic selection}

Figure A10 extends the analysis of the dynamic effect of UI extension on job finding hazard rates and wage presented in Figure 5 in the paper. It does so by adding bounds correcting for the attrition over unemployment spell (dynamic selection). Two bounds for dynamic UI effects are marked with + symbols, and connected with a solid vertical line. They corresponds to an upper and a lower bounds constructed by assuming that the difference in attrition around the age- 40 cutoff at each point in time corresponds to highest or lowest value of observed values in the distribution of outcome of interest.

In panel a, the upper (lower) bound measures the effect of the UI extension on hazard of finding a job at time $\mathrm{t}$ after layoff by assuming that all the differentially attrited individuals by time $t$ would have (not) found the job at $t$ if they have stayed unemployed until then. In panel $b$, the upper (lower) bound measures the effect of the UI extension on post-unemployment wages of jobs found at time $t$ after layoff by assuming that all the attrited individuals by time $t$ would have found the job at $t$ with a wage corresponding to the upper (lower) part of the wage distribution observed from the matches created at time $t$.

\section{References}

Baily, M. N. (1978). Some aspects of optimal unemployment insurance. Journal of Public Economics 10(3), 379-402. 17, 19

Boone, J. and J. C. van Ours (2012). Why is there a spike in the job finding rate at benefit exhaustion? De Economist 160(4), 413-438. 35

Card, D., R. Chetty, and A. Weber (2007a). Cash-on-hand and competing models of intertemporal behavior: New evidence from the labor market. The Quarterly Journal of Economics 122(4), 1511-1560. 27, 28, 29, 32, 33

Card, D., R. Chetty, and A. Weber (2007b). The spike at benefit exhaustion: Leaving the unemployment system or starting a new job? American Economic Review 97(2), 113-118. 35 
Chetty, R. (2006). A general formula for the optimal level of social insurance. Journal of Public Economics 90(10), 1879-1901. 17, 19

Coile, C. and J. Gruber (2007). Future social security entitlements and the retirement decision. The review of Economics and Statistics 89(2), 234-246. 34

Gauthier-Loiselle, M. (2011). Find a job now, start working later does unemployment insurance subsidize leisure? Technical report. 35

Gruber, J. (1997). The consumption smoothing benefits of unemployment insurance. American Economic Review 87(1), 192-205. 19

Lalive, R. (2007). Unemployment benefits, unemployment duration, and postunemployment jobs: A regression discontinuity approach. American Economic Review 97(2), 108-112. 28, 29

Meyer, B. D. (1990, July). Unemployment insurance and unemployment spells. Econometrica 58(4), 757-82. 35

Moffitt, R. (1985, April). Unemployment insurance and the distribution of unemployment spells. Journal of Econometrics 28(1), 85-101. 35

Schmieder, J. F., T. von Wachter, and S. Bender (2013). The effect of unemployment insurance extensions on reemployment wages. Technical report. 28, 29

Schmieder, J. F., T. von Wachter, and S. Bender (2016). The effect of unemployment benefits and nonemployment durations on wages. American Economic Review 106(3), 739-77. 28

Shimer, R. and I. Werning $(2007,08)$. Reservation wages and unemployment insurance. The Quarterly Journal of Economics 122(3), 1145-1185. 16

Stock, J. H. and D. A. Wise (1990). Pensions, the option value of work, and retirement. Econometrica 58(5), 1151-1180. 34 
Appendix Figure A1

UI Effect on Predicted Non-Employment Duration
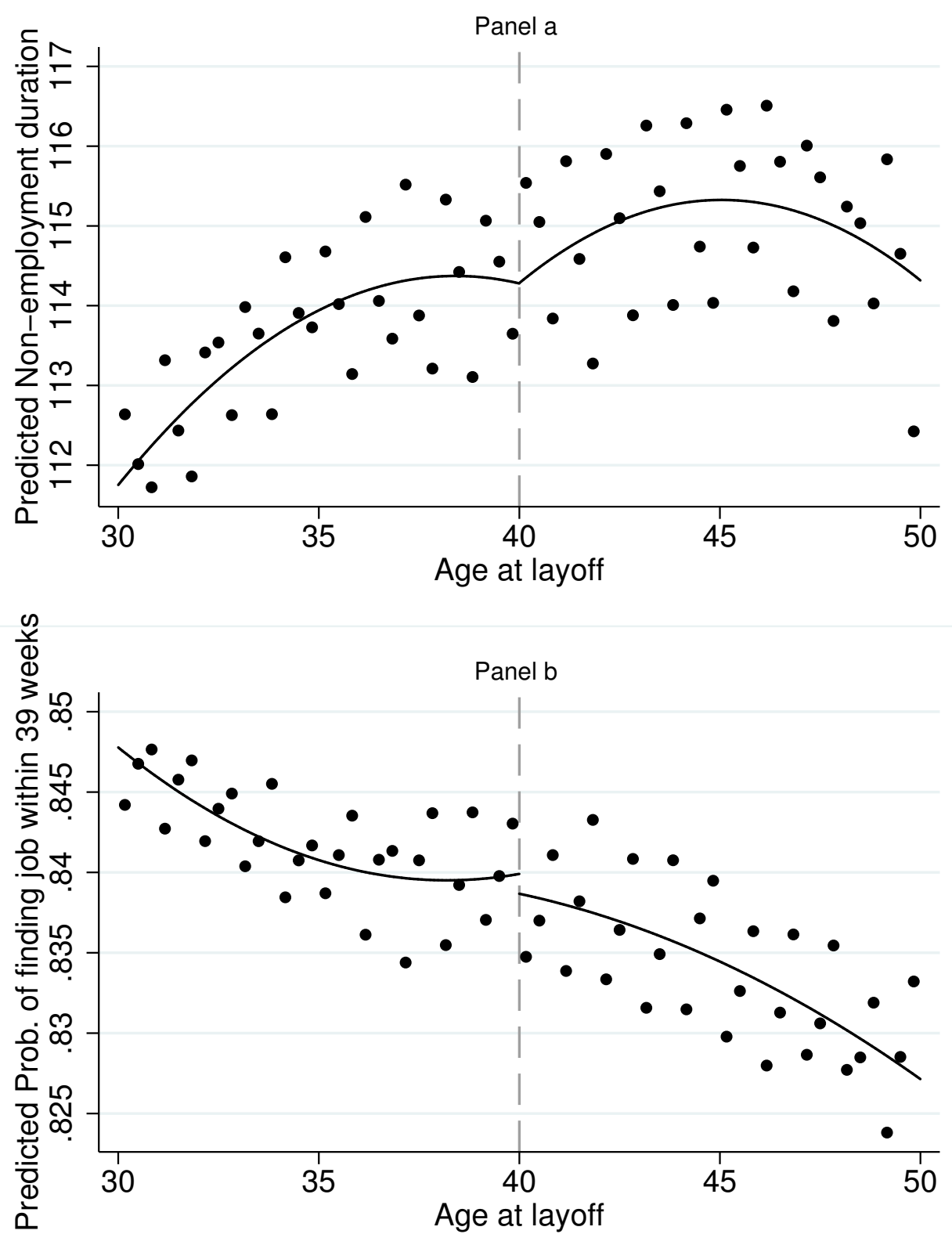

Note: Panel a plots the predicted non-employment durations (time to next job) for each age. Observations with non-employment durations of more than two years are excluded. Panel b plots the predicted probability of finding a job within 39 weeks of layoff for each
age. The dashed line denotes the cutoff for extended Ul benefits eligibility. The solid line represents quadratic fits.
Appendix Figure A2

UI Effect on Predicted Wage
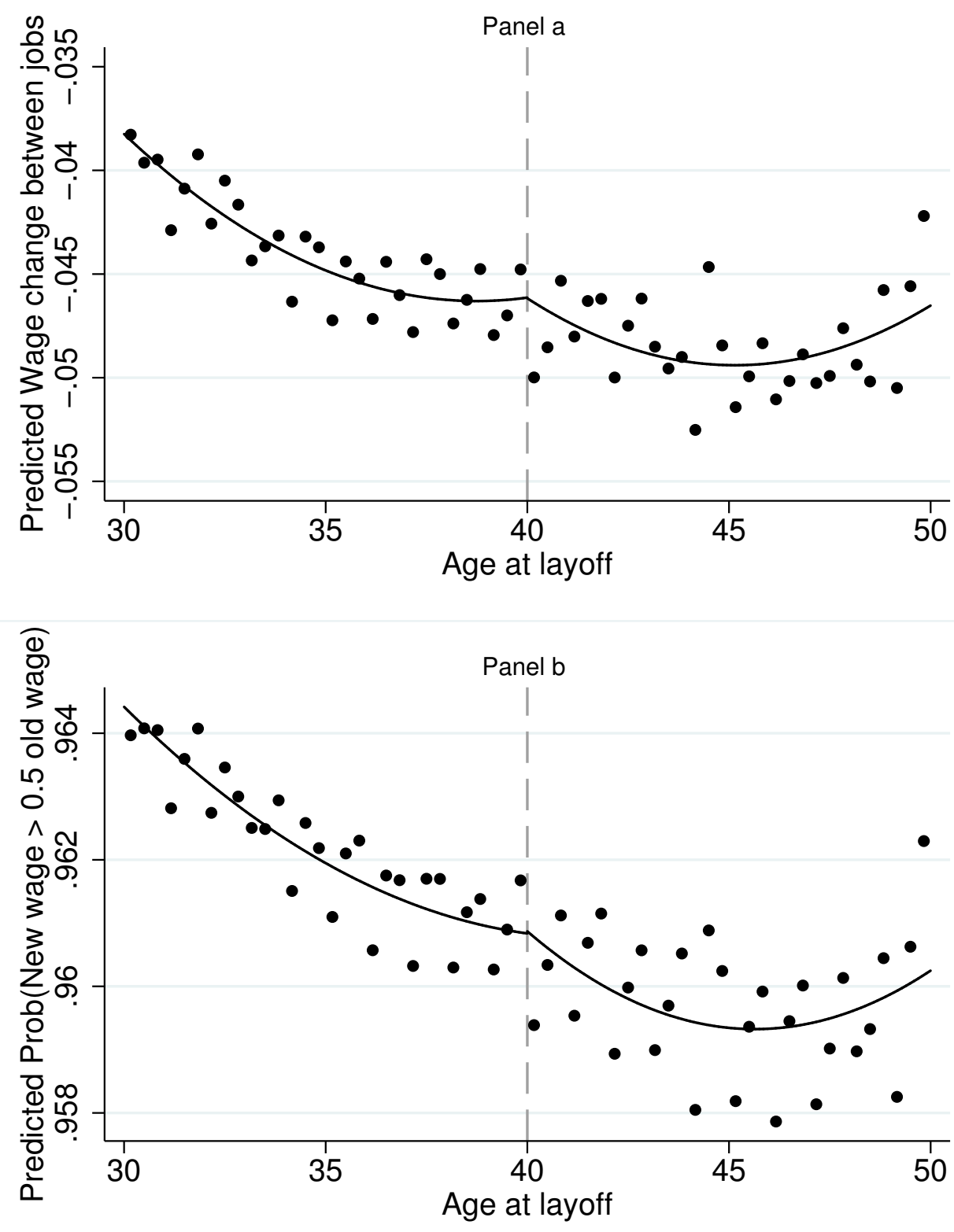

Note: Panel a plots the predicted change in log wage between the post- and pre-unemployment job for each age. Panel $b$ plots the with predicted non-employment durations of more than two years are excluded. The dashed line denotes the cutoff for extended UI
benefits eligibility. The solid line represents quadratic fits. 
Appendix Figure A3

Dynamic Effect of UI Extension on Hazard Rate

Panel a
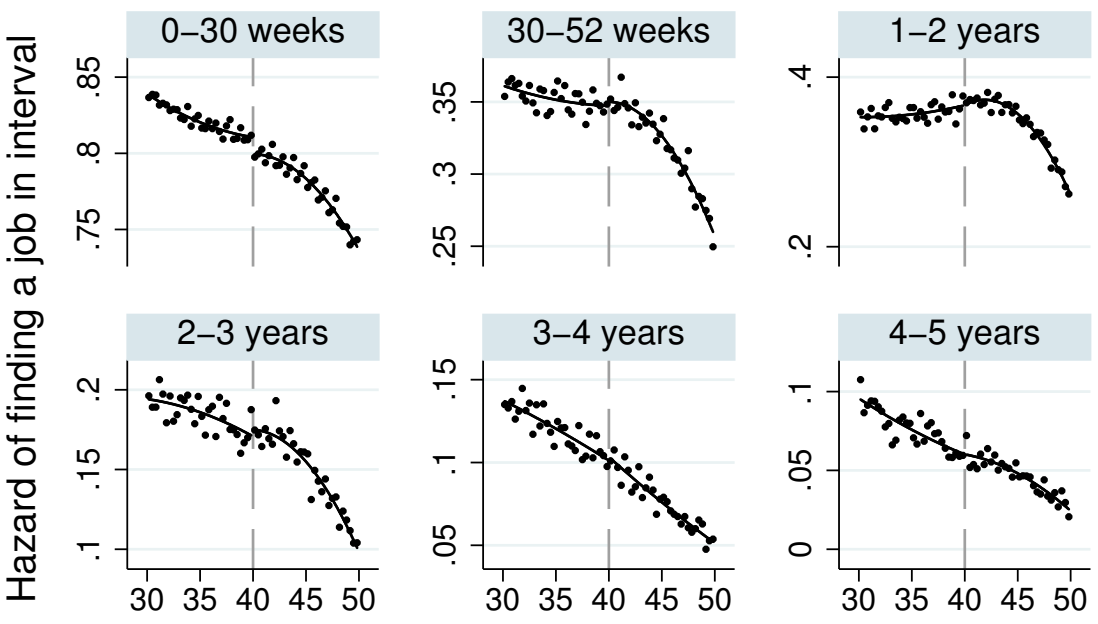

Age at layoff

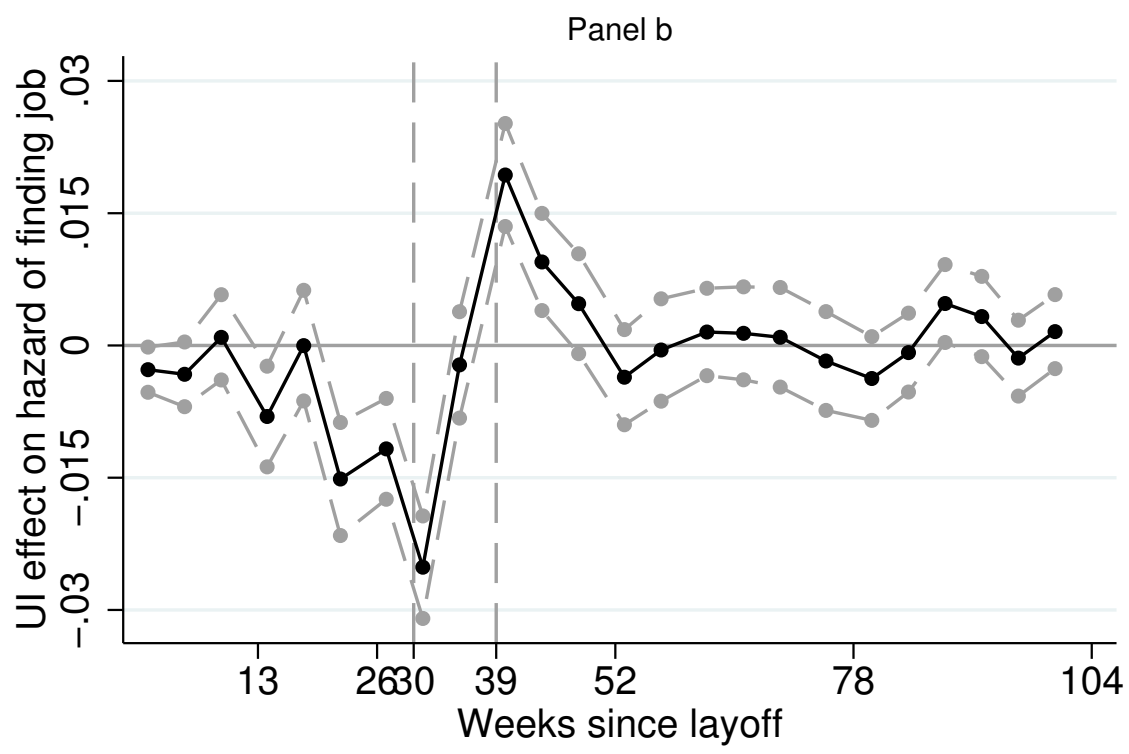

Note: Panel a plots the hazard of finding a job across the non-employment period against the age at layoff. That is, for instance, the probability of finding a job in weeks 30-52 conditional on not having found a job until week 30 . Panel b plots the RD coefficients from different regressions for monthly hazard rates,
Appendix Figure A4

Dynamic Effect of UI Extension on Wage

Panel a

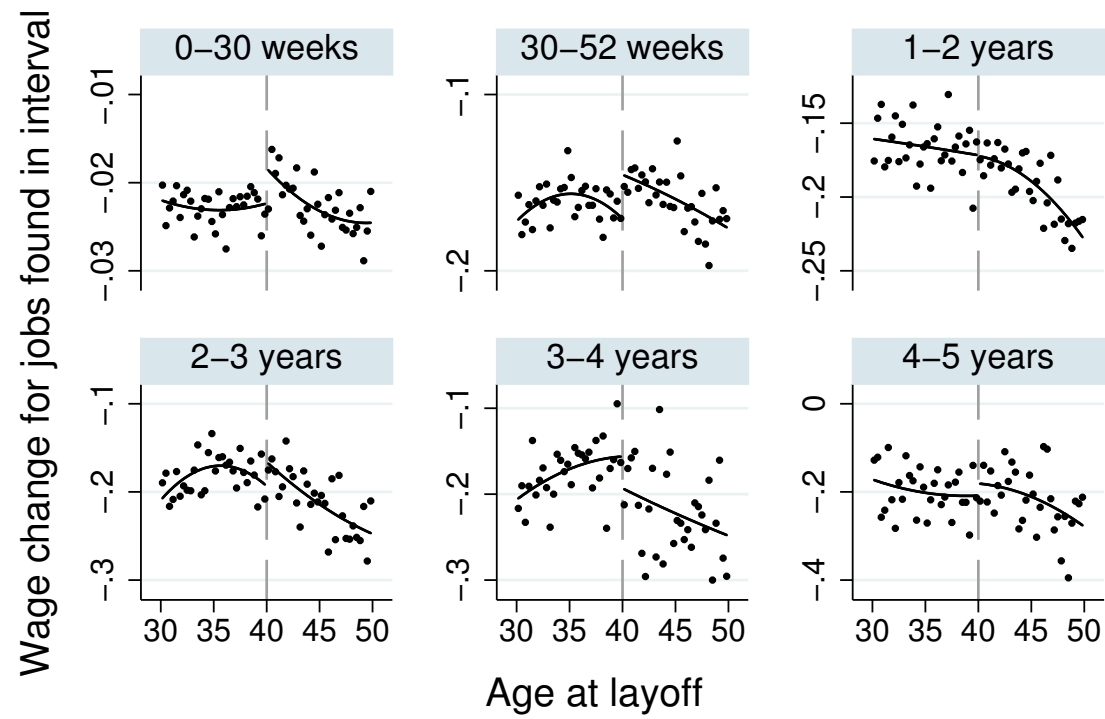

Panel b

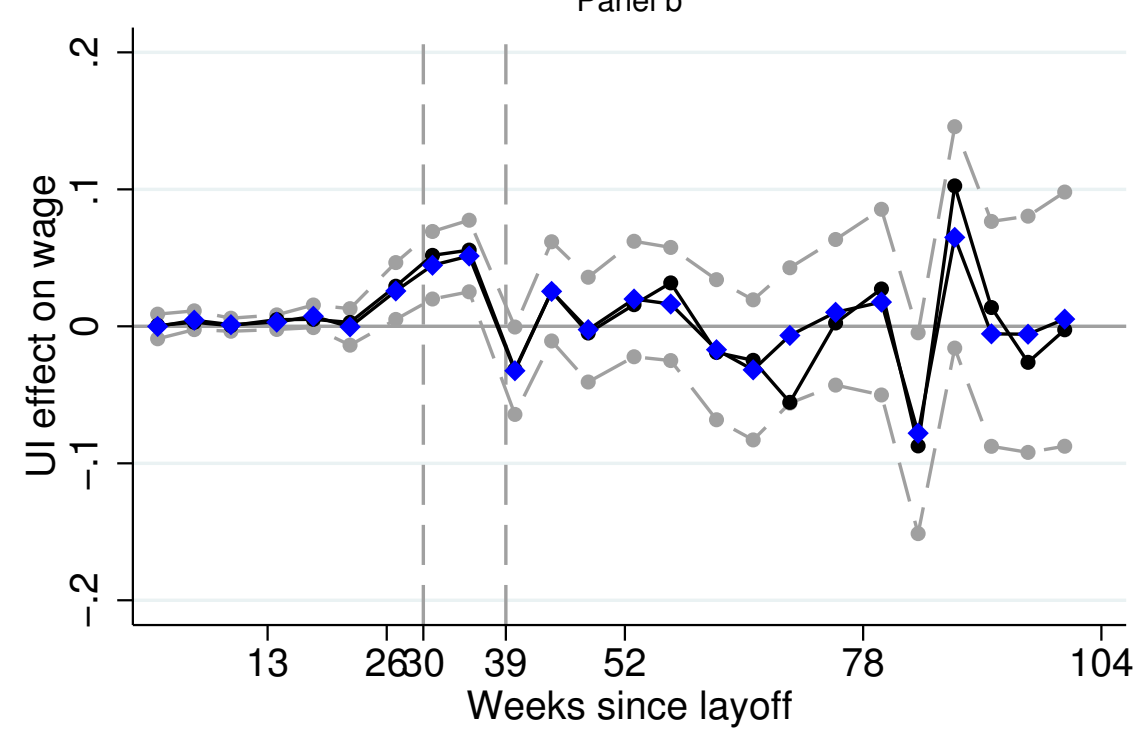

Note: Panel a plots log wage changes for individuals who exit unemployment in different periods against the age at layoff. Panel b plots the RD coefficients from different regressions for wage change in each non-employment month. 
Appendix Figure A5
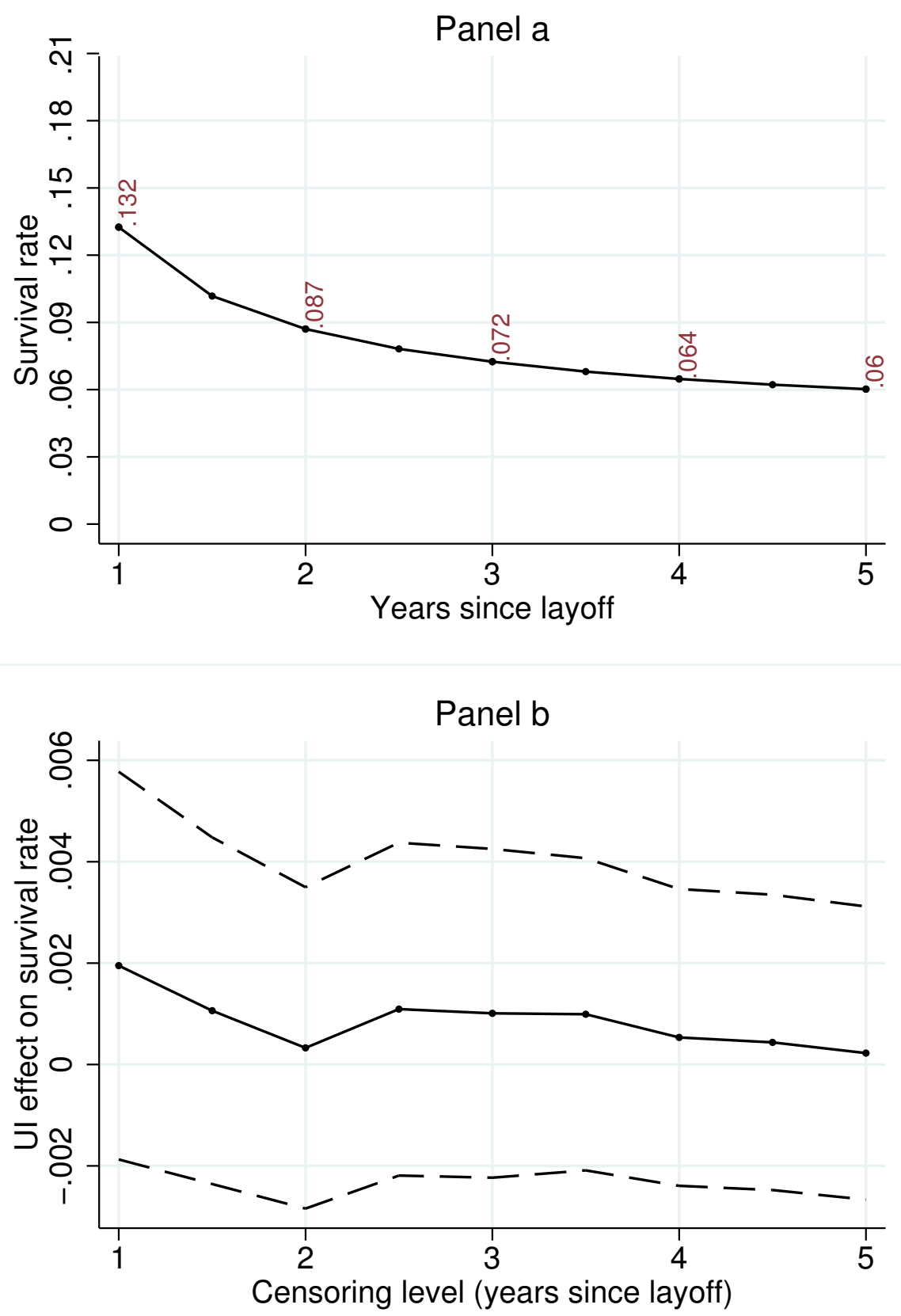
Panel A plots the survival rate again the unemployment duration. Panel B plots the effect of the Ul extension on each
lelve of survival rate. The RD estiamtes are measured using the optimal bandwitch following Imbens and Kalyanaraman (2012).
Appendix Figure A6

Panel a

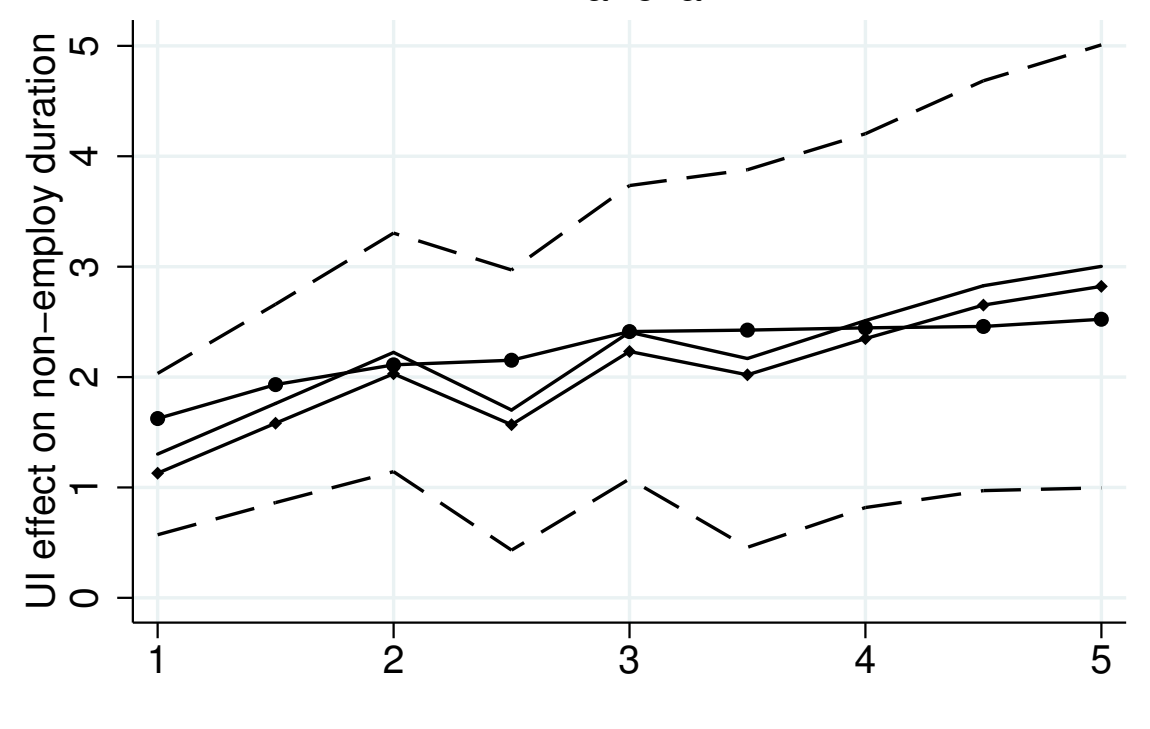

Panel b

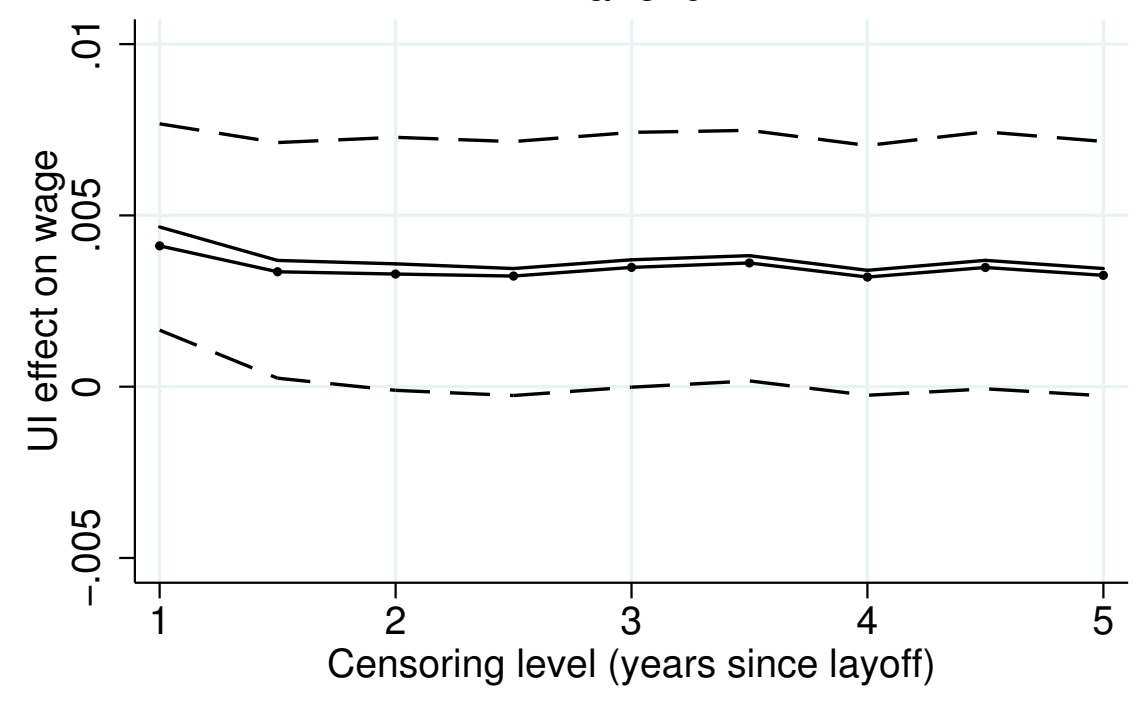

Panel A plots three measures of UI duration effect. First, solid line corresponds to the UI duration effect based on censored measure of duration. Second, the line with diamond marker is the simple correction of the latter were the correction multiplier is the corresponding CDF. Third measure of wage measure in solid line, and the correct version marked by squares. All unemployment spells, which are censored on censored date of the dataset before they reach 5 years, are excluded. See section 1.3 in the Online Appendix for details of how these measures are defined. 
Appendix Figure A7
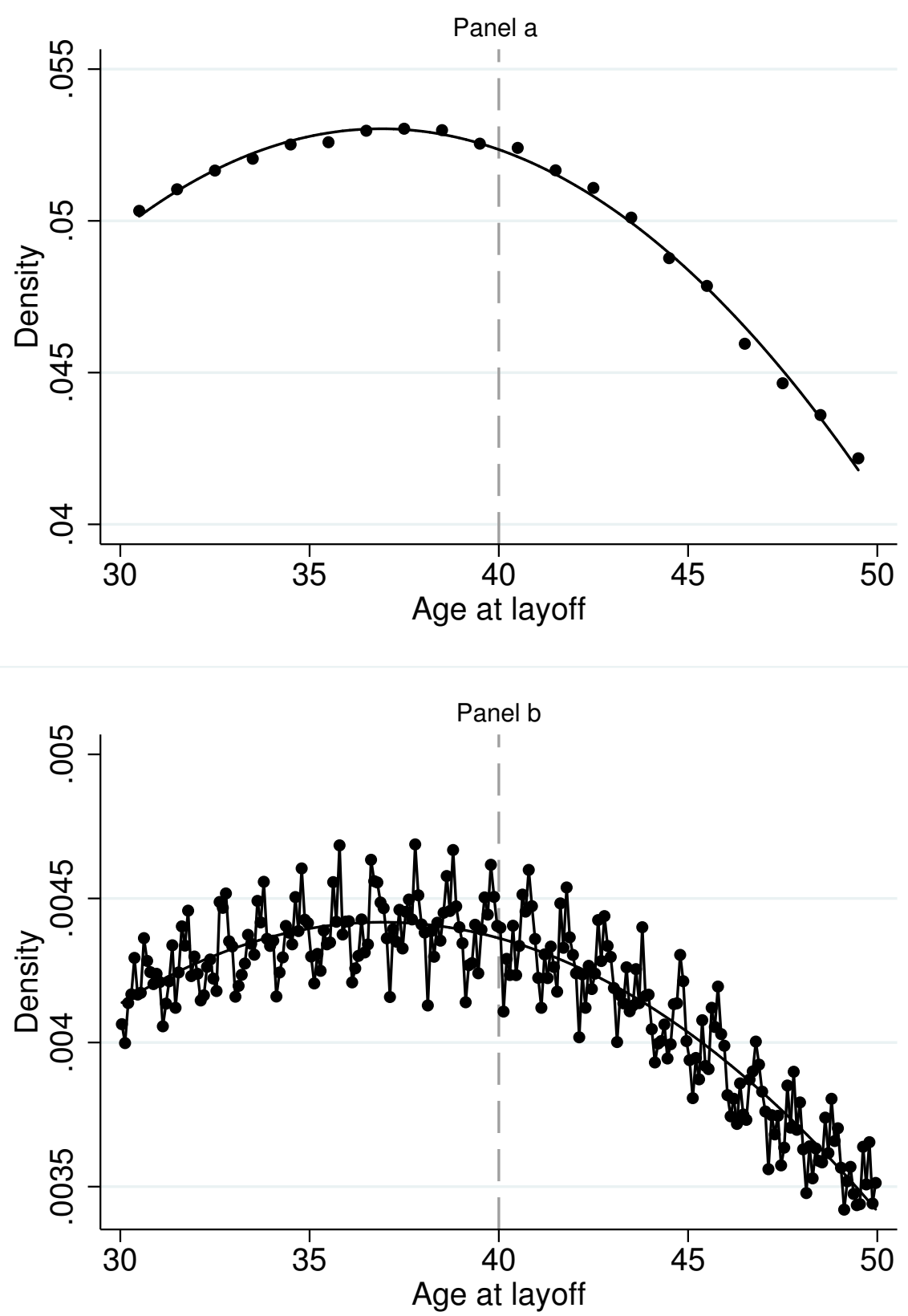

Panel a plots the frequency of job separations by age-year category, i.e. the total number of individuals in the analysis sample within each age-year category. Panel $b$ does the same at monthly frequency. The dashed line denotes the cutoff for
extended UI benefits eligibility.
Appendix Figure A8

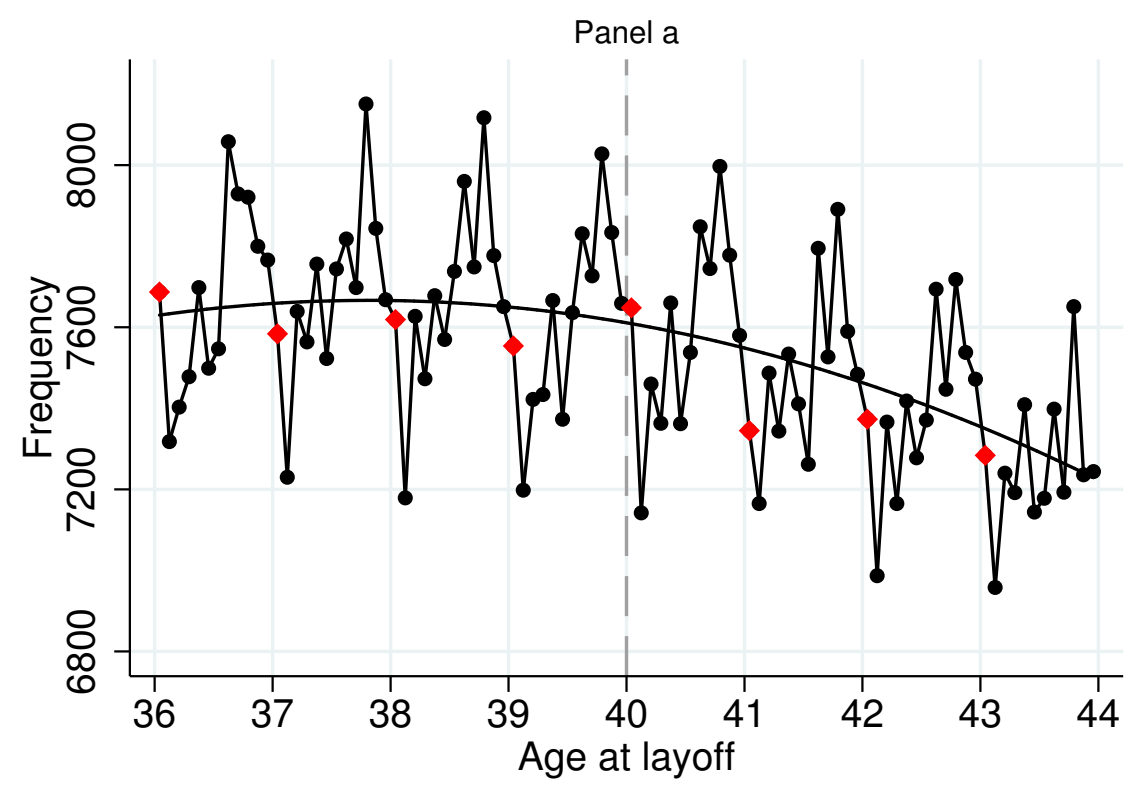

Panel b
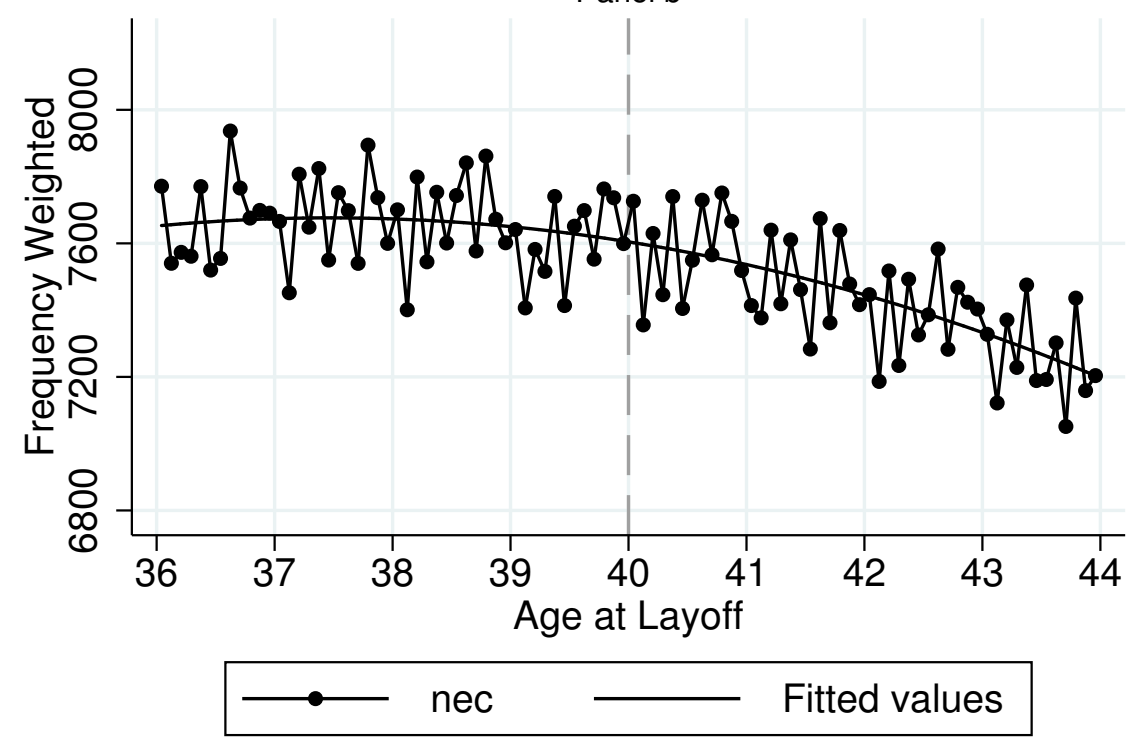

Panel a plots the frequency of job separations by age-month category for individuals aged 36 to 44 . The red dots highlight the first month of each year. Panel b is similar to Panel a, except that individuals are weighted by birth months in the
population. The dashed line denotes the cutoff for extended UI benefits eligibility. 
Appendix Figure A9

The effect of $\mathrm{Ul}$ extension on survival rate

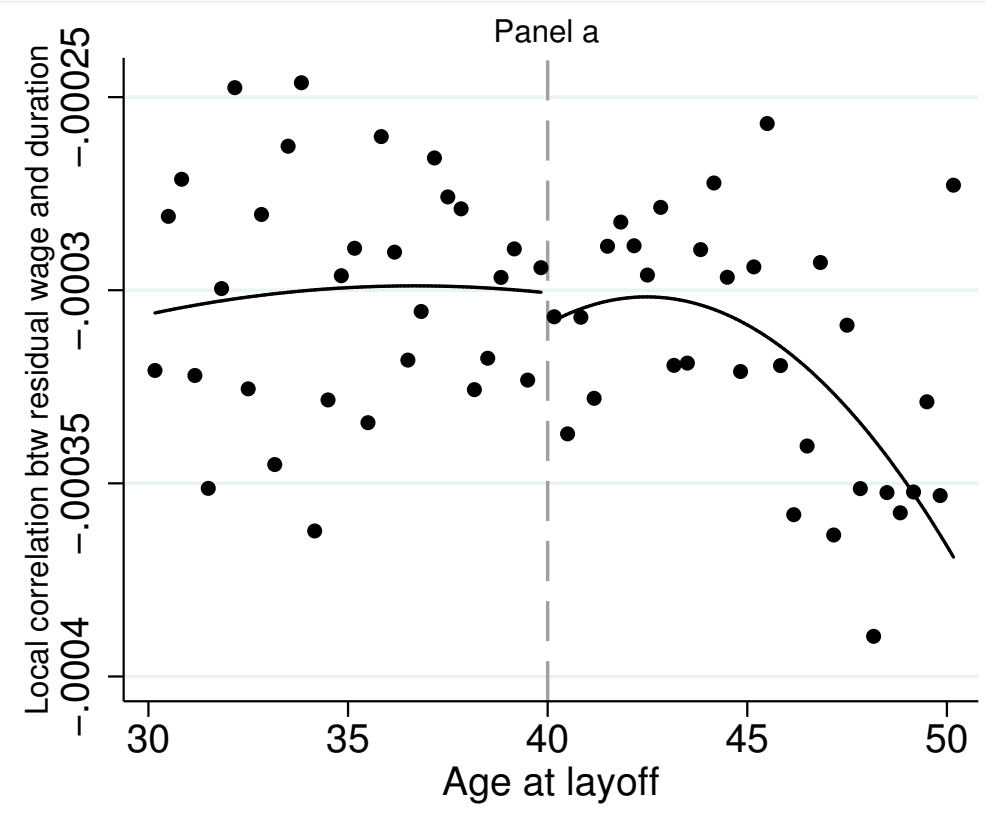

Panel b

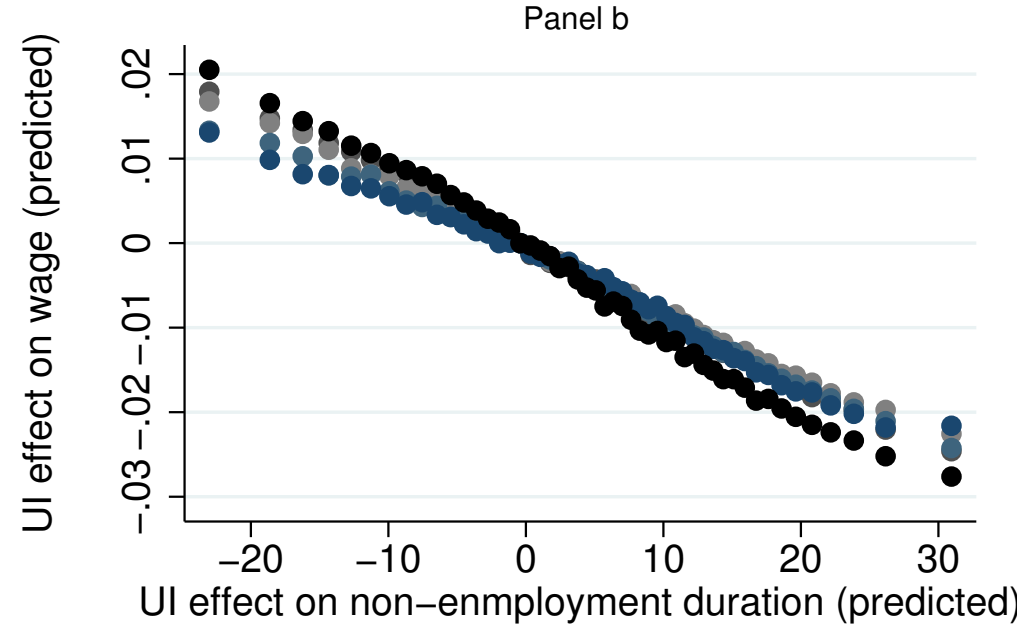

- 1. Highest Negative DD

- 3

- 4 5. lowest Negative DP

Subfigure $\mathrm{a}$ is measuring the effect of $\mathrm{Ul}$ extension on the correlation between two resduals. Subfigure $b$ plots the predicted wage change against predicted non-employment duration effect of UI extension, by groups with different degree of observed dudarion dependence. (see Section A.4)
Appendix Figure A10
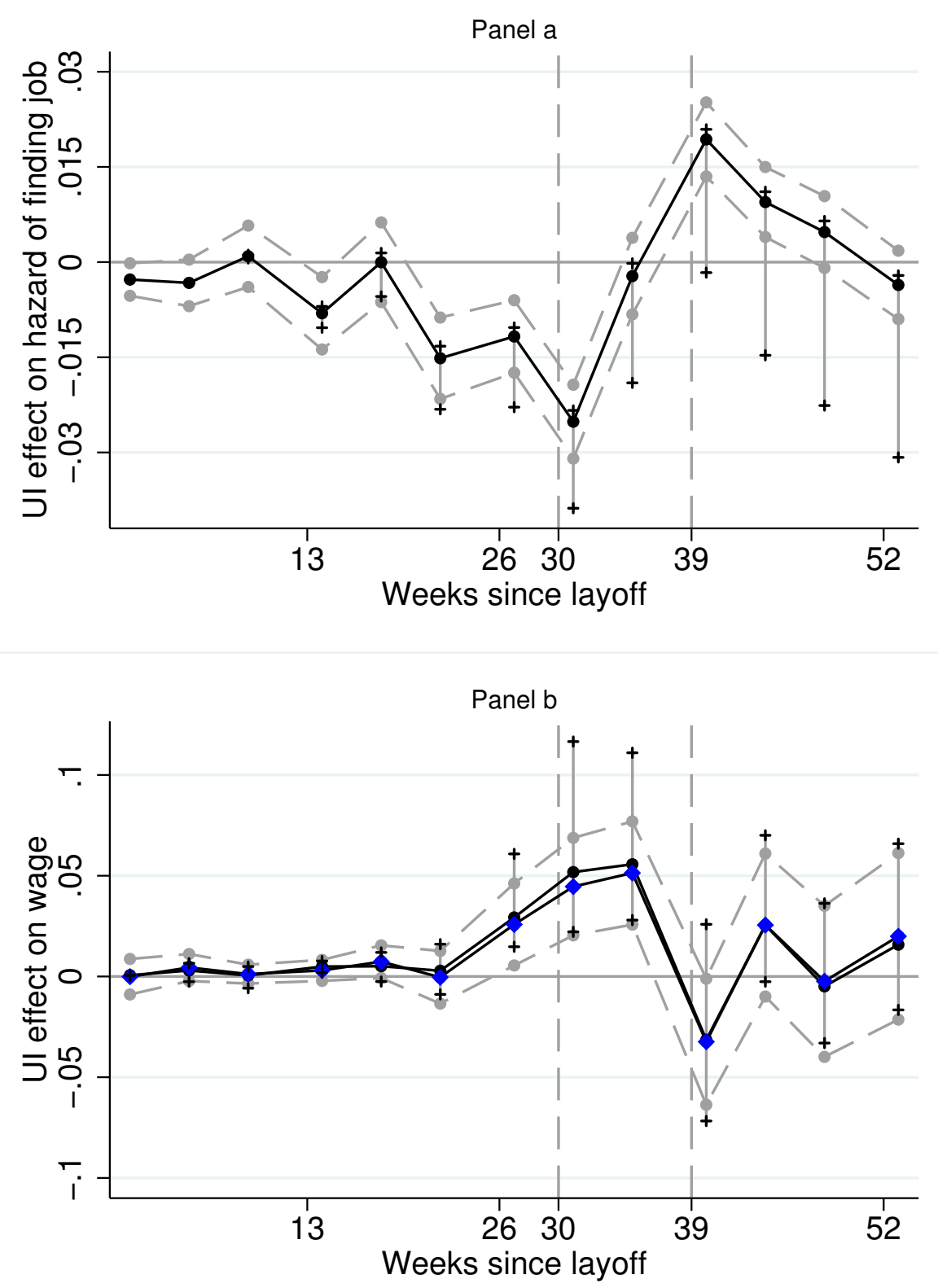

Note: This figure extends the analysis of the dynamic effect of $\mathrm{Ul}$ extension on job finding hazard rates and wage presented in Figure Vil and VII) Th the paper. It does so by adding bounds correcting tor the attrition over the unemployment spell (dynamic selection). Two bounds for dynamic Ul effects are marked with + symbols, and connected with a solid vertical line. cutoff at each point in time corresponds to highest or lowest value of observed values in the distribution of outcome of interest. 
Appendix Figure A11: The role of seasonality

UI Effect on Non-Employment Duration
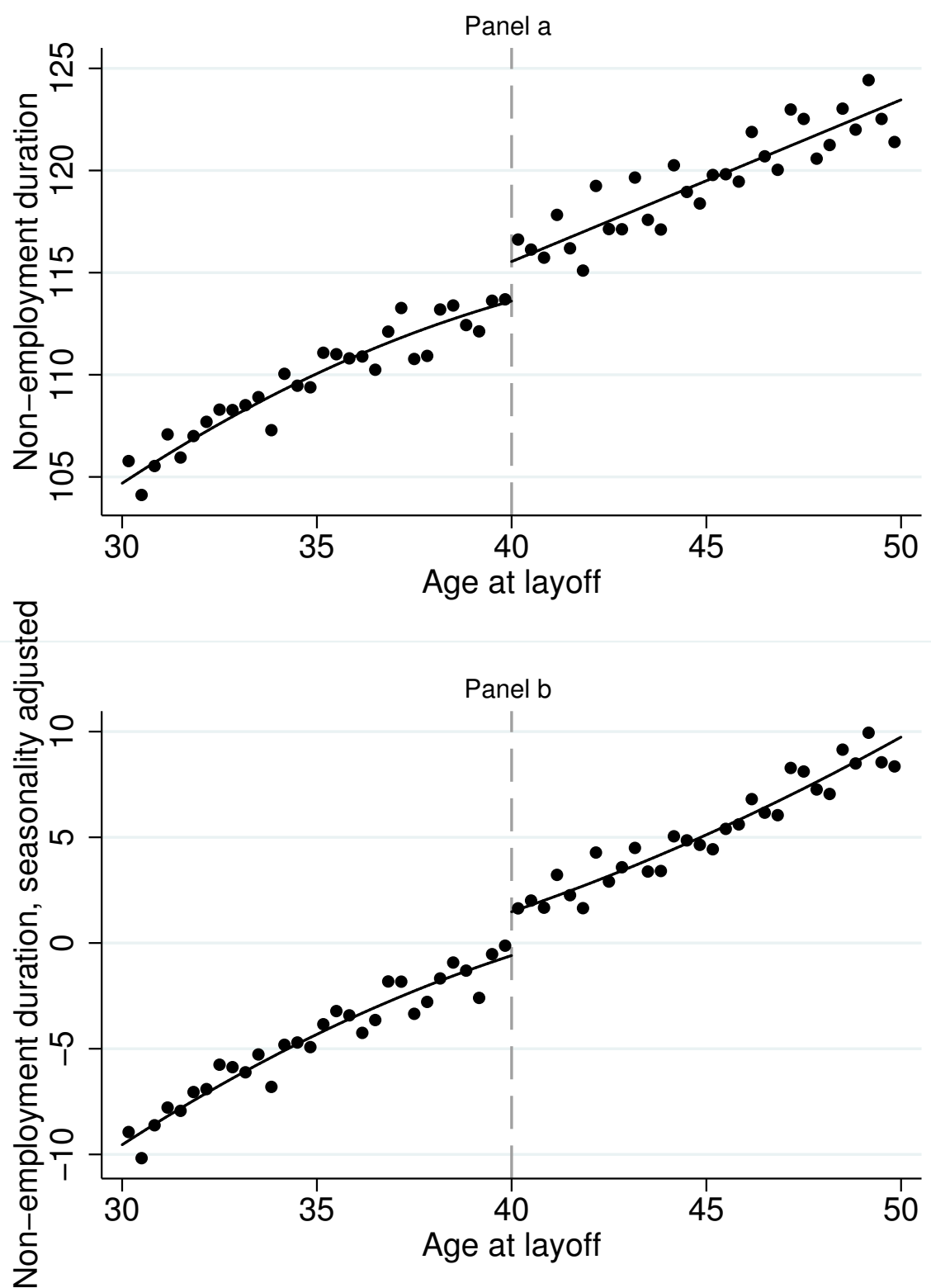

Note: Panel a plots average non-employment durations (time to next job) for each age. Observations with non-employment is adjusted for seasnal patterns using birth and layeff calondar month fixed effects similar to Tabile for The The dashed vertical line denotes the cutoff for Ul benefit eligibility extension from 30 to 39 weeks at the age-40 threshold.
Appendix Figure A12: The role of seasonality UI Effect on Wage
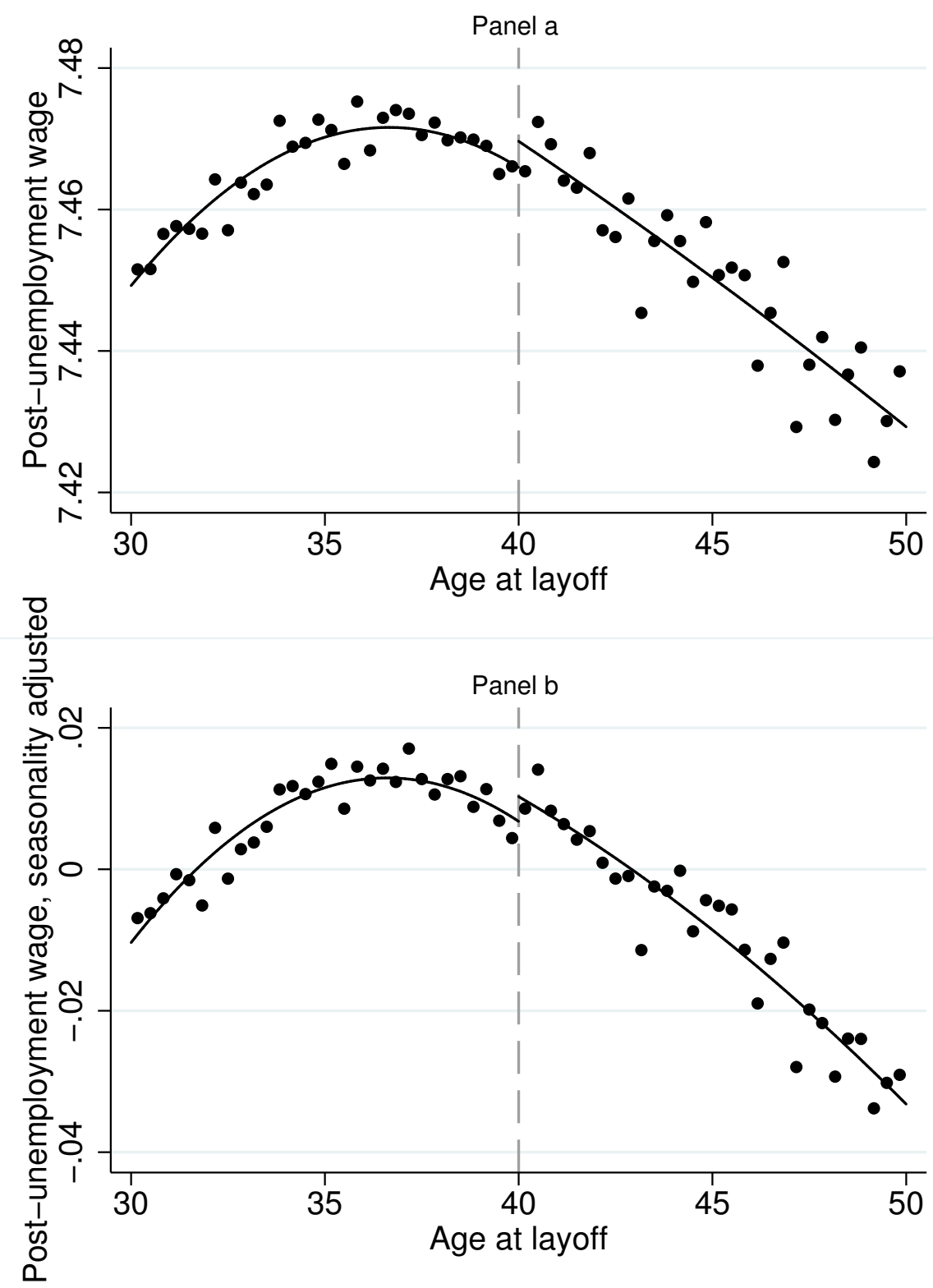

Note: Panel a plots average change in log wage at post-unemployment jobs for each age. Panel $b$ plots the same outcome bu similar to Table A6. For both subfigures observations with non-employment durations of more than two years are excluded. The dashed vertical line denotes the cutoff for Ul eligibility extension from 30 to 39 weeks at the age-40 threshold. The solid
lines represent quadratic fits. Age bins corresponds to 4 -month intervals. 
Appendix Figure A13

UI wage vs. duration effects
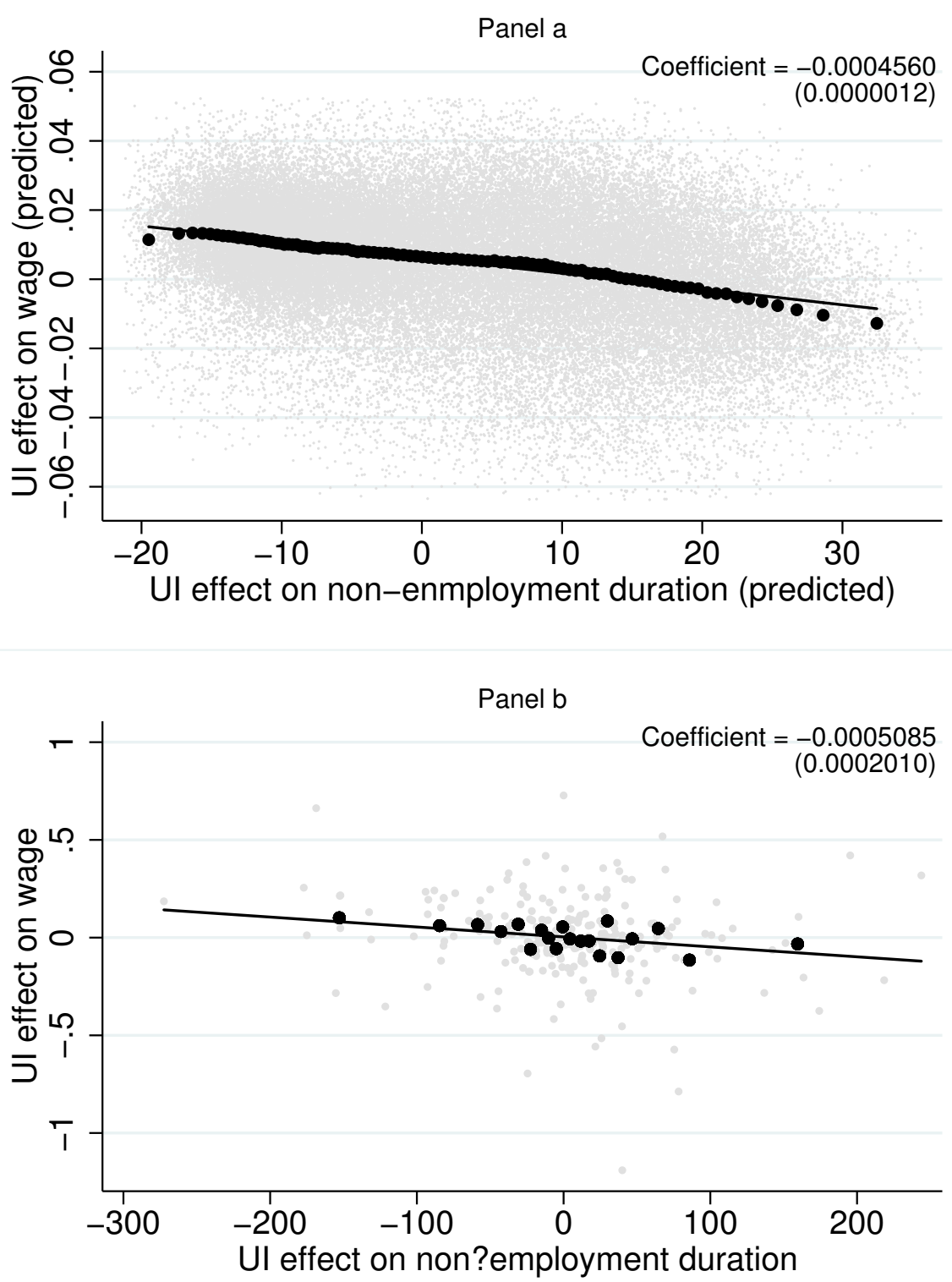

Note: This figure provides empirical evidence for a negative relation between the UI extension effect on non-employment duration
its effect on post-unemployment wage. Panel a plots the UI effect on wage against the non-employemnt effect, both predicted its effect on post-unemployment wage. Panel a plots the Ul effect on wage against the non-employemnt effect, both predicted
using ex-ante pre-determinedobservables, e.g. inudstry, occupation, tenure, etc. It shows both row data as well as a $100-$ binned using ex-ante pre-determinedobservables, e.g. inudstry, occupation, tenure, etc. It shows both row data as well as a 100-binned
scatter plot, where the solid line and the coefficient correspond to the best linear fit on the underlying data using OLS. The raw data correspond to a random $5 \%$ of the population, trimmed at $.1 \%$. Panel b is replicates the re-sampling method similar to
figure $\mathrm{Vb}$ but with full interactions among few covartiates selected using a machine learning algorithm (see Appendix B.3).
Appendix Figure A14

UI wage vs. duration effects, Ul extension 20-30 wks
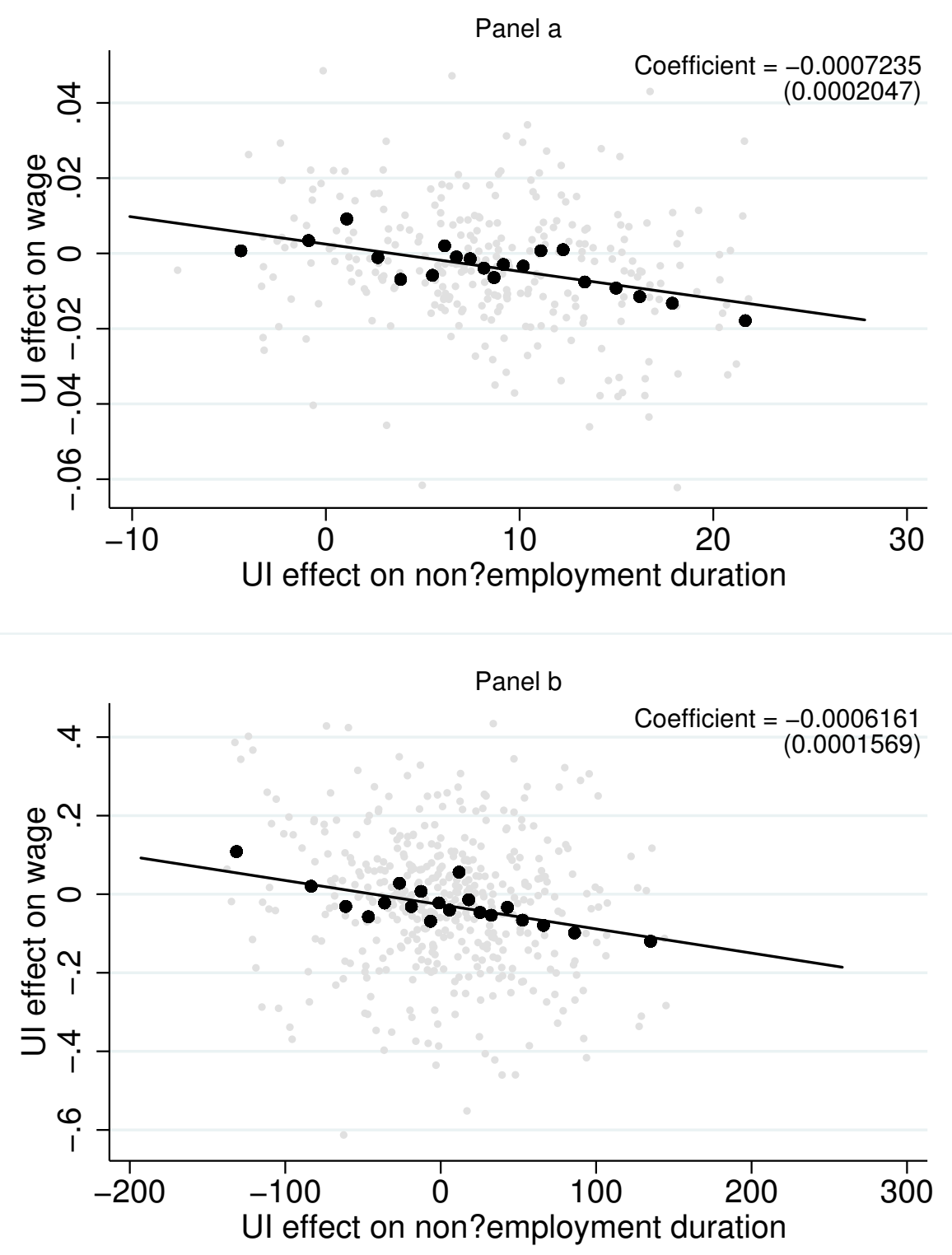
Note: This figure provides empirical evidence for a negative relation between the UI effect on non-employment duration and its
effect on post-unemployment wage for the analysis sample in Card, Chetty, Weber (2007a). Both panels plot the estimated UI dummy indicators plus first-order interactions between them Sur subgroups in the sample. Subgroups in panel a are derined by between dummy indicators (see Appendix B.3). They show both row data (trimmed at 1\%) as well as a binned scatter plot,
where the solid line and the coefficient correspond to the best linear fit on the underlying data using OLS. 
Appendix Table A1: Descriptive Statistics

\begin{tabular}{|c|c|c|c|c|}
\hline & Population & Sample 1 & Sample 2 & Final Sample \\
\hline & $(1)$ & (2) & (3) & (5) \\
\hline Female & 0.40 & 0.33 & 0.26 & 0.25 \\
\hline Married & 0.33 & 0.46 & 0.54 & 0.53 \\
\hline Austrian & 0.59 & 0.73 & 0.78 & 0.77 \\
\hline \multirow[t]{2}{*}{ Age } & 36 & 37 & 40 & 40 \\
\hline & (11) & (11) & (6) & (6) \\
\hline Education, more than compulsory & 0.57 & 0.52 & 0.51 & 0.53 \\
\hline Blue-collar & 0.56 & 0.74 & 0.77 & 0.76 \\
\hline \multirow{2}{*}{ Tenure } & 1290 & 907 & 1008 & 984 \\
\hline & (1687) & (1373) & (1371) & (1384) \\
\hline \multicolumn{5}{|l|}{ Share of time employed } \\
\hline Last 2 years & 0.87 & 0.83 & 0.88 & 0.88 \\
\hline Last 5 years & 0.77 & 0.75 & 0.87 & 0.87 \\
\hline Last 10 years & 0.65 & 0.66 & 0.85 & 0.85 \\
\hline \multirow[t]{2}{*}{ Monthly wage (real Euros) } & 1663 & 1614 & 1798 & 2007 \\
\hline & (2417) & (1534) & (1702) & (1875) \\
\hline \multirow[t]{7}{*}{ Firm characterisit } & 901 & 316 & 236 & 225 \\
\hline & (3228) & (1684) & (1248) & (1127) \\
\hline & 0.61 & 0.65 & 0.71 & 0.71 \\
\hline & 35.71 & 35.75 & 36.46 & 36.75 \\
\hline & 5.50 & 6.06 & 5.33 & 5.16 \\
\hline & 1733 & 1671 & 1787 & 1992 \\
\hline & (700) & (678) & (694) & (643) \\
\hline \multirow[t]{4}{*}{ Industry } & 0.03 & 0.04 & 0.04 & 0.04 \\
\hline & 0.19 & 0.18 & 0.18 & 0.17 \\
\hline & 0.16 & 0.30 & 0.36 & 0.37 \\
\hline & 0.62 & 0.48 & 0.42 & 0.42 \\
\hline \multicolumn{5}{|l|}{ Post layoff outcomes } \\
\hline \multirow[t]{2}{*}{ Non-employment duration } & 87 & 122 & 116 & 114 \\
\hline & (133) & (117) & (111) & (113) \\
\hline Find job within 30 weeks & 0.70 & 0.74 & 0.80 & 0.80 \\
\hline Find job within 2 years & 0.80 & 0.86 & 0.91 & 0.91 \\
\hline Temporary layoffs & 0.43 & 0.46 & 0.52 & 0.52 \\
\hline \multirow{2}{*}{$\begin{array}{l}\text { Recalled } \\
\text { Wage change }\end{array}$} & 0.33 & 0.52 & 0.56 & 0.56 \\
\hline & 0.020 & -0.019 & -0.041 & -0.046 \\
\hline Wage change & $(0.376)$ & $(0.343)$ & $(0.323)$ & $(0.315)$ \\
\hline If recalled & 0.022 & 0.026 & 0.023 & 0.020 \\
\hline If change firm & 0.019 & -0.050 & -0.092 & -0.098 \\
\hline \multirow[t]{2}{*}{ Post-unemployment tenure } & 938 & 554 & 606 & 558 \\
\hline & (1443) & (962) & (1016) & (868) \\
\hline If recalled & 667 & 432 & 463 & 439 \\
\hline If change firm & 1069 & 686 & 791 & 711 \\
\hline Observations & 17192624 & 5942834 & 2261089 & 1738787 \\
\hline \multicolumn{5}{|l|}{ Sample restrictions: } \\
\hline Age & $20-60$ & $20-60$ & $30-50$ & $30-50$ \\
\hline \multirow{2}{*}{$\begin{array}{l}\text { Minimum tenure of } 28 \text { weeks } \\
\text { Laid-off workers }\end{array}$} & Yes & Yes & Yes & Yes \\
\hline & & Yes & Yes & Yes \\
\hline \multirow{2}{*}{$\begin{array}{ll}\text { Experience } & 3 \text { years over } 5 \text { years } \\
& 6 \text { years over } 10 \text { years }\end{array}$} & & & Yes & Yes \\
\hline & & & Yes & Yes \\
\hline Layoff after August 1, 1989 & & & & Yes \\
\hline
\end{tabular}


Appendix Table A2: Sensivity of RD design to bandwidth and functional form

\begin{tabular}{|c|c|c|c|c|c|c|c|c|c|c|c|c|}
\hline \multirow[b]{2}{*}{ Dependent variable } & \multicolumn{11}{|c|}{ Discontinuity at age 40} & \multirow{2}{*}{$\begin{array}{c}\text { Mean } \\
\text { Dep. Var. }\end{array}$} \\
\hline & (1) & (2) & (3) & $(4)$ & $(5)$ & $(6)$ & (7) & (8) & (9) & $(10)$ & $(11)$ & \\
\hline Non-employment duration (days) & $\begin{array}{l}1.932^{* * *} \\
(0.526)\end{array}$ & $\begin{array}{l}1.798^{* *} \\
(0.699)\end{array}$ & $\begin{array}{l}1.467^{*} \\
(0.873)\end{array}$ & $\begin{array}{l}1.667^{* *} \\
(0.742)\end{array}$ & $\begin{array}{l}1.880^{* *} \\
(0.780)\end{array}$ & $\begin{array}{l}1.591^{* *} \\
(0.658)\end{array}$ & $\begin{array}{l}1.451^{* *} \\
(0.658)\end{array}$ & $\begin{array}{l}1.451^{*} \\
(0.783)\end{array}$ & $\begin{array}{l}1.649^{* * *} \\
(0.595)\end{array}$ & $\begin{array}{l}1.278^{* *} \\
(0.595)\end{array}$ & $\begin{array}{l}1.278 \\
(0.847)\end{array}$ & 114.7 \\
\hline $\begin{array}{r}\text { Observations } \\
\text { Bandwidth } \\
\text { Polynomial degree }\end{array}$ & $\begin{array}{c}1,589,178 \\
10 \\
2\end{array}$ & $\begin{array}{c}1,589,178 \\
10 \\
3\end{array}$ & $\begin{array}{c}1,589,178 \\
10 \\
4\end{array}$ & $\begin{array}{c}827,737 \\
5 \\
2\end{array}$ & $\begin{array}{c}335,141 \\
2 \\
1\end{array}$ & $\begin{array}{c}542,464 \\
3.246 \\
1\end{array}$ & $\begin{array}{c}542,464 \\
5.096 \\
2\end{array}$ & $\begin{array}{c}542,464 \\
5.096 \\
2\end{array}$ & $\begin{array}{c}661,437 \\
3.971 \\
1\end{array}$ & $\begin{array}{c}661,437 \\
4.152 \\
2\end{array}$ & $\begin{array}{c}661,437 \\
4.152 \\
2\end{array}$ & \\
\hline Find job within 30 weeks & $\begin{array}{c}-0.00988^{* * *} \\
(0.00178)\end{array}$ & $\begin{array}{c}-0.00624^{* * *} \\
(0.00237)\end{array}$ & $\begin{array}{l}-0.00556^{*} \\
(0.00295)\end{array}$ & $\begin{array}{c}-0.00575^{\star *} \\
(0.00249)\end{array}$ & $\begin{array}{c}-0.00707^{\star * *} \\
(0.00262)\end{array}$ & $\begin{array}{c}-0.00584^{* * *} \\
(0.00215)\end{array}$ & $\begin{array}{c}-0.00553^{* *} \\
(0.00215)\end{array}$ & $\begin{array}{c}-0.00553^{* *} \\
(0.00257)\end{array}$ & $\begin{array}{c}-0.00582^{* * *} \\
(0.00212)\end{array}$ & $\begin{array}{c}-0.00564^{* * *} \\
(0.00212)\end{array}$ & $\begin{array}{c}-0.00564^{* *} \\
(0.00264)\end{array}$ & 0.806 \\
\hline $\begin{array}{r}\text { Observations } \\
\text { Bandwidth } \\
\text { Polynomial degree }\end{array}$ & $\begin{array}{c}1,738,787 \\
10 \\
2\end{array}$ & $\begin{array}{c}1,738,787 \\
10 \\
3\end{array}$ & $\begin{array}{c}1,738,787 \\
10 \\
4\end{array}$ & $\begin{array}{c}900,827 \\
5 \\
2\end{array}$ & $\begin{array}{c}364,314 \\
2 \\
1\end{array}$ & $\begin{array}{c}610,818 \\
3.359 \\
1\end{array}$ & $\begin{array}{c}610,818 \\
5.168 \\
2\end{array}$ & $\begin{array}{c}610,818 \\
5.168 \\
2\end{array}$ & $\begin{array}{c}630,268 \\
3.470 \\
1\end{array}$ & $\begin{array}{c}630,268 \\
4.731 \\
2\end{array}$ & $\begin{array}{c}630,268 \\
4.731 \\
2\end{array}$ & \\
\hline Find job within 39 weeks & $\begin{array}{l}-0.0131^{* * *} \\
(0.00164)\end{array}$ & $\begin{array}{c}-0.00918^{* * *} \\
(0.00219)\end{array}$ & $\begin{array}{c}-0.00853^{* * *} \\
(0.00273)\end{array}$ & $\begin{array}{c}-0.00916^{* * *} \\
(0.00230)\end{array}$ & $\begin{array}{c}-0.00945^{\star \star \star} \\
(0.00241)\end{array}$ & $\begin{array}{c}-0.00866^{* * *} \\
(0.00203)\end{array}$ & $\begin{array}{c}-0.00833^{* * *} \\
(0.00203)\end{array}$ & $\begin{array}{c}-0.00833^{* * *} \\
(0.00242)\end{array}$ & $\begin{array}{c}-0.00880^{* * *} \\
(0.00183)\end{array}$ & $\begin{array}{c}-0.00874^{* * *} \\
(0.00183)\end{array}$ & $\begin{array}{c}-0.00874^{* * *} \\
(0.00223)\end{array}$ & 0.842 \\
\hline $\begin{array}{r}\text { Observations } \\
\text { Bandwidth } \\
\text { Polynomial degree }\end{array}$ & $\begin{array}{c}1,738,787 \\
10 \\
2\end{array}$ & $\begin{array}{c}1,738,787 \\
10 \\
3\end{array}$ & $\begin{array}{c}1,738,787 \\
10 \\
4\end{array}$ & $\begin{array}{c}900,827 \\
5 \\
2\end{array}$ & $\begin{array}{c}364,314 \\
2 \\
1\end{array}$ & $\begin{array}{c}593,629 \\
3.266 \\
1\end{array}$ & $\begin{array}{c}593,629 \\
5.049 \\
2\end{array}$ & $\begin{array}{c}593,629 \\
5.049 \\
2\end{array}$ & $\begin{array}{c}723,726 \\
3.991 \\
1\end{array}$ & $\begin{array}{c}723,726 \\
5.817 \\
2\end{array}$ & $\begin{array}{c}723,726 \\
5.817 \\
2\end{array}$ & \\
\hline Wage change between jobs & $\begin{array}{l}0.00449^{* * *} \\
(0.00170)\end{array}$ & $\begin{array}{l}0.00411^{*} \\
(0.00226)\end{array}$ & $\begin{array}{l}0.00598^{* *} \\
(0.00283)\end{array}$ & $\begin{array}{l}0.00569^{* *} \\
(0.00238)\end{array}$ & $\begin{array}{l}0.00517^{* *} \\
(0.00251)\end{array}$ & $\begin{array}{l}0.00482^{* *} \\
(0.00219)\end{array}$ & $\begin{array}{l}0.00477^{* *} \\
(0.00219)\end{array}$ & $\begin{array}{l}0.00477^{*} \\
(0.00264)\end{array}$ & $\begin{array}{c}0.00470^{* * *} \\
(0.00174)\end{array}$ & $\begin{array}{c}0.00513^{* * *} \\
(0.00174)\end{array}$ & $\begin{array}{l}0.00513^{* *} \\
(0.00251)\end{array}$ & -0.0440 \\
\hline $\begin{array}{r}\text { Observations } \\
\text { Bandwidth } \\
\text { Polynomial degree }\end{array}$ & $\begin{array}{c}1,187,476 \\
10 \\
2\end{array}$ & $\begin{array}{c}1,187,476 \\
10 \\
3\end{array}$ & $\begin{array}{c}1,187,476 \\
10 \\
4\end{array}$ & $\begin{array}{c}617,733 \\
5 \\
2\end{array}$ & $\begin{array}{c}249,752 \\
2 \\
1\end{array}$ & $\begin{array}{c}387,710 \\
3.114 \\
1\end{array}$ & $\begin{array}{c}387,710 \\
4.681 \\
2\end{array}$ & $\begin{array}{c}387,710 \\
4.681 \\
2\end{array}$ & $\begin{array}{c}610,472 \\
4.936 \\
1\end{array}$ & $\begin{array}{c}610,472 \\
5.060 \\
2\end{array}$ & $\begin{array}{c}610,472 \\
5.060 \\
2\end{array}$ & \\
\hline Log re-employment wage & $\begin{array}{c}0.00350 \\
(0.00234)\end{array}$ & $\begin{array}{l}0.00552^{*} \\
(0.00311)\end{array}$ & $\begin{array}{l}0.00695^{*} \\
(0.00389)\end{array}$ & $\begin{array}{l}0.00724^{* *} \\
(0.00330)\end{array}$ & $\begin{array}{c}0.00346 \\
(0.00348)\end{array}$ & $\begin{array}{c}0.00448 \\
(0.00300)\end{array}$ & $\begin{array}{l}0.00526^{*} \\
(0.00300)\end{array}$ & $\begin{array}{c}0.00526 \\
(0.00353)\end{array}$ & $\begin{array}{l}0.00500^{*} \\
(0.00283)\end{array}$ & $\begin{array}{l}0.00601^{* *} \\
(0.00283)\end{array}$ & $\begin{array}{l}0.00601^{*} \\
(0.00346)\end{array}$ & 7.468 \\
\hline $\begin{array}{r}\text { Observations } \\
\text { Bandwidth } \\
\text { Polynomial degree }\end{array}$ & $\begin{array}{c}1,189,446 \\
10 \\
2\end{array}$ & $\begin{array}{c}1,189,446 \\
10 \\
3\end{array}$ & $\begin{array}{c}1,189,446 \\
10 \\
4\end{array}$ & $\begin{array}{c}618,898 \\
5 \\
2\end{array}$ & $\begin{array}{c}250,254 \\
2 \\
1\end{array}$ & $\begin{array}{c}394,772 \\
3.161 \\
1\end{array}$ & $\begin{array}{c}394,772 \\
5.088 \\
2\end{array}$ & $\begin{array}{c}394,772 \\
5.088 \\
2\end{array}$ & $\begin{array}{c}441,122 \\
3.539 \\
1\end{array}$ & $\begin{array}{c}441,122 \\
5.123 \\
2\end{array}$ & $\begin{array}{c}441,122 \\
5.123 \\
2\end{array}$ & \\
\hline New wage > UI benefit & $\begin{array}{l}0.00388^{* * *} \\
(0.00105)\end{array}$ & $\begin{array}{l}0.00378^{* * *} \\
(0.00139)\end{array}$ & $\begin{array}{c}0.00495^{\star * *} \\
(0.00174)\end{array}$ & $\begin{array}{c}0.00453^{* * *} \\
(0.00145)\end{array}$ & $\begin{array}{c}0.00476^{\star * *} \\
(0.00153)\end{array}$ & $\begin{array}{c}0.00470^{* * *} \\
(0.00141)\end{array}$ & $\begin{array}{c}0.00504^{* * *} \\
(0.00141)\end{array}$ & $\begin{array}{c}0.00504^{* * *} \\
(0.00167)\end{array}$ & $\begin{array}{c}0.00413^{* * *} \\
(0.00117)\end{array}$ & $\begin{array}{c}0.00485^{\star * *} \\
(0.00117)\end{array}$ & $\begin{array}{c}0.00485^{\star * *} \\
(0.00156)\end{array}$ & 0.962 \\
\hline $\begin{array}{r}\text { Observations } \\
\text { Bandwidth } \\
\text { Polynomial degree }\end{array}$ & $\begin{array}{c}1,187,476 \\
10 \\
2\end{array}$ & $\begin{array}{c}1,187,476 \\
10 \\
3\end{array}$ & $\begin{array}{c}1,187,476 \\
10 \\
4\end{array}$ & $\begin{array}{c}617,733 \\
5 \\
2\end{array}$ & $\begin{array}{c}249,752 \\
2 \\
1\end{array}$ & $\begin{array}{c}353,675 \\
2.838 \\
1\end{array}$ & $\begin{array}{c}353,675 \\
4.512 \\
2\end{array}$ & $\begin{array}{c}353,675 \\
4.512 \\
2\end{array}$ & $\begin{array}{c}512,798 \\
4.134 \\
1\end{array}$ & $\begin{array}{l}512,798 \\
4.856 \\
2\end{array}$ & $\begin{array}{c}512,798 \\
4.856 \\
2\end{array}$ & \\
\hline
\end{tabular}

Note: Column 1-5 reposrts the RD results using different polynomial degrees and bandwidth. Column 6-11 use local-polynomials using triangular kernel. Column 6-8 based on optimal

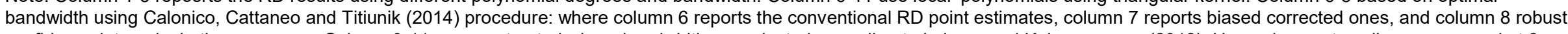

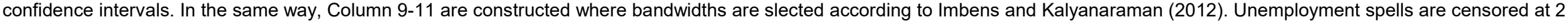

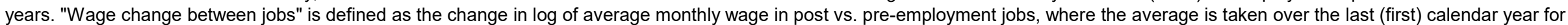
the pre (post)-unemployment job. ${ }^{* *}$ Significant at the 1 percent level. ${ }^{* *}$ Significant at the 5 percent level. ${ }^{*}$ Significant at the 10 percent level. 
Appendix Table A3: Selection on observables

\begin{tabular}{|c|c|c|c|c|c|c|c|c|c|c|c|c|}
\hline \multirow[b]{2}{*}{$\begin{array}{l}\text { Dependent variable } \\
\text { Female }\end{array}$} & \multicolumn{11}{|c|}{ Discontinuity at age 40} & \multirow{3}{*}{$\begin{array}{c}\begin{array}{c}\text { Mean } \\
\text { Dep. Var. }\end{array} \\
0.255\end{array}$} \\
\hline & $\begin{array}{c}1(1) \\
-0.000963 \\
(0.00194)\end{array}$ & $\begin{array}{c}-5 \\
0.00396 \\
(0.00258)\end{array}$ & $\begin{array}{c}(3) \\
0.00322 \\
(0.00322)\end{array}$ & $\begin{array}{c}(4) \\
0.00210 \\
(0.00274)\end{array}$ & $\begin{array}{c}(5) \\
0.00467 \\
(0.00289)\end{array}$ & $\begin{array}{c}(6) \\
0.00284 \\
(0.00229)\end{array}$ & $\begin{array}{c}(7) \\
0.00268 \\
(0.00229)\end{array}$ & $\begin{array}{c}(8) \\
0.00268 \\
(0.00275)\end{array}$ & $\begin{array}{c}(9) \\
0.00245 \\
(0.00222)\end{array}$ & $\begin{array}{c}(10) \\
0.00242 \\
(0.00222)\end{array}$ & $\begin{array}{c}(11) \\
0.00242 \\
(0.00265)\end{array}$ & \\
\hline $\begin{array}{r}\text { Observations } \\
\text { Bandwidth } \\
\text { Polynomial degree }\end{array}$ & $\begin{array}{c}1,738,787 \\
10 \\
2\end{array}$ & $\begin{array}{c}1,738,787 \\
10 \\
3\end{array}$ & $\begin{array}{c}1,738,787 \\
10 \\
4\end{array}$ & $\begin{array}{l}900,827 \\
5 \\
2\end{array}$ & $\begin{array}{l}364,314 \\
2 \\
1\end{array}$ & $\begin{array}{c}630,268 \\
3.469 \\
1\end{array}$ & $\begin{array}{c}630,268 \\
5.267 \\
2\end{array}$ & $\begin{array}{c}630,268 \\
5.267 \\
2\end{array}$ & $\begin{array}{c}671,618 \\
3.702 \\
1\end{array}$ & $\begin{array}{l}671,618 \\
5.689 \\
2\end{array}$ & $\begin{array}{c}671,618 \\
5.689 \\
2\end{array}$ & \\
\hline Blue Collar & $\begin{array}{l}0.000367 \\
(0.00190)\end{array}$ & $\begin{array}{l}0.000462 \\
(0.00253)\end{array}$ & $\begin{array}{c}0.00411 \\
(0.00316)\end{array}$ & $\begin{array}{l}0.000951 \\
(0.00268)\end{array}$ & $\begin{array}{c}0.00356 \\
(0.00282)\end{array}$ & $\begin{array}{l}0.00743^{\star *} \\
(0.00290)\end{array}$ & $\begin{array}{c}0.00865^{\star * \star} \\
(0.00290)\end{array}$ & $\begin{array}{c}0.00865^{\star \star *} \\
(0.00325)\end{array}$ & $\begin{array}{c}0.00348 \\
(0.00243)\end{array}$ & $\begin{array}{l}0.00418^{*} \\
(0.00243)\end{array}$ & $\begin{array}{c}0.00418 \\
(0.00278)\end{array}$ & 0.762 \\
\hline $\begin{array}{r}\text { Observations } \\
\text { Bandwidth } \\
\text { Polynomial degree }\end{array}$ & $\begin{array}{c}1,738,787 \\
10 \\
2\end{array}$ & $\begin{array}{c}1,738,787 \\
10 \\
3\end{array}$ & $\begin{array}{c}1,738,787 \\
10 \\
4\end{array}$ & $\begin{array}{l}900,827 \\
5 \\
2\end{array}$ & $\begin{array}{l}364,314 \\
2 \\
1\end{array}$ & $\begin{array}{c}318,432 \\
1.745 \\
1\end{array}$ & $\begin{array}{c}318,432 \\
3.361 \\
2\end{array}$ & $\begin{array}{c}318,432 \\
3.361 \\
2\end{array}$ & $\begin{array}{c}458,201 \\
2.516 \\
1\end{array}$ & $\begin{array}{c}458,201 \\
4.435 \\
2\end{array}$ & $\begin{array}{c}458,201 \\
4.435 \\
2\end{array}$ & \\
\hline Married & $\begin{array}{c}0.00245 \\
(0.00221)\end{array}$ & $\begin{array}{l}-0.00281 \\
(0.00295)\end{array}$ & $\begin{array}{l}-0.00154 \\
(0.00368)\end{array}$ & $\begin{array}{l}-0.00145 \\
(0.00313)\end{array}$ & $\begin{array}{c}-0.00279 \\
(0.00330)\end{array}$ & $\begin{array}{l}-0.00144 \\
(0.00273)\end{array}$ & $\begin{array}{l}-0.00145 \\
(0.00273)\end{array}$ & $\begin{array}{l}-0.00145 \\
(0.00328)\end{array}$ & $\begin{array}{l}-0.00124 \\
(0.00220)\end{array}$ & $\begin{array}{l}-0.00150 \\
(0.00220)\end{array}$ & $\begin{array}{l}-0.00150 \\
(0.00312)\end{array}$ & 0.544 \\
\hline $\begin{array}{r}\text { Observations } \\
\text { Bandwidth } \\
\text { Polynomial degree }\end{array}$ & $\begin{array}{c}1,738,787 \\
10 \\
2\end{array}$ & $\begin{array}{c}1,738,787 \\
10 \\
3\end{array}$ & $\begin{array}{c}1,738,787 \\
10 \\
4\end{array}$ & $\begin{array}{l}900,827 \\
5 \\
2\end{array}$ & $\begin{array}{l}364,314 \\
2 \\
1\end{array}$ & $\begin{array}{c}627,241 \\
3.452 \\
1\end{array}$ & $\begin{array}{l}627,241 \\
5.205 \\
2\end{array}$ & $\begin{array}{l}627,241 \\
5.205 \\
2\end{array}$ & $\begin{array}{c}957,654 \\
5.324 \\
1\end{array}$ & $\begin{array}{l}957,654 \\
5.576 \\
2\end{array}$ & $\begin{array}{l}957,654 \\
5.576 \\
2\end{array}$ & \\
\hline Austrian & $\begin{array}{c}0.00746^{\star \star \star} \\
(0.00187)\end{array}$ & $\begin{array}{c}0.00125 \\
(0.00249)\end{array}$ & $\begin{array}{c}0.00112 \\
(0.00311)\end{array}$ & $\begin{array}{c}0.00115 \\
(0.00260)\end{array}$ & $\begin{array}{c}0.00389 \\
(0.00272)\end{array}$ & $\begin{array}{c}0.00275 \\
(0.00205)\end{array}$ & $\begin{array}{c}0.00295 \\
(0.00205)\end{array}$ & $\begin{array}{c}0.00295 \\
(0.00246)\end{array}$ & $\begin{array}{c}0.00214 \\
(0.00189)\end{array}$ & $\begin{array}{c}0.00249 \\
(0.00189)\end{array}$ & $\begin{array}{c}0.00249 \\
(0.00243)\end{array}$ & 0.784 \\
\hline $\begin{array}{r}\text { Observations } \\
\text { Bandwidth } \\
\text { Polynomial degree }\end{array}$ & $\begin{array}{c}1,738,787 \\
10 \\
2\end{array}$ & $\begin{array}{c}1,738,787 \\
10 \\
3\end{array}$ & $\begin{array}{c}1,738,787 \\
10 \\
4\end{array}$ & $\begin{array}{l}900,827 \\
5 \\
2\end{array}$ & $\begin{array}{l}364,314 \\
2 \\
1\end{array}$ & $\begin{array}{c}585,425 \\
3.224 \\
1\end{array}$ & $\begin{array}{c}585,425 \\
4.907 \\
2\end{array}$ & $\begin{array}{c}585,425 \\
4.907 \\
2\end{array}$ & $\begin{array}{c}687,206 \\
3.790 \\
1\end{array}$ & $\begin{array}{c}687,206 \\
4.839 \\
2\end{array}$ & $\begin{array}{c}687,206 \\
4.839 \\
2\end{array}$ & \\
\hline Pre-unemployment wage & $\begin{array}{l}-0.00181 \\
(0.00198)\end{array}$ & $\begin{array}{c}0.00196 \\
(0.00264)\end{array}$ & $\begin{array}{l}0.000972 \\
(0.00330)\end{array}$ & $\begin{array}{c}0.00156 \\
(0.00280)\end{array}$ & $\begin{array}{l}-0.00210 \\
(0.00295)\end{array}$ & $\begin{array}{l}0.000110 \\
(0.00244)\end{array}$ & $\begin{array}{l}0.000746 \\
(0.00244)\end{array}$ & $\begin{array}{l}0.000746 \\
(0.00287)\end{array}$ & $\begin{array}{l}0.000122 \\
(0.00219)\end{array}$ & $\begin{array}{c}0.00100 \\
(0.00219)\end{array}$ & $\begin{array}{c}0.00100 \\
(0.00284)\end{array}$ & 7.526 \\
\hline $\begin{array}{r}\text { Observations } \\
\text { Bandwidth } \\
\text { Polynomial degree }\end{array}$ & $\begin{array}{c}1,735,733 \\
10 \\
2\end{array}$ & $\begin{array}{c}1,735,733 \\
10 \\
3\end{array}$ & $\begin{array}{c}1,735,733 \\
10 \\
4\end{array}$ & $\begin{array}{l}899,037 \\
5 \\
2\end{array}$ & $\begin{array}{l}363,569 \\
2 \\
1\end{array}$ & $\begin{array}{c}626,525 \\
3.457 \\
1\end{array}$ & $\begin{array}{c}626,525 \\
5.557 \\
2\end{array}$ & $\begin{array}{c}626,525 \\
5.557 \\
2\end{array}$ & $\begin{array}{c}772,814 \\
4.281 \\
1\end{array}$ & $\begin{array}{l}772,814 \\
5.346 \\
2\end{array}$ & $\begin{array}{l}772,814 \\
5.346 \\
2\end{array}$ & \\
\hline Temporary Layoffs & $\begin{array}{l}-0.00297 \\
(0.00227)\end{array}$ & $\begin{array}{l}-0.00517^{\star} \\
(0.00302)\end{array}$ & $\begin{array}{l}-0.00262 \\
(0.00377)\end{array}$ & $\begin{array}{l}-0.00374 \\
(0.00319)\end{array}$ & $\begin{array}{l}-0.00402 \\
(0.00336)\end{array}$ & $\begin{array}{l}-0.00190 \\
(0.00296)\end{array}$ & $\begin{array}{l}-0.00148 \\
(0.00296)\end{array}$ & $\begin{array}{l}-0.00148 \\
(0.00354)\end{array}$ & $\begin{array}{c}-0.00259 \\
(0.00268)\end{array}$ & $\begin{array}{l}-0.00202 \\
(0.00268)\end{array}$ & $\begin{array}{l}-0.00202 \\
(0.00344)\end{array}$ & 0.527 \\
\hline $\begin{array}{r}\text { Observations } \\
\text { Bandwidth } \\
\text { Polynomial degree }\end{array}$ & $\begin{array}{c}1,677,158 \\
10 \\
2\end{array}$ & $\begin{array}{c}1,677,158 \\
10 \\
3\end{array}$ & $\begin{array}{c}1,677,158 \\
10 \\
4\end{array}$ & $\begin{array}{l}871,076 \\
5 \\
2\end{array}$ & $\begin{array}{l}352,873 \\
2 \\
1\end{array}$ & $\begin{array}{c}496,365 \\
2.822 \\
1\end{array}$ & $\begin{array}{c}496,365 \\
4.348 \\
2\end{array}$ & $\begin{array}{l}496,365 \\
4.348 \\
2\end{array}$ & $\begin{array}{c}606,992 \\
3.452 \\
1\end{array}$ & $\begin{array}{l}606,992 \\
4.385 \\
2\end{array}$ & $\begin{array}{l}606,992 \\
4.385 \\
2\end{array}$ & \\
\hline Tenure & $\begin{array}{l}14.83^{* *} \\
(6.149)\end{array}$ & $\begin{array}{l}17.17^{* *} \\
(8.186)\end{array}$ & $\begin{array}{c}14.19 \\
(10.22)\end{array}$ & $\begin{array}{l}17.67^{* *} \\
(8.479)\end{array}$ & $\begin{array}{c}13.48 \\
(8.852)\end{array}$ & $\begin{array}{l}15.19^{* *} \\
(7.061)\end{array}$ & $\begin{array}{l}15.18^{* *} \\
(7.061)\end{array}$ & $\begin{array}{l}15.18^{*} \\
(8.501)\end{array}$ & $\begin{array}{l}14.91^{* *} \\
(6.449)\end{array}$ & $\begin{array}{l}13.69^{* *} \\
(6.449)\end{array}$ & $\begin{array}{c}13.69 \\
(8.993)\end{array}$ & 976.8 \\
\hline $\begin{array}{r}\text { Observations } \\
\text { Bandwidth } \\
\text { Polynomial degree }\end{array}$ & $\begin{array}{c}1,738,787 \\
10 \\
2\end{array}$ & $\begin{array}{c}1,738,787 \\
10 \\
3\end{array}$ & $\begin{array}{c}1,738,787 \\
10 \\
4\end{array}$ & $\begin{array}{l}900,827 \\
5 \\
2\end{array}$ & $\begin{array}{l}364,314 \\
2 \\
1\end{array}$ & $\begin{array}{c}648,105 \\
3.572 \\
1\end{array}$ & $\begin{array}{l}648,105 \\
5.403 \\
2\end{array}$ & $\begin{array}{l}648,105 \\
5.403 \\
2\end{array}$ & $\begin{array}{c}774,718 \\
4.284 \\
1\end{array}$ & $\begin{array}{l}774,718 \\
4.623 \\
2\end{array}$ & $\begin{array}{l}774,718 \\
4.623 \\
2\end{array}$ & \\
\hline Tenure $>1$ year & $\begin{array}{c}0.00123 \\
(0.00222)\end{array}$ & $\begin{array}{c}0.00420 \\
(0.00296)\end{array}$ & $\begin{array}{c}0.00255 \\
(0.00369)\end{array}$ & $\begin{array}{c}0.00284 \\
(0.00313)\end{array}$ & $\begin{array}{c}0.00360 \\
(0.00329)\end{array}$ & $\begin{array}{c}0.00369 \\
(0.00270)\end{array}$ & $\begin{array}{c}0.00411 \\
(0.00270)\end{array}$ & $\begin{array}{c}0.00411 \\
(0.00323)\end{array}$ & $\begin{array}{c}0.00371 \\
(0.00269)\end{array}$ & $\begin{array}{c}0.00396 \\
(0.00269)\end{array}$ & $\begin{array}{c}0.00396 \\
(0.00301)\end{array}$ & 0.442 \\
\hline $\begin{array}{r}\text { Observations } \\
\text { Bandwidth } \\
\text { Polynomial degree }\end{array}$ & $\begin{array}{c}1,738,787 \\
10 \\
2\end{array}$ & $\begin{array}{c}1,738,787 \\
10 \\
3\end{array}$ & $\begin{array}{c}1,738,787 \\
10 \\
4\end{array}$ & $\begin{array}{l}900,827 \\
5 \\
2\end{array}$ & $\begin{array}{l}364,314 \\
2 \\
1\end{array}$ & $\begin{array}{c}593,629 \\
3.268 \\
1\end{array}$ & $\begin{array}{l}593,629 \\
5.030 \\
2\end{array}$ & $\begin{array}{l}593,629 \\
5.030 \\
2\end{array}$ & $\begin{array}{c}596,095 \\
3.282 \\
1\end{array}$ & $\begin{array}{c}596,095 \\
6.364 \\
2\end{array}$ & $\begin{array}{c}596,095 \\
6.364 \\
2\end{array}$ & \\
\hline Tenure $>5$ year & $\begin{array}{c}0.00489^{* * *} \\
(0.00161)\end{array}$ & $\begin{array}{c}0.00650^{* * *} \\
(0.00214)\end{array}$ & $\begin{array}{l}0.00549^{* *} \\
(0.00267)\end{array}$ & $\begin{array}{c}0.00616^{\star \star *} \\
(0.00228)\end{array}$ & $\begin{array}{l}0.00550^{\star *} \\
(0.00239)\end{array}$ & $\begin{array}{c}0.00569^{\star * *} \\
(0.00198)\end{array}$ & $\begin{array}{c}0.00542^{\star \star *} \\
(0.00198)\end{array}$ & $\begin{array}{l}0.00542^{* *} \\
(0.00237)\end{array}$ & $\begin{array}{c}0.00563^{\star \star *} \\
(0.00177)\end{array}$ & $\begin{array}{l}0.00432^{* *} \\
(0.00177)\end{array}$ & $\begin{array}{l}0.00432^{*} \\
(0.00259)\end{array}$ & 0.155 \\
\hline $\begin{array}{r}\text { Observations } \\
\text { Bandwidth } \\
\text { Polynomial degree }\end{array}$ & $\begin{array}{c}1,738,787 \\
10 \\
2\end{array}$ & $\begin{array}{c}1,738,787 \\
10 \\
3\end{array}$ & $\begin{array}{c}1,738,787 \\
10 \\
4\end{array}$ & $\begin{array}{l}900,827 \\
5 \\
2\end{array}$ & $\begin{array}{l}364,314 \\
2 \\
1\end{array}$ & $\begin{array}{c}610,181 \\
3.355 \\
1\end{array}$ & $\begin{array}{c}610,181 \\
5.152 \\
2\end{array}$ & $\begin{array}{c}610,181 \\
5.152 \\
2\end{array}$ & $\begin{array}{c}754,988 \\
4.175 \\
1\end{array}$ & $\begin{array}{c}754,988 \\
4.184 \\
2\end{array}$ & $\begin{array}{c}754,988 \\
4.184 \\
2\end{array}$ & \\
\hline
\end{tabular}




\begin{tabular}{|c|c|c|c|c|c|c|c|c|c|c|}
\hline \multirow[b]{2}{*}{ Dependent variable } & \multicolumn{5}{|c|}{ Predicted Dependent Variable } & \multicolumn{5}{|c|}{ Actual Dependent Variable } \\
\hline & (1) & (2) & (3) & (4) & (5) & (11) & (12) & (13) & (14) & (15) \\
\hline Non-employment duration (days) & $\begin{array}{c}0.123 \\
(0.238)\end{array}$ & $\begin{array}{c}0.138 \\
(0.336)\end{array}$ & $\begin{array}{c}0.163 \\
(0.353)\end{array}$ & $\begin{array}{l}-0.141 \\
(0.363)\end{array}$ & $\begin{array}{l}0.00148 \\
(0.337)\end{array}$ & $\begin{array}{l}1.963^{\star \star \star} \\
(0.467)\end{array}$ & $\begin{array}{l}1.519^{* *} \\
(0.659)\end{array}$ & $\begin{array}{l}1.693^{* *} \\
(0.691)\end{array}$ & $\begin{array}{l}1.442^{\star \star} \\
(0.660)\end{array}$ & $\begin{array}{c}1.303 \\
(0.814)\end{array}$ \\
\hline $\begin{array}{r}\text { Observations } \\
\text { Bandwidth } \\
\text { Polynomial degree }\end{array}$ & $\begin{array}{c}1,645,711 \\
10 \\
2\end{array}$ & $\begin{array}{c}856,739 \\
5 \\
2\end{array}$ & $\begin{array}{c}346,664 \\
2 \\
1\end{array}$ & $\begin{array}{c}418,121 \\
2.413 \\
2\end{array}$ & $\begin{array}{c}549,406 \\
3.180 \\
2\end{array}$ & $\begin{array}{c}1,587,101 \\
10 \\
2\end{array}$ & $\begin{array}{c}826,509 \\
5 \\
2\end{array}$ & $\begin{array}{c}334,615 \\
2 \\
1\end{array}$ & $\begin{array}{c}629,912 \\
3.784 \\
2\end{array}$ & $\begin{array}{c}888,947 \\
5.389 \\
2\end{array}$ \\
\hline Find job within 30 weeks & $\begin{array}{c}0.00147 \\
(0.000909)\end{array}$ & $\begin{array}{c}0.00201 \\
(0.00128)\end{array}$ & $\begin{array}{c}0.00218 \\
(0.00135)\end{array}$ & $\begin{array}{c}0.00181 \\
(0.00125)\end{array}$ & $\begin{array}{c}0.00182 \\
(0.00118)\end{array}$ & $\begin{array}{c}-0.00873^{* * *} \\
(0.00153)\end{array}$ & $\begin{array}{l}-0.00375^{*} \\
(0.00215)\end{array}$ & $\begin{array}{c}-0.00485^{* *} \\
(0.00227)\end{array}$ & $\begin{array}{l}-0.00388^{*} \\
(0.00229)\end{array}$ & $\begin{array}{l}-0.00431^{*} \\
(0.00259)\end{array}$ \\
\hline $\begin{array}{r}\text { Observations } \\
\text { Bandwidth } \\
\text { Polynomial degree }\end{array}$ & $\begin{array}{c}1,737,535 \\
10 \\
2\end{array}$ & $\begin{array}{c}900,137 \\
5 \\
2\end{array}$ & $\begin{array}{c}364,008 \\
2 \\
1\end{array}$ & $\begin{array}{c}574,854 \\
3.166 \\
2\end{array}$ & $\begin{array}{c}594,294 \\
3.271\end{array}$ & $\begin{array}{c}1,734,481 \\
10 \\
2\end{array}$ & $\begin{array}{c}898,347 \\
5 \\
2\end{array}$ & $\begin{array}{c}363,263 \\
2 \\
1\end{array}$ & $\begin{array}{c}604,203 \\
3.335 \\
2\end{array}$ & $\begin{array}{c}831,655 \\
4.621 \\
2\end{array}$ \\
\hline Find job within 39 weeks & $\begin{array}{c}0.00124 \\
(0.000760)\end{array}$ & $\begin{array}{c}0.00174 \\
(0.00107)\end{array}$ & $\begin{array}{c}0.00177 \\
(0.00113)\end{array}$ & $\begin{array}{c}0.00145 \\
(0.00103)\end{array}$ & $\begin{array}{l}0.000982 \\
(0.00112)\end{array}$ & $\begin{array}{l}-0.0122^{* * *} \\
(0.00146)\end{array}$ & $\begin{array}{c}-0.00748^{* * *} \\
(0.00205)\end{array}$ & $\begin{array}{c}-0.00765^{* * *} \\
(0.00216)\end{array}$ & $\begin{array}{c}-0.00694^{* * *} \\
(0.00221)\end{array}$ & $\begin{array}{c}-0.00704^{* * *} \\
(0.00220)\end{array}$ \\
\hline $\begin{array}{r}\text { Observations } \\
\text { Bandwidth } \\
\text { Polynomial degree }\end{array}$ & $\begin{array}{c}1,737,535 \\
10 \\
2\end{array}$ & $\begin{array}{c}900,137 \\
5 \\
2\end{array}$ & $\begin{array}{c}364,008 \\
2 \\
1\end{array}$ & $\begin{array}{c}596,022 \\
3.283 \\
2\end{array}$ & $\begin{array}{c}544,321 \\
2.994 \\
2\end{array}$ & $\begin{array}{c}1,734,481 \\
10 \\
2\end{array}$ & $\begin{array}{c}898,347 \\
5 \\
2\end{array}$ & $\begin{array}{c}363,263 \\
2 \\
1\end{array}$ & $\begin{array}{c}582,556 \\
3.216 \\
2\end{array}$ & $\begin{array}{c}761,866 \\
4.225 \\
2\end{array}$ \\
\hline Wage change between jobs & $\begin{array}{l}-3.35 e-05 \\
(0.000868)\end{array}$ & $\begin{array}{l}-0.00101 \\
(0.00123)\end{array}$ & $\begin{array}{l}-0.00158 \\
(0.00131)\end{array}$ & $\begin{array}{l}-0.00165 \\
(0.00127)\end{array}$ & $\begin{array}{l}-0.00399 \\
(0.00316)\end{array}$ & $\begin{array}{l}0.00494^{* * *} \\
(0.00147)\end{array}$ & $\begin{array}{c}0.00661^{* * *} \\
(0.00207)\end{array}$ & $\begin{array}{c}0.00630^{* * *} \\
(0.00218)\end{array}$ & $\begin{array}{c}0.00633^{* * *} \\
(0.00228)\end{array}$ & $\begin{array}{c}0.00615^{* * *} \\
(0.00183)\end{array}$ \\
\hline $\begin{array}{r}\text { Observations } \\
\text { Bandwidth } \\
\text { Polynomial degree }\end{array}$ & $\begin{array}{c}1,187,475 \\
10 \\
2\end{array}$ & $\begin{array}{c}617,733 \\
5 \\
2\end{array}$ & $\begin{array}{c}249,752 \\
2 \\
1\end{array}$ & $\begin{array}{c}425,599 \\
3.414 \\
2\end{array}$ & $\begin{array}{c}1,058,248 \\
8.808 \\
2\end{array}$ & $\begin{array}{c}1,187,475 \\
10 \\
2\end{array}$ & $\begin{array}{c}617,733 \\
5 \\
2\end{array}$ & $\begin{array}{c}249,752 \\
2 \\
1\end{array}$ & $\begin{array}{c}385,067 \\
3.096 \\
2\end{array}$ & $\begin{array}{c}584,273 \\
4.721 \\
2\end{array}$ \\
\hline Log re-employment wage & $\begin{array}{l}-0.00151 \\
(0.00175)\end{array}$ & $\begin{array}{l}4.87 e-05 \\
(0.00250)\end{array}$ & $\begin{array}{l}-0.00386 \\
(0.00264)\end{array}$ & $\begin{array}{l}-0.000772 \\
(0.00241)\end{array}$ & $\begin{array}{l}-0.00109 \\
(0.00260)\end{array}$ & $\begin{array}{l}0.00431^{* * *} \\
(0.00157)\end{array}$ & $\begin{array}{c}0.00714^{* * *} \\
(0.00219)\end{array}$ & $\begin{array}{c}0.00753^{* * *} \\
(0.00230)\end{array}$ & $\begin{array}{l}0.00717^{* * *} \\
(0.00244)\end{array}$ & $\begin{array}{l}0.00722^{* * *} \\
(0.00226)\end{array}$ \\
\hline $\begin{array}{r}\text { Observations } \\
\text { Bandwidth } \\
\text { Polynomial degree }\end{array}$ & $\begin{array}{c}1,189,445 \\
10 \\
2\end{array}$ & $\begin{array}{c}618,898 \\
5 \\
2\end{array}$ & $\begin{array}{c}250,254 \\
2 \\
1\end{array}$ & $\begin{array}{c}453,200 \\
3.634 \\
2\end{array}$ & $\begin{array}{c}493,455 \\
3.962 \\
2\end{array}$ & $\begin{array}{c}1,187,475 \\
10 \\
2\end{array}$ & $\begin{array}{c}617,733 \\
5 \\
2\end{array}$ & $\begin{array}{c}249,752 \\
2 \\
1\end{array}$ & $\begin{array}{c}374,501 \\
3.012 \\
2\end{array}$ & $\begin{array}{c}630,705 \\
5.106 \\
2\end{array}$ \\
\hline New wage > Ul benefit & $\begin{array}{c}3.48 \mathrm{e}-05 \\
(0.000255)\end{array}$ & $\begin{array}{l}-0.000422 \\
(0.000362)\end{array}$ & $\begin{array}{l}-0.000714^{*} \\
(0.000382)\end{array}$ & $\begin{array}{l}-0.000673^{*} \\
(0.000386)\end{array}$ & $\begin{array}{l}-0.00114^{*} \\
(0.000642)\end{array}$ & $\begin{array}{l}0.00391^{* * *} \\
(0.00102)\end{array}$ & $\begin{array}{c}0.00494^{* * *} \\
(0.00141)\end{array}$ & $\begin{array}{c}0.00539^{* * *} \\
(0.00148)\end{array}$ & $\begin{array}{c}0.00565^{\star * *} \\
(0.00160)\end{array}$ & $\begin{array}{c}0.00529^{* * *} \\
(0.00144)\end{array}$ \\
\hline $\begin{array}{r}\text { Observations } \\
\text { Bandwidth } \\
\text { Polynomial degree }\end{array}$ & $\begin{array}{c}1,187,475 \\
10 \\
2\end{array}$ & $\begin{array}{c}617,733 \\
5 \\
2\end{array}$ & $\begin{array}{c}249,752 \\
2 \\
1\end{array}$ & $\begin{array}{c}341,895 \\
2.742 \\
2\end{array}$ & $\begin{array}{c}648,027 \\
5.252 \\
2\end{array}$ & $\begin{array}{c}1,187,475 \\
10 \\
2\end{array}$ & $\begin{array}{c}617,733 \\
5 \\
2\end{array}$ & $\begin{array}{c}249,752 \\
2 \\
1\end{array}$ & $\begin{array}{c}351,021 \\
2.819 \\
2\end{array}$ & $\begin{array}{c}537,480 \\
4.335 \\
2\end{array}$ \\
\hline
\end{tabular}

first three columns of each panel reposits the RD results using different polynomial degrees and bandwidth. The last two columns use local-polynomials based on triangular kernel, reporting biased corrected estiamtes, robust confidence intervals on a optimal bandwidth according to Calonico, Cattaneo and Titiunik (2014) and Imbens and Kalyanaraman (2012), repectively.

*** Significant at the 1 percent level. ${ }^{* *}$ Significant at the 5 percent level. * Significant at the 10 percent level. 


\begin{tabular}{|c|c|c|c|c|c|c|c|c|c|c|c|c|c|c|c|}
\hline \multirow[b]{3}{*}{ Dependent variable } & \multicolumn{5}{|c|}{ Placebo I } & \multicolumn{5}{|c|}{ Placebo II } & \multicolumn{5}{|c|}{ Treated } \\
\hline & \multicolumn{5}{|c|}{ Pre 1989 Reform } & \multicolumn{5}{|c|}{ Post 1989 Reform \& Not Eligible for 9-week Extension } & \multicolumn{5}{|c|}{ Post 1989 Reform \& Eligible for 9-week Extension } \\
\hline & (1) & $(2)$ & $(3)$ & $(4)$ & $(5)$ & $(6)$ & $(7)$ & $(8)$ & $(9)$ & $\frac{(10)}{10}$ & $(11)$ & $(12)$ & $(13)$ & $(14)$ & $(15)$ \\
\hline Non-employment duration (days) & $\begin{array}{c}-0.184 \\
(0.832)\end{array}$ & $\begin{array}{c}0.281 \\
(1.197)\end{array}$ & $\begin{array}{c}-0.982 \\
(1.272)\end{array}$ & $\begin{array}{l}-0.247 \\
(1.150)\end{array}$ & $\begin{array}{l}-0.541 \\
(1.205)\end{array}$ & $\begin{array}{c}1.237 \\
(0.974)\end{array}$ & $\begin{array}{c}0.793 \\
(1.358)\end{array}$ & $\begin{array}{l}-0.342 \\
(1.429)\end{array}$ & $\begin{array}{c}0.189 \\
(1.402)\end{array}$ & $\begin{array}{l}0.0879 \\
(1.244)\end{array}$ & $\begin{array}{c}1.963^{* * *} \\
(0.467)\end{array}$ & $\begin{array}{l}1.519^{\star *} \\
(0.659)\end{array}$ & $\begin{array}{l}1.693^{* *} \\
(0.691)\end{array}$ & $\begin{array}{l}1.442^{* *} \\
(0.660)\end{array}$ & $\begin{array}{c}1.303 \\
(0.814)\end{array}$ \\
\hline Observations & 539,287 & 271,416 & 107,784 & 232,305 & 319,149 & 585,005 & 300,266 & 121,850 & 218,466 & 353,392 & $1,587,101$ & 826,509 & 334,615 & 629,912 & 888,947 \\
\hline Bandwidth & 10 & 5 & 2 & 4.273 & 5.872 & 10 & 5 & 2 & 5.479 & 6.641 & 10 & 5 & 2 & 3.784 & 5.389 \\
\hline Polynomial degree & 2 & 2 & 1 & 2 & 2 & 2 & 2 & 1 & 2 & 2 & 2 & 2 & 1 & 2 & 2 \\
\hline Find job within 30 weeks & $\begin{array}{c}0.00332 \\
(0.00285)\end{array}$ & $\begin{array}{c}0.00212 \\
(0.00407)\end{array}$ & $\begin{array}{c}0.00664 \\
(0.00432)\end{array}$ & $\begin{array}{c}0.00754 \\
(0.00473)\end{array}$ & $\begin{array}{c}0.00467 \\
(0.00525)\end{array}$ & $\begin{array}{c}-0.00380 \\
(0.00294)\end{array}$ & $\begin{array}{l}0.000875 \\
(0.00409)\end{array}$ & $\begin{array}{c}0.00568 \\
(0.00429)\end{array}$ & $\begin{array}{c}0.00717 \\
(0.00521)\end{array}$ & $\begin{array}{c}0.00287 \\
(0.00407)\end{array}$ & $\begin{array}{c}-0.00873^{* * *} \\
(0.00153)\end{array}$ & $\begin{array}{c}-0.00375^{*} \\
(0.00215)\end{array}$ & $\begin{array}{c}-0.00485^{\star *} \\
(0.00227)\end{array}$ & $\begin{array}{l}-0.00388^{*} \\
(0.00229)\end{array}$ & $\begin{array}{l}-0.00431^{*} \\
(0.00259)\end{array}$ \\
\hline Observations & 604,186 & 303,091 & 120,500 & 164,731 & 510,965 & 677,132 & 345,429 & 139,726 & 147,784 & 353,493 & $1,734,481$ & 898,347 & 363,263 & 604,203 & 831,655 \\
\hline Bandwidth & 10 & 5 & 2 & 2.735 & 8.422 & 10 & 5 & 2 & 3.781 & 5.561 & 10 & 5 & 2 & 3.335 & 4.621 \\
\hline Polynomial degree & 2 & 2 & 1 & 2 & & 2 & 2 & 1 & 2 & 2 & 2 & 2 & 1 & 2 & 2 \\
\hline Find job within 39 weeks & $\begin{array}{r}-5.29 \mathrm{e}-05 \\
(0.00268)\end{array}$ & $\begin{array}{c}-0.000298 \\
(0.00381)\end{array}$ & $\begin{array}{c}0.00325 \\
(0.00405)\end{array}$ & $\begin{array}{c}0.00231 \\
(0.00386)\end{array}$ & $\begin{array}{l}0.000856 \\
(0.00344)\end{array}$ & $\begin{array}{c}-0.00458 \\
(0.00284)\end{array}$ & $\begin{array}{r}-0.000897 \\
(0.00395)\end{array}$ & $\begin{array}{c}0.00198 \\
(0.00414)\end{array}$ & $\begin{array}{c}0.00318 \\
(0.00455)\end{array}$ & $\begin{array}{c}0.00277 \\
(0.00448)\end{array}$ & $\begin{array}{c}-0.0122^{\star * *} \\
(0.00146)\end{array}$ & $\begin{array}{c}-0.00748^{* * *} \\
(0.00205)\end{array}$ & $\begin{array}{c}-0.00765^{* * *} \\
(0.00216)\end{array}$ & $\begin{array}{c}-0.00694^{* * *} \\
(0.00221)\end{array}$ & $\begin{array}{c}-0.00704^{\star * \star} \\
(0.00220)\end{array}$ \\
\hline Observations & 604,186 & 303,091 & 120,500 & 225,051 & 486,010 & 677,132 & 345,429 & 139,726 & 188,131 & 342,177 & $1,734,481$ & 898,347 & 363,263 & 582,556 & 761,866 \\
\hline Bandwidth & 10 & 5 & 2 & 3.715 & 8.010 & 10 & 5 & 2 & 4.437 & 4.584 & 10 & 5 & 2 & 3.216 & 4.225 \\
\hline Polynomial degree & 2 & 2 & 1 & 2 & 2 & 2 & 2 & 1 & 2 & 2 & 2 & 2 & 1 & 2 & 2 \\
\hline Wage change between jobs & $\begin{array}{c}-0.000692 \\
(0.00281)\end{array}$ & $\begin{array}{l}0.000429 \\
(0.00399)\end{array}$ & $\begin{array}{c}0.00403 \\
(0.00425)\end{array}$ & $\begin{array}{l}0.000319 \\
(0.00413)\end{array}$ & $\begin{array}{l}0.000711 \\
(0.00441)\end{array}$ & $\begin{array}{c}-0.00409 \\
(0.00294)\end{array}$ & $\begin{array}{c}0.00232 \\
(0.00406)\end{array}$ & $\begin{array}{c}0.00458 \\
(0.00427)\end{array}$ & $\begin{array}{l}0.00950^{*} \\
(0.00562)\end{array}$ & $\begin{array}{c}0.0164^{\star *} \\
(0.00808)\end{array}$ & $\begin{array}{c}0.00494^{* * *} \\
(0.00147)\end{array}$ & $\begin{array}{c}0.00661^{* * *} \\
(0.00207)\end{array}$ & $\begin{array}{c}0.00630^{\star * *} \\
(0.00218)\end{array}$ & $\begin{array}{c}0.00633^{* * *} \\
(0.00228)\end{array}$ & $\begin{array}{c}0.00615^{\star * *} \\
(0.00183)\end{array}$ \\
\hline Observations & 418,965 & 212,388 & 84,426 & 156,967 & 251,387 & 476,251 & 243,188 & 98,617 & 90,133 & 280,363 & $1,187,475$ & 617,733 & 249,752 & 385,067 & 584,273 \\
\hline Bandwidth & 10 & 5 & 2 & 3.690 & 5.917 & 10 & 5 & 2 & 3.232 & 3.563 & 10 & 5 & 2 & 3.096 & 4.721 \\
\hline Polynomial degree & 2 & 2 & 1 & 2 & 2 & 2 & 2 & 1 & 2 & 2 & 2 & 2 & 1 & 2 & 2 \\
\hline Log re-employment wage & $\begin{array}{l}-0.00267 \\
(0.00303)\end{array}$ & $\begin{array}{c}-0.00209 \\
(0.00430)\end{array}$ & $\begin{array}{c}0.00252 \\
(0.00459)\end{array}$ & $\begin{array}{l}-0.00176 \\
(0.00449)\end{array}$ & $\begin{array}{l}-0.00199 \\
(0.00409)\end{array}$ & $\begin{array}{c}-0.00472 \\
(0.00313)\end{array}$ & $\begin{array}{l}0.000807 \\
(0.00432)\end{array}$ & $\begin{array}{c}0.00259 \\
(0.00452)\end{array}$ & $\begin{array}{c}0.00812 \\
(0.00589)\end{array}$ & $\begin{array}{c}0.00664 \\
(0.00534)\end{array}$ & $\begin{array}{c}0.00431^{* * *} \\
(0.00157)\end{array}$ & $\begin{array}{c}0.00714^{\star \star *} \\
(0.00219)\end{array}$ & $\begin{array}{c}0.00753^{\text {***}} \\
(0.00230)\end{array}$ & $\begin{array}{c}0.00717^{\star * *} \\
(0.00244)\end{array}$ & $\begin{array}{c}0.00722^{* * *} \\
(0.00226)\end{array}$ \\
\hline Observations & 418,965 & 212,388 & 84,426 & 158,171 & 273,130 & 476,251 & 243,188 & 98,617 & 91,884 & 234,757 & $1,187,475$ & 617,733 & 249,752 & 374,501 & 630,705 \\
\hline Bandwidth & 10 & 5 & 2 & 3.719 & 6.432 & 10 & 5 & 2 & 3.200 & 4.158 & 10 & 5 & 2 & 3.012 & 5.106 \\
\hline Polynomial degree & 2 & 2 & 1 & 2 & 2 & 2 & 2 & 1 & 2 & 2 & 2 & 2 & 1 & 2 & 2 \\
\hline New wage $>$ Ul benefit & $\begin{array}{l}-0.00191 \\
(0.00183)\end{array}$ & $\begin{array}{r}-0.000216 \\
(0.00260)\end{array}$ & $\begin{array}{l}0.000928 \\
(0.00278)\end{array}$ & $\begin{array}{r}-0.000311 \\
(0.00280)\end{array}$ & $\begin{array}{l}-0.00105 \\
(0.00253)\end{array}$ & $\begin{array}{c}-0.00154 \\
(0.00173)\end{array}$ & $\begin{array}{c}0.00186 \\
(0.00236)\end{array}$ & $\begin{array}{c}0.00167 \\
(0.00246)\end{array}$ & $\begin{array}{c}0.00248 \\
(0.00281)\end{array}$ & $\begin{array}{c}0.00126 \\
(0.00212)\end{array}$ & $\begin{array}{c}0.00391^{* * *} \\
(0.00102)\end{array}$ & $\begin{array}{c}0.00494^{\star * *} \\
(0.00141)\end{array}$ & $\begin{array}{c}0.00539^{\star * *} \\
(0.00148)\end{array}$ & $\begin{array}{c}0.00565^{\star \star *} \\
(0.00160)\end{array}$ & $\begin{array}{c}0.00529^{\star * *} \\
(0.00144)\end{array}$ \\
\hline Observations & 418,965 & 212,388 & 84,426 & 143,864 & 216,979 & 476,251 & 243,188 & 98,617 & 124,811 & 323,457 & $1,187,475$ & 617,733 & 249,752 & 351,021 & 537,480 \\
\hline Bandwidth & 10 & 5 & 2 & 3.384 & 5.106 & 10 & 5 & 2 & 4.132 & 6.915 & 10 & 5 & 2 & 2.819 & 4.335 \\
\hline Polynomial degree & 2 & 2 & 1 & 2 & 2 & 2 & 2 & 1 & 2 & 2 & 2 & 2 & 1 & 2 & 2 \\
\hline
\end{tabular}

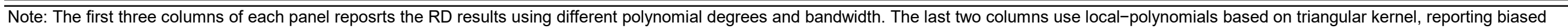
corrected estiamtes, robust confidence intervals on a optimal bandwidth according to Calonico, Cattaneo and Titiunik (2014) and Imbens and Kalyanaraman (2012), repectively.

${ }^{* *}$ Significant at the 1 percent level. ${ }^{* *}$ Significant at the 5 percent level. ${ }^{*}$ Significant at the 10 percent level. 


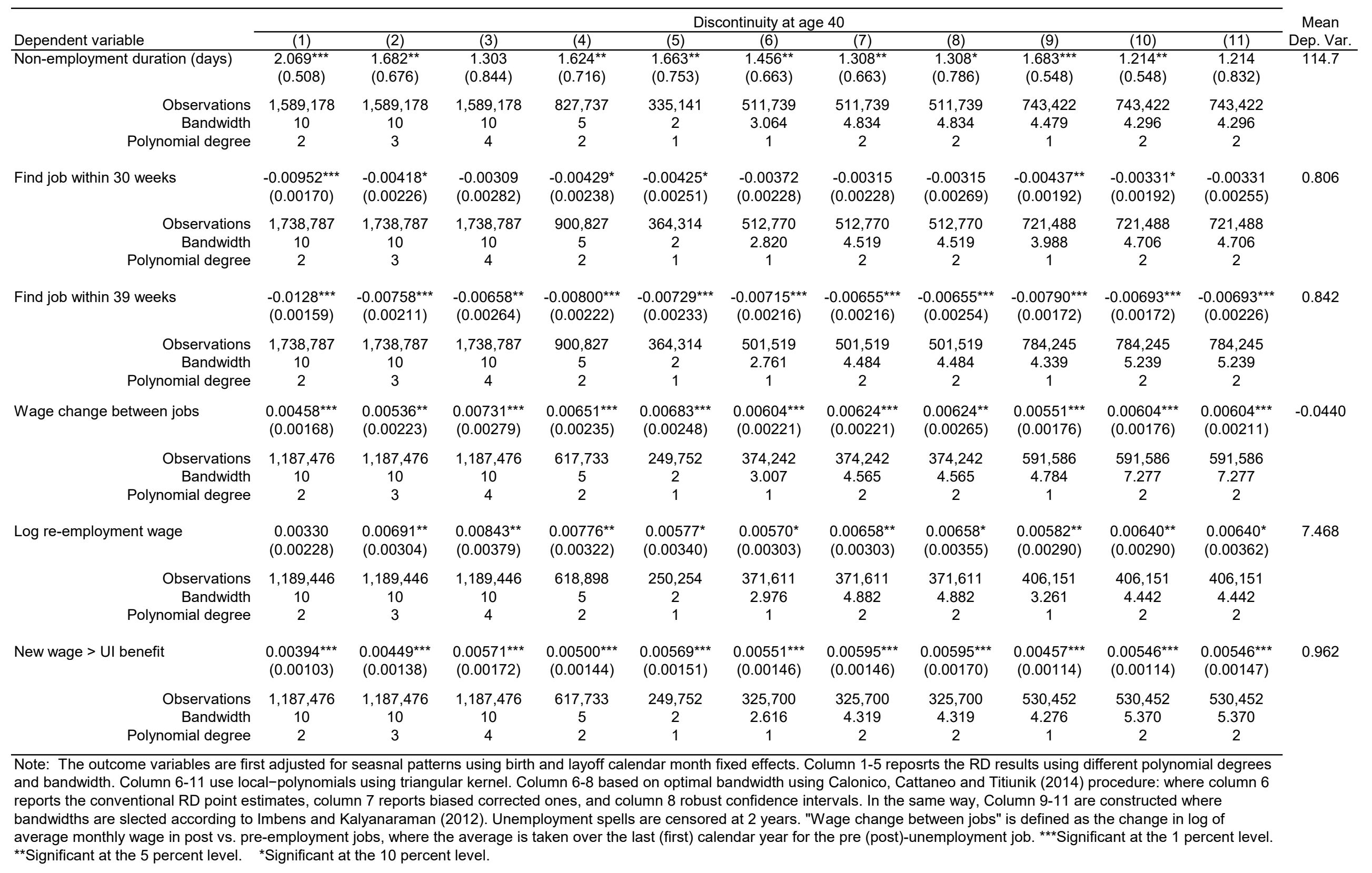


Appendix Table A7: Effect of UI Benefit Extension by Predicted likelihood of UI Exhaustion

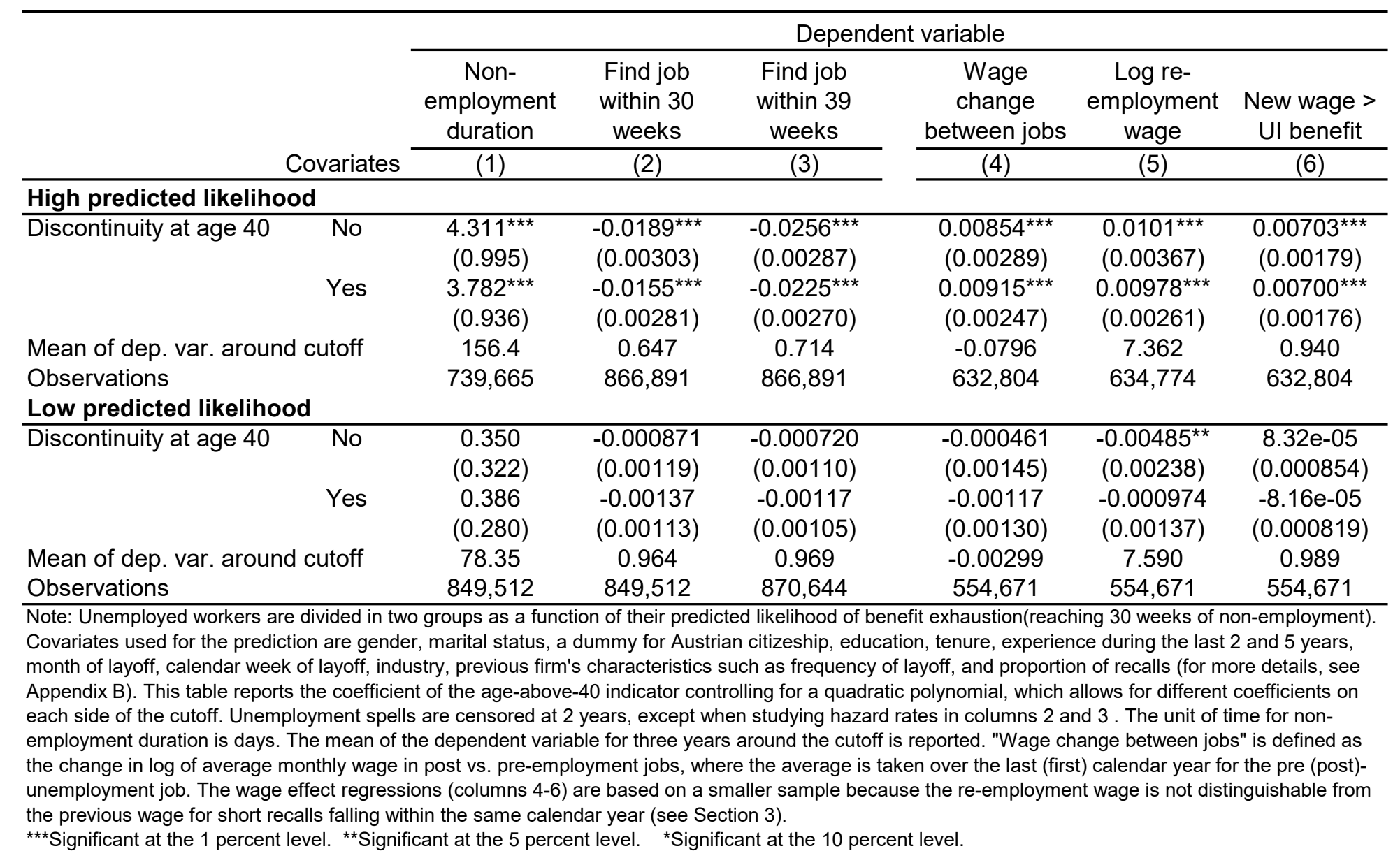




\section{Appendix Table A8: Firm Sorting Effect of UI Benefit Extension from 30 to 39 Weeks}

\begin{tabular}{|c|c|c|c|c|c|c|c|c|}
\hline \multirow{3}{*}{\multicolumn{2}{|c|}{ Covariates }} & \multicolumn{6}{|c|}{ Post-unemployment Firm level Outcomes } & \multirow[b]{2}{*}{$\begin{array}{l}\text { Wage } \\
\text { change }\end{array}$} \\
\hline & & $\begin{array}{l}\text { Change in } \\
\text { Firm size }\end{array}$ & $\begin{array}{c}\text { New firm } \\
\text { size > Old } \\
\text { firm size }\end{array}$ & $\begin{array}{c}\text { Change in } \\
\text { male } \\
\text { proportion }\end{array}$ & $\begin{array}{c}\text { Change in } \\
\text { average } \\
\text { age }\end{array}$ & $\begin{array}{c}\text { Change in } \\
\text { log average } \\
\text { wage }\end{array}$ & $\begin{array}{c}\text { Change in } \\
\text { adjusted } \\
\text { wage }\end{array}$ & \\
\hline & & (1) & $(2)$ & (3) & (4) & (5) & (6) & $(7)$ \\
\hline \multirow[t]{2}{*}{ Discontinuity at age 40} & No & $\begin{array}{c}9.428 \\
(8.604)\end{array}$ & $\begin{array}{l}0.000107 \\
(0.00314)\end{array}$ & $\begin{array}{c}0.00148 \\
(0.00142)\end{array}$ & $\begin{array}{l}0.00180^{\star *} \\
(0.000797)\end{array}$ & $\begin{array}{l}0.00331^{* \star} \\
(0.00168)\end{array}$ & $\begin{array}{c}0.00184 \\
(0.00199)\end{array}$ & $\begin{array}{l}0.00489^{* *} \\
(0.00193)\end{array}$ \\
\hline & Yes & $\begin{array}{l}8.028 \\
(8.414)\end{array}$ & $\begin{array}{l}-5.96 e-05 \\
(0.00301)\end{array}$ & $\begin{array}{l}0.000603 \\
(0.00124)\end{array}$ & $\begin{array}{l}0.00142^{* *} \\
(0.000722)\end{array}$ & $\begin{array}{l}0.00270^{*} \\
(0.00147)\end{array}$ & $\begin{array}{c}0.00274 \\
(0.00189)\end{array}$ & $\begin{array}{c}0.00433^{* * *} \\
(0.00164)\end{array}$ \\
\hline \multirow{2}{*}{\multicolumn{2}{|c|}{$\begin{array}{l}\text { Mean of dep. var. around cutoff } \\
\text { Observations }\end{array}$}} & 280.2 & 0.427 & -0.0404 & -0.00453 & -0.0206 & 0.00354 & -0.0604 \\
\hline & & 859,445 & 860,870 & 858,034 & 859,416 & 857,641 & 827,178 & 860,870 \\
\hline
\end{tabular}

Note: This table reports the coefficient of the age-above-40 indicator controlling for a quadratic polynomial, which allows for different coefficients on each side

of the cutoff. Sample excluds workers laid-off from a firm with less than 10 workers. 
Ul effect on wage

\begin{tabular}{lcc} 
& $(1)$ & $(2)$ \\
\hline Dependent variable & & R-square \\
\hline UI effect on non-employment duration (level) & -0.000489 & 0.461 \\
& $(0.000264)$ & \\
UI effect on non-employment duration (change) & $-0.123^{\star}$ & 0.627 \\
& $(0.0475)$ & \\
Initial UI duration & $-2.38 \mathrm{e}-05$ & 0.003 \\
& $(0.000203)$ & 0.006 \\
UI extension (level) & $-2.35 \mathrm{e}-05$ & \\
Ul extension (change) & $(0.000150)$ & 0.021 \\
& -0.0131 & \\
Observations & $(0.0444)$ & \\
\hline Note
\end{tabular}

\section{Note:}

This table reports the results of five regressions within our met-analysis sample of Figure Va with the UI wage effect as the dependent variable. Depending on regression, the right hand side variable varies from UI duration effect measured in days, in changes relative to initial non-employment duration, initial UI duration, UI extension in level, and as a share relative to the initial UI duration, respectively. The first regression corresponds to scatter plot of the Figure Va itself.

${ }^{* * *}$ Significant at the 1 percent level. ${ }^{* *}$ Significant at the 5 percent level. ${ }^{*}$ Significant at the 10 percent level. 
Appendix Table A10

\begin{tabular}{|c|c|c|c|c|c|c|c|c|c|}
\hline \multicolumn{2}{|c|}{$\begin{array}{c}\text { Potential UI } \\
\text { duration (weeks) }\end{array}$} & \multicolumn{2}{|c|}{ Eligibility criteria } & \multirow[b]{2}{*}{ Research Design } & \multirow[b]{2}{*}{ Availability of Studies } & \multicolumn{2}{|c|}{ UI Effect on } & \multicolumn{2}{|r|}{ Meta Analysis } \\
\hline $\begin{array}{l}\text { Base } \\
\text { level }\end{array}$ & $\begin{array}{l}\text { Extended } \\
\text { to }\end{array}$ & $\begin{array}{l}\text { Work experience } \\
\text { before job } \\
\text { separation }\end{array}$ & Others & & & Duration & Wage & $\begin{array}{c}\begin{array}{c}\text { Included } \\
\text { in } \\
\text { Figure V }\end{array} \\
\end{array}$ & Comment \\
\hline 0 & 20 & $\begin{array}{l}52 \text { weeks out of last } \\
2 \mathrm{yrs} .\end{array}$ & & & $\begin{array}{l}\text { NA, several exceptions to eligibility rule, not } \\
\text { verifyable in the data }\end{array}$ & & & NA & \\
\hline 0 & 20 & & $\begin{array}{l}\text { age }<25 \& \text { first UI } \\
\text { benefits claim }\end{array}$ & & $\begin{array}{l}\text { NA, large number of individuals claim benefits } \\
\text { without satisfying all criteria; reasons not } \\
\text { distinguishable in data }\end{array}$ & & & NA & \\
\hline 0 & 20 & $\begin{array}{l}26 \text { weeks out of last } \\
1 \text { year }\end{array}$ & repeated unemployment & & $\begin{array}{l}\text { NA, eligibility for new claim versus left-over } \\
\text { benefits from previous claim hard to verify in } \\
\text { data, in addition issue of dynamic treatment } \\
\text { effects }\end{array}$ & & & NA & \\
\hline 20 & 30 & 3 out of last $5 \mathrm{yrs}$. & & $\mathrm{RD}$ at experience cutoff & Card, Chetty, Weber (2007) & $\mathrm{x}$ & $\mathrm{x}$ & Yes & \\
\hline 30 & 39 & 6 out of last $10 \mathrm{yrs}$ & age $>40$ & $\begin{array}{l}\text { RD at age cutoff } \\
\mathrm{RD} \text { at age cutoff } \\
\mathrm{RD} \text { at experience cutoff }\end{array}$ & $\begin{array}{l}\text { Degen (2014) } \\
\text { Nekoei, Weber (2015) } \\
\text { NA, because of low frequency of obs. around } \\
\text { cutoff }\end{array}$ & $\begin{array}{l}\mathrm{x} \\
\mathrm{x}\end{array}$ & $x$ & $\begin{array}{l}\text { No } \\
\text { Yes } \\
\text { NA }\end{array}$ & Not included, since only UI duration effect reported \\
\hline 39 & 52 & 9 out of last $15 \mathrm{yrs}$. & age $>50$ & $\begin{array}{l}\text { DiD age and time } \\
\text { RD at age cutoff } \\
\text { DiD age and experience } \\
\text { RD at experience cutoff }\end{array}$ & $\begin{array}{l}\text { Lalive, van Ours, Zweimüller (2006) } \\
\text { Lalive (2007) } \\
\text { Lalive, van Ours, Zweimüller (2006) } \\
\text { NA, because of low frequency of obs. around } \\
\text { cutoff }\end{array}$ & $\begin{array}{l}x \\
x \\
x\end{array}$ & $x$ & $\begin{array}{l}\text { No } \\
\text { Yes } \\
\text { No } \\
\text { NA }\end{array}$ & $\begin{array}{l}\text { Not included, since only UI duration effect reported } \\
\text { Results reported separately for men and women } \\
\text { Not included, since only UI duration effect reported }\end{array}$ \\
\hline 30 & & & & DiD at age $\&$ region cutoff & Lalive \& Zweimüller (2004) & $\mathrm{x}$ & & No & Not included, since only UI duration effect reported \\
\hline 39 & & & & RD at age cutoff & Lalive (2007) & $\mathrm{x}$ & $\mathrm{x}$ & No & Not included, since estimates are contaminated by sorting \\
\hline 39 & 209 & 15 out of last $25 \mathrm{yrs}$. & $\begin{array}{l}\text { age }>50 \text { \& only in } \\
\text { regions exposed to steel } \\
\text { industry crisis }\end{array}$ & $\begin{array}{l}\mathrm{RD} \text { at region cutoff } \\
\mathrm{RD} \text { at age cutoff }\end{array}$ & Lalive (2008) & $\mathrm{x}$ & & No & Not included, since only UI duration effect reported \\
\hline 39 & & & & DiD at age \& region cutoff & Landais, Lalive, Zweimüller (2015) & $\mathrm{x}$ & $\mathrm{x}$ & No & $\begin{array}{l}\text { Not included, since estimates are contaminated by } \\
\text { sorting. McCrary test rejects not-sorting }\end{array}$ \\
\hline 52 & & & & $\mathrm{RD}$ at experience cutoff & $\begin{array}{l}\text { NA, because of low frequency of obs. around } \\
\text { cutoff }\end{array}$ & & & NA & \\
\hline \multicolumn{10}{|c|}{ Severance Pay } \\
\hline & & & job tenure $>36$ months & $\mathrm{RD}$ at tenure cutoff & Card, Chetty, Weber (2007) & $\mathrm{x}$ & $\mathrm{x}$ & No & $\begin{array}{l}\text { Cash-on-hand instead of benefit conditional on } \\
\text { unemployment state }\end{array}$ \\
\hline & & & $\begin{array}{l}\text { further cutoffs in SP } \\
\text { schedule }\end{array}$ & & $\begin{array}{l}\text { NA, because of low frequency of obs. around } \\
\text { cutoff }\end{array}$ & & & NA & \\
\hline
\end{tabular}




\section{Appendix Table 11: Effect of UI Benefit Extension from 30 to 39 Weeks}

Dependent variable

\begin{tabular}{|c|c|c|c|c|c|c|c|}
\hline \multirow{2}{*}{\multicolumn{2}{|c|}{ Covariates }} & $\begin{array}{l}\text { Non- } \\
\text { employment } \\
\text { duration }\end{array}$ & $\begin{array}{c}\text { Find job } \\
\text { within } 30 \\
\text { weeks }\end{array}$ & $\begin{array}{c}\text { Find job } \\
\text { within } 39 \\
\text { weeks }\end{array}$ & $\begin{array}{c}\text { Wage } \\
\text { change } \\
\text { between jobs }\end{array}$ & $\begin{array}{l}\text { Log re- } \\
\text { employment } \\
\text { wage }\end{array}$ & $\begin{array}{l}\text { New wage > } \\
\text { Ul benefit }\end{array}$ \\
\hline & & (1) & $(2)$ & (3) & $(4)$ & $(5)$ & $(6)$ \\
\hline \multirow[t]{2}{*}{$\overline{\text { Discontinuity at age } 40}$} & No & $\begin{array}{l}2.052^{* * *} \\
(0.536)\end{array}$ & $\begin{array}{l}-0.01000^{* * *} \\
(0.00181)\end{array}$ & $\begin{array}{l}-0.0133^{* * *} \\
(0.00168)\end{array}$ & $\begin{array}{l}0.00449^{* * *} \\
(0.00173)\end{array}$ & $\begin{array}{l}0.00409^{*} \\
(0.00238)\end{array}$ & $\begin{array}{l}0.00387^{* * *} \\
(0.00107)\end{array}$ \\
\hline & Yes & $\begin{array}{l}1.994^{* * *} \\
(0.475)\end{array}$ & $\begin{array}{c}-0.00842^{* * *} \\
(0.00156)\end{array}$ & $\begin{array}{r}-0.0120^{* * *} \\
(0.00149)\end{array}$ & $\begin{array}{l}0.00454^{* * *} \\
(0.00149)\end{array}$ & $\begin{array}{l}0.00504^{* * *} \\
(0.00158)\end{array}$ & $\begin{array}{l}0.00381^{* * *} \\
(0.00103)\end{array}$ \\
\hline \multicolumn{2}{|c|}{$\begin{array}{l}\text { Mean of dep. var. around cutoff } \\
\text { Observations }\end{array}$} & $\begin{array}{c}114.7 \\
1,589,178\end{array}$ & $\begin{array}{c}0.806 \\
1,738,787\end{array}$ & $\begin{array}{c}0.842 \\
1,738,787\end{array}$ & $\begin{array}{c}-0.0440 \\
1,187,476\end{array}$ & $\begin{array}{c}7.468 \\
1,189,446\end{array}$ & $\begin{array}{c}0.962 \\
1,187,476\end{array}$ \\
\hline
\end{tabular}

Note: This table provides the results similar to the Table 2 in the main text of the paper, but where the age variables have been rounded. This method is free from the seasonal paterns. We thank a referee for suggeting it. This table reports the coefficient of the age-above-40 indicator controlling for a quadratic polynomial, which allows for different coefficients on each side of the cutoff. Unemployment spells are censored at 2 years, except when studying hazard rates in columns 2 and 3 . The unit of time for non-employment duration is days. The mean of the dependent variable for three years around the cutoff is reported. "Wage change between jobs" is defined as the change in the log of the average monthly wage in post vs. pre-employment jobs, where the average is taken over the last (first) calendar year for the pre (post)-unemployment job. The wage effect regressions (columns 4-6) are based on a smaller sample because the re-employment wage is not distinguishable from the previous wage for short recalls falling within the same calendar year (see Section 1). The covariates used are individual characteristics, such as gender, marital status, a dummy for Austrian citizenship, education, tenure, experience during the last 2 and 5 years, month of layoff, calendar week of layoff; and previous firm's characteristics such as industry, frequency of layoff, and proportion of recalls.

${ }^{* * *}$ Significant at the 1 percent level. ${ }^{* *}$ Significant at the 5 percent level. ${ }^{*}$ Significant at the 10 percent level. 